\title{
CARACTERIZAÇÃO E AVALIAÇÃO DO INTERVALO HÍDRICO ÓTIMO DE UM LATOSSOLO ROXO
}

\author{
CÁSSIO ANTONIO TORMENA
}

Engenheiro Agrônomo

Orientador: Prof. Dr. ÁLVARO PIRES DA SILVA

Tese apresentada à Escola Superior de Agricultura "Luiz de Queiroz", Universidade de São Paulo, para obtenção do título de Doutor em Agronomia, Área de Concentração: Solos e Nutrição de Plantas.

\author{
PIRACICABA \\ Estado de São Paulo - Brasil \\ Outubro - 1998
}


Dados Internacionais de Catalogaçāo na Publicaçāo (CIP) DIVISĀO DE BIBLIOTECA E DOCUMENTAÇĀO - Campus "Luiz de Queiroz"/USP

Tormena, Cássio Antonio

Caracterização e avaliação do intervalo hidrico ótimo de um latossolo roxo / Cássio Antonio Tormena. - - Piracicaba, 1998.

$106 \mathrm{p}$.

Tese (doutorado) - - Escola Superior de Agricultura Luiz de Queiroz, 1998.

Bibliografia.

1. Crescimento vegetal 2. Densidade do solo 3. Fisica do solo 4. Latossolo roxo 5. P'lantio direto 6. Resistência à penetração 7. Umidade do solo I. Titulo 
Este trabalho é dedicado aos meus pais, Isidoro e Maria, que tanto trabalharam para a minha formação;

À Denise, que com seu amor e compreensão, permitiu-me a concretização desta importante etapa de nossas vidas

e ao Henrique, que ensina-me que é preciso estar sempre aprendendo. 


\section{AGRADECIMENTOS}

Ao Professor Álvaro Pires da Silva, pela orientação competente, pela amizade e confiança e pela importante contribuição para a minha formação cientifica e crescimento profissional.

Ao Prof. Paulo Leonel Libardi, pela confiança em meu trabalho.

Aos Professores Luis R. F. Alleoni e Quirijn de Jong van Lier, pelas sugestōes apresentadas.

Aos colegas de curso Vladia Correchel, Andréa Sanchez, Vilson Klein e Silvia Imhoff.

Ao amigo Antônio Carlos Andrade Gonçalves, pelo apoio.

Ao colegas Marcos Nanni e Roberto Rezende pelo companheirismo e amizade.

Aos funcionários do Laboratório de Física de Solos, Wladimir J. Rosignolo e Luciano Dias Ferraz.

Às bibliotecárias Eliana M. G. Sabino e Kátia M. A. Ferraz.

A Universidade Estadual de Maringá e à ESALQ/USP pela oportunidade de realização do curso.

A Coordenação do Curso de Pós-Graduação em Solos e Nutrição de Plantas da ESALQ.

À CAPES pela concessão da bolsa de estudos.

A todos que, direta ou indiretamente, contribuíram para a realização deste trabalho. 


\section{SUMÁRIO}

Página

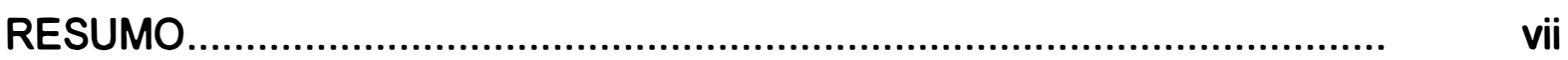

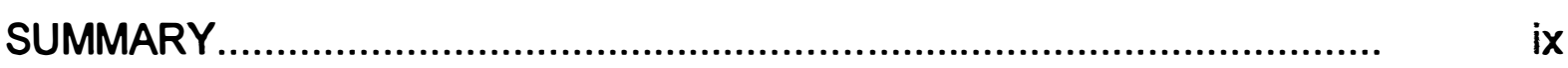

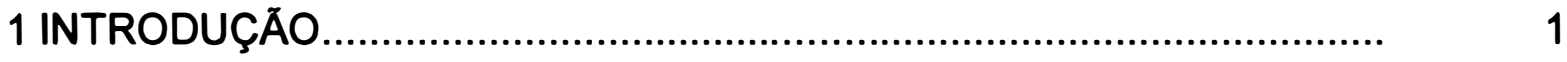

2 REVISÃO DE LITERATURA .............................................................. 4

2.1 Relações entre estrutura, propriedades físicas do solo e crescimento das plantas.......................................................................................... 5

2.2 Relações entre umidade do solo, resistência à penetração e crescimento das plantas ....................................................................... 8

2.3 Avaliação dos efeitos do manejo na qualidade física do solo para o crescimento das plantas.

2.40 conceito do Intervalo Hídrico Ótimo do solo..................................... 14

2.4.1 Quantificação do Intervalo Hídrico Ótimo do solo............................... 18

2.5 Avaliação da estrutura e da qualidade física em solos tropicais

3 CARACTERIZAÇÃO DO INTERVALO HIDRICO ÓTIMO DE UM LATOSSOLO ROXO SOB PLANTIO DIRETO.......................................... 23

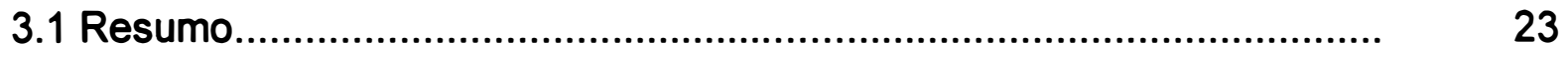

3.2 Summary ............................................................................... 24

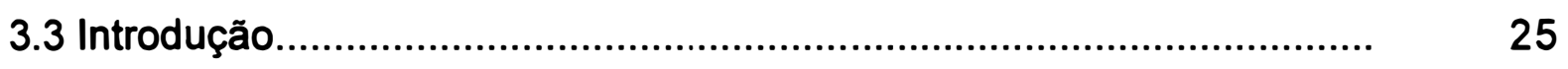

3.4 Material e métodos......................................................................... 29

3.5 Resultados e discussão.................................................................. 33

3.6 Conclusões..................................................................................... 40

4 AJUSTE DA CURVA DE RETENÇÃO PARA DADOS OBTIDOS COM VARIAÇĀO DE DENSIDADE DO SOLO ............................................... 42

4.1 Resumo ...................................................................................... 42

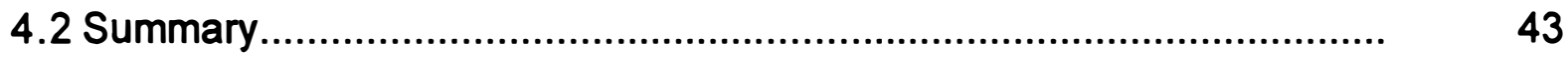




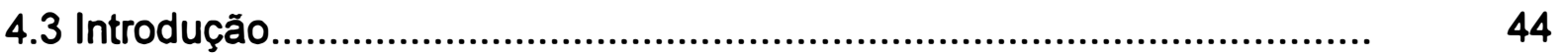

4.4 Material e métodos......................................................................... 48

4.5 Resultados e discussão.................................................................. 50

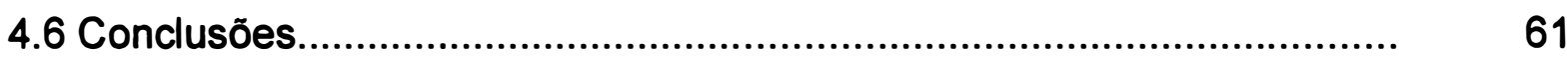

5 EFEITOS DO SISTEMA DE PLANTIO DIRETO E DO PREPARO CONVENCIONAL NO INTERVALO HÍDRICO ÓTIMO DE UM

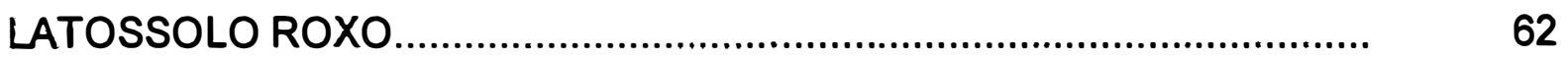

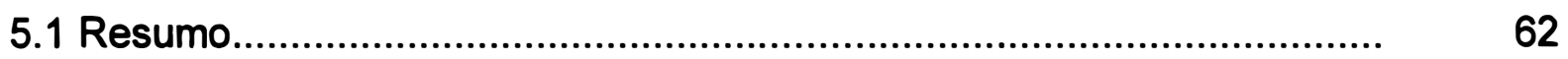

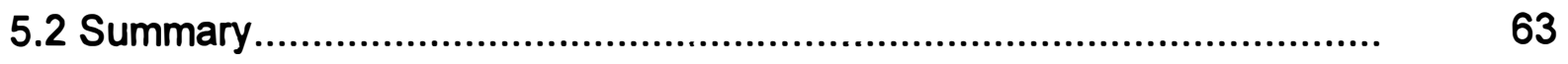

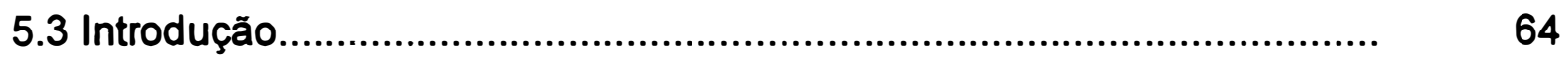

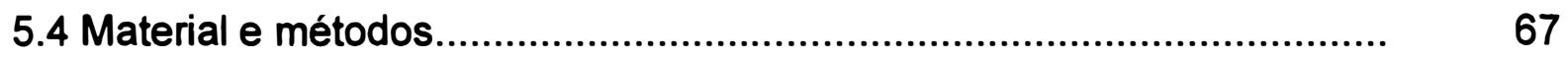

5.5 Resultados e discussão.................................................................... 71

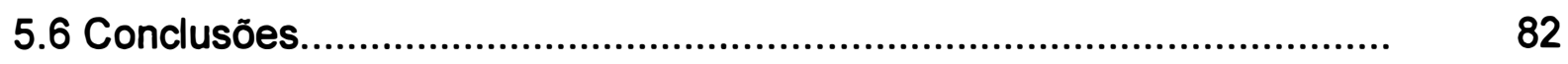

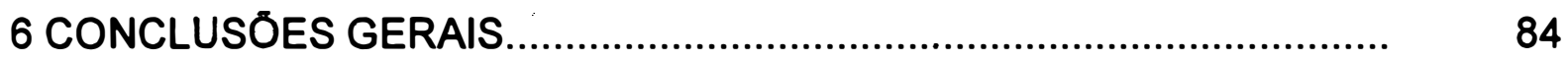

REFERÊNCIAS BIBLIOGRÁFICAS........................................................ 86 


\title{
CARACTERIZAÇÃO E AVALIAÇÃO DO INTERVALO HÍDRICO ÓTIMO DE UM LATOSSOLO ROXO
}

\author{
Autor: CÁSSIO ANTONIO TORMENA \\ Orientador: Prof. Dr. ALVARO PIRES DA SILVA
}

\section{RESUMO}

Considerando as propriedades físicas do solo e não havendo limitações térmicas, os fatores que afetam diretamente a produtividade das culturas são 0 potencial da água no solo, a aeração e a resistência do solo à penetração das raízes. O Intervalo Hídrico Ótimo (IHO) do solo é definido como a faixa de conteúdos de água dentro da qual as limitações ao crescimento das plantas, devido ao potencial da água no solo, aeração e resistência à penetração, são mínimas. O IHO representa a faixa de conteúdos de água definidos no limite superior pela umidade do solo na capacidade de campo ( $\psi=-0,01 \mathrm{MPa})$ ou a umidade na qual a porosidade de aeração torna-se limitante (10\%) (o menor valor), e no limite inferior pela umidade no ponto de murchamento permanente ( $\psi=-1,5 \mathrm{MPa}$ ) ou pela umidade na qual a resistência do solo à penetração das raízes (2,0 MPa) torna-se limitante (o maior valor). O IHO é considerado um índice da qualidade estrutural do solo para os crescimento das plantas e ainda não foi estudado em solos tropicais.

O objetivo desta pesquisa foi caracterizar o IHO num Latossolo Roxo com manejo de alta intensidade e sob condições irrigadas, com preparo 
convencional e plantio direto. Inicialmente foi feita a avaliação e caracterização do IHO sob plantio direto utilizando a metodologia descrita na literatura. Também foi desenvolvido um procedimento para simplificar a determinação da curva de retenção de água, necessária à determinação do IHO, e para ajustar a curva de retenção por meio da função utilizada por van Genuchten (1980). Esta função foi utilizada para obter as estimativas dos conteúdos de água nos limites críticos de potencial mátrico, utilizados para a determinação e comparação do IHO nos sistemas de plantio direto e preparo convencional.

No sistema de plantio direto, o limite superior do IHO foi dominado pela umidade na capacidade de campo. A umidade do solo na resistência à penetração de 2,0 MPa foi o limite inferior a partir da densidade de $1,1 \mathrm{Mg} \mathrm{m}^{-3}$, a partir da qual o IHO foi negativamente correlacionado com a densidade do solo. A densidade do solo influenciou o ajuste da curva de retenção e a inserção do parâmetro $n$, como uma função quadrática da densidade do solo, permitiu a obtenção de estimativas confiáveis do conteúdo de água em toda faixa de potenciais utilizados. Comparando o IHO entre os sistemas de preparo, obteve-se menores valores médios do IHO no sistema de plantio direto em comparação com o preparo convencional. A resistência do solo à penetração das raízes determinou com maior freqüência o limite inferior do IHO comparado ao ponto de murchamento permanente, enquanto que a capacidade de campo determinou o limite superior do IHO. Os resultados demonstraram que a umidade na porosidade de aeração de $10 \%$ não impôs limitação ao IHO do solo, nas condições estudadas. 


\title{
CHARACTERIZATION AND EVALUATION OF THE OPTIMUM HYDRIC INTERVAL OF A OXISOL
}

\author{
Author: CÁSSIO ANTONIO TORMENA \\ Adviser: Prof. Dr. ÁLVARO PIRES DA SILVA
}

\section{SUMMARY}

Nonthermal physical properties of soil that may influence crop productivity relate to matric potential, aeration and soil penetrometer resistance. The range of soil water content in which limitations for plant growth associated with matric potential, aeration and mechanical are minimal is defined as the Optimum Hydric Interval $(\mathrm{OHI})$. The $\mathrm{OHI}$ represents the range in water contents defined at the upper end by water content at field capacity $(\psi=-0,01 \mathrm{MPa})$ or the water content at which aeration becomes limiting (whichever is smaller) and at the lower end by the water content at wilting point $(\psi=-1,5 \mathrm{MPa})$ or the water content at which soil resistance to penetration by roots becomes limiting (whichever is larger). The $\mathrm{OHI}$ has been proposed and evaluated as an index of structural quality of soils for crop growth and has not yet been studied in tropical soils.

The objective of this research was to characterize the $\mathrm{OHI}$ of an Oxisol (Typic Hapludox) cropped to corn under no-tillage and conventional tillage. A procedure to incorporate the bulk density in Van Genuchten (1980) function in 
order to fit the soil water retention curve to do estimated soil water contents in the critical matric potential. Undisturbed soil cores were taken from 0 to $10 \mathrm{~cm}$. Soil water retention, soil resistance, air-filled porosity and bulk density were measured. Water contents at critical limits associated with field capacity ( $\psi=-$ $0,01 \mathrm{MPa})$, wilting point $(\psi=-1,5 \mathrm{MPa})$, air-filled porosity $(10 \%)$ and soil resistance $(2,0 \mathrm{MPa})$ were estimated and the $\mathrm{OHI}$ calculated for each measured bulk density.

In no-tillage, the upper limit of $\mathrm{OHI}$ was dominated by soil water content in the field capacity. Soil water content in soil penetration resistance of $2,0 \mathrm{MPa}$ was the lower limit to soil density higher to $1,1 \mathrm{Mg} \mathrm{m}^{-3}$, in which $\mathrm{OHI}$ was correlated negatively with bulk density. The incorporation of the bulk density in Van Genuchten (1980) model conducted to reliable estimates of soil water contents in all potentials. The $\mathrm{OHI}$ was significantly influenced by tillage systems and was smaller in no-tillage than conventional tillage. Soil penetration resistance determined the lower limit of the $\mathrm{OHI}$ compared to wilting point and field capacity was the upper limit. The air-filled porosity of $10 \%$ was not limited the $\mathrm{OHI}$ in the studied soil conditions. 


\section{INTRODUÇÃO}

As práticas de manejo do solo podem influenciar a sustentabilidade e a produtividade dos ecossistemas agrícolas por meio da degradação de propriedades do solo que determinam o desenvolvimento e a produtividade das culturas. Não havendo limitações térmicas, as propriedades físicas do solo que influenciam diretamente a produtividade das culturas são aquelas relacionadas com o fornecimento de água, de oxigênio e com a resistência do solo à penetração das raízes. Esses fatores físicos estão estreitamente relacionadas à condição estrutural e ao conteúdo de água do solo e, portanto, sujeitos a modificações detrimentais em relação à produtividade das culturas. Assim, a avaliação dos impactos das práticas de manejo sobre a qualidade física do solo deveria ser feita por meio de parâmetros que determinam as condições físicas para o crescimento das plantas.

Condições físicas do solo, favoráveis para o crescimento das plantas, têm sido associadas a uma porosidade de aeração mínima de $10 \%$, necessária para a adequada difusão de oxigênio no solo; com um limite de resistência à penetração de 2,0 MPa e com uma ampla disponibilidade de água no solo entre a capacidade de campo (CC) e o ponto de murchamento permanente (PMP). Entre estes, a disponibilidade de água tem sido mais diretamente ligada com a qualidade do solo para o crescimento das plantas. Os efeitos destes fatores físicos sobre o crescimento das plantas ocorrem por meio da atuação simultânea e de complexas interações envolvendo resistência do solo à penetração, aeração e disponibilidade de água. Além disso, uma modificação da umidade do solo promove modificações na aeração e na resistência do solo 
à penetração das raízes. Num solo com estrutura degradada, a reduzida aeração ou a excessiva resistência do solo à penetração das raízes podem constituir-se em impedimentos ao crescimento das plantas, independentemente da disponibilidade hídrica ser adequada.

O reconhecimento das interações entre os vários parâmetros físicos do solo que atuam sobre o crescimento radicular exige que as avaliações das condições físicas do solo sejam feitas através de parâmetros que integrem estas variações, permitindo quantificar, de forma apropriada, o ambiente físico na zona radicular dos solos. O Intervalo Hídrico Ótimo do Solo (IHO) é um parâmetro que descreve uma faixa de conteúdos de água no solo em que as limitações ao crescimento das plantas, associadas com a aeração, com a resistência à penetração e disponibilidade de água, são mínimas. Os limites desta faixa de água referem-se aos conteúdos de água na capacidade de campo e ponto de murcha permanente, bem como aqueles em que a resistência à penetração e a aeração do solo são críticos para o crescimento das plantas. A vantagem da utilização do $\mathrm{IHO}$ deve-se à integração, num único parâmetro, dos fatores físicos do solo diretamente relacionados com o crescimento das plantas. O IHO foi determinado sob diferentes condições de textura e manejo de solos em países de clima temperado. Os resultados obtidos nestes estudos indicam que o IHO é um indicador da qualidade estrutural do solo para a produtividade das culturas. O IHO é negativamente correlacionado com a densidade e com o teor de argila dos solos, ou seja, a compactação em solos argilosos aumenta a probabilidade de as culturas serem expostas às limitações por excessiva resistência à penetração ou reduzida difusão de oxigênio no solo.

Nos solos tropicais ainda não foram realizados estudos visando a sua determinação; o primeiro passo é sua quantificação para avaliar também seu desempenho como um índice da qualidade estrutural e física destes solos. Entre os solos tropicais, os Latossolos merecem especial atenção em relação à avaliação do IHO, uma vez que corrigidas as suas limitações químicas, a 
obtenção de elevadas produtividades tem relação direta com a qualidade física do solo. As condições físicas nos Latossolos sempre foram relacionadas com a estabilidade da estrutura devido à sua forte microagregação entre os seus constituintes minerais e em geral associadas com a infiltração de água no solo e resistência à erosão. Neste contexto, o conceito do IHO é um parâmetro integrador útil na avaliação dos efeitos dos sistemas de manejo sobre a qualidade física destes solos para o crescimento das plantas.

A premissa básica deste trabalho baseia-se na hipótese de que, no solo utilizado nesta pesquisa, o IHO é influenciado pelos sistemas de preparo do solo adotado, diante dos efeitos destes sobre a estrutura do solo. $O$ objetivo geral desta pesquisa foi o de caracterizar o Intervalo Hídrico Ótimo de um Latossolo Roxo, de textura muito argilosa, sob diferentes sistemas de preparo do solo: plantio direto e preparo convencional, nos quais os efeitos relativos à linha e à entrelinha da cultura do milho também foram incorporados para ampliar a variabilidade das condições estruturais do solo. Os objetivos específicos foram: (I) caracterizar e descrever o conceito do IHO num solo sob condições tropicais; (II) caracterizar o IHO neste solo, na condição de plantio direto, a partir da metodologia descrita na literatura; (III) desenvolver um procedimento para estimar os conteúdos de água na CC e PMP, incorporando a variação da densidade do solo, numa função não linear utilizada para a descrição da curva de retenção de água no solo; (IV) avaliar os efeitos dos sistemas de plantio direto e preparo convencional no IHO do solo estudado.

A tese é disposta em capitulos compondo, além da revisão geral de literatura apresentada no item 2, os itens 3, 4 e 5 . Desta forma os objetivos (I) e (II) são atendidos pelos itens 3 e 5; o objetivo especifico (III) está descrito no item 4 e o objetivo específico (IV) é descrito e atendido no item 5 do presente trabalho. Sendo assim, algumas sobreposições ocorrem entre os itens 3,4 e 5 . 


\section{REVISÃO DE LITERATURA}

O aumento e a manutenção da produtividade do solo é fundamental para a sustentabilidade da agricultura e para atender as necessidades básicas de alimentos decorrentes do crescimento da população. O potencial de produção de biomassa das culturas é determinado pelo potencial genético das plantas e por fatores relacionados ao solo e ao clima. O solo fornece água, ar, nutrientes e o suporte mecânico para o crescimento das plantas. $O$ manejo do solo pode modificar as condições físicas, químicas e biológicas necessárias para o crescimento e produtividade das culturas.

$\mathrm{Na}$ maior parte dos solos tropicais, o declínio da fertilidade é freqüentemente citado como um dos fatores que contribuem para a ocorrência de sistemas agrícolas não sustentáveis, apesar da facilidade de correção deste tipo de limitação. Neste contexto, embora menos citadas, as condições físicas do solo são mais críticas para o manejo sustentável dos sistemas agrícolas e exercem grande influência sobre a produtividade das culturas. As práticas de manejo podem induzir a degradação da estrutura e deterioração das condições físicas do solo na zona radicular reduzindo, conseqüentemente, a produtividade das culturas. Atualmente, uma grande parte das avaliações em solos tropicais demonstram que, em relação à fertilidade, a produtividade das culturas é determinada pelas condições físicas na zona radicular dos solos. As alterações nas propriedades e processos físicos do solo, pelos sistemas de manejo, afetam a funcionalidade da estrutura do solo. Desta forma, os sistemas de manejo deveriam ser avaliados por meio dos seus efeitos nos atributos 
físicos do solo que influenciam diretamente o crescimento das plantas.

\subsection{Relações entre estrutura, propriedades fisicas do solo e crescimento das plantas}

A condição física do solo tem um papel determinante no crescimento e produtividade das culturas. No entanto, apesar da importância do assunto, grande parte das informações nessa área são vagas, qualitativas e, com freqüência, carecem de dados científicos (Russel, 1952). A preocupação em estudar vários aspectos da estrutura do solo demonstra a evolução no assunto, apesar que a maioria dos autores menciona a dificuldade em relacionar, quantitativamente, 0 desenvolvimento de plantas com as propriedades físicas do solo (Hamblin, 1985). As interações, envolvendo os aspectos dinâmicos da estrutura do solo, do clima e do manejo, aumentam as dificuldades para a quantificação da estrutura e das condições físicas do solo que determinam o crescimento das plantas (Hadas, 1997). Atualmente, reconhece-se que o estudo de aspectos relacionados à disponibilidade de água e à estrutura do solo são de fundamental importância para o entendimento de muitos processos de significância agrícola (Dexter \& Youngs, 1992; Hadas, 1997) necessários para o manejo do solo num contexto econômico e sustentável (Lal, 1994; Lal \& Stewart, 1995).

O arranjo das partículas do solo estabelece as proporções dos componentes sólidos, líquidos e gasosos, determinando o fornecimento de água, oxigênio e a resistência à penetração das raízes no solo. $A$ organização destes componentes determina a estrutura do solo (Kay, 1990), a qual controla a magnitude com que as propriedades físicas do solo interferem diretamente no crescimento das plantas. A estrutura ideal do solo é aquela que possibilita uma grande área de contato raiz-solo, além de suficiente espaço poroso para o movimento de água e gases e pouca resistência do solo à penetração das raízes (Kopi \& Douglas, 1991). Neste contexto, muitos aspectos da estrutura do 
solo foram revisados por Dexter (1988), Boone (1988), Kay (1990) e Hadas (1997). No entanto, a relação entre estrutura e produtividade das culturas ainda é pouco compreendida devido às dificuldades em quantificar os efeitos das alterações na estrutura sobre os atributos físicos do solo. A variabilidade espacial e temporal da estrutura é um dos fatores que dificultam esta quantificação (Dexter, 1988), bem como as interações entre vários atributos físicos do solo e destes com as condições climáticas, ampliando as dificuldades neste sentido. Por exemplo, uma variação na umidade do solo afeta o potencial mátrico, a aeração, a resistência do solo à penetração das raízes, a estabilidade dos agregados e a condutividade hidráulica do solo. Além desses aspectos, é necessário levar em conta que as necessidades das culturas em termos de condições físicas do solo variam em função da espécie envolvida e com o estádio fenológico.

As propriedades físicas do solo relacionadas com a produtividade das culturas podem ser divididas em duas categorias (Letey, 1985):

- aquelas diretamente relacionadas com 0 desenvolvimento das plantas. São as propriedades físicas do solo que determinam o fornecimento de água, de oxigênio, de temperatura e resistência mecânica para a emergência das plântulas e crescimento das raízes. Estes fatores físicos do solo determinam a taxa dos processos físiológicos, ligados com o crescimento radicular, com a fotossíntese e com o crescimento foliar.

- aquelas indiretamente relacionadas com o desenvolvimento das plantas, tais como a granulometria do solo, densidade do solo, agregação e porosidade. Atualmente, a maior parte das avaliações dos impactos dos sistemas de manejo sobre a estrutura dos solos é feita avaliando estes fatores físicos. Os efeitos destes fatores sobre a produtividade das culturas ocorrem por suas influências sobre a retenção de água, aeração, temperatura e resistência do solo à penetração das raízes.

Entre os fatores físicos do solo diretamente relacionados com o 
desenvolvimento das plantas, o conteúdo de água do solo é o mais intensivamente estudado. $O$ conteúdo de água entre a capacidade de campo (potencial mátrico igual a $-0,01 \mathrm{MPa}$ ) e o ponto de murchamento permanente (potencial mátrico igual a -1,5 MPa) foi definido por Viehmeyer \& Hendrickson (1927) como o conteúdo de água disponível (AD) às plantas. O conceito de água disponivel entre os potenciais de $-0,01$ e $-1,5 \mathrm{MPa}$, na zona radicular dos solos, tem sido utilizado no desenvolvimento de estratégias de manejo do solo (Cassel \& Nielsen, 1986), apesar das críticas ao conceito (Ritchie, 1981). Embora seja comumente relacionada entre os potenciais de $-0,01$ e $-1,5 \mathrm{MPa}$ a $A D$ é medida em limites de potenciais bastante variáveis (Dexter, 1988) e tem sido utilizada no manejo da irrigação e em estudos de crescimento de raízes (Jones et al., 1991). O conceito de $A D$ incorpora uma ampla variação de tamanhos de poros, e sua utilização como indicador da qualidade do solo para o crescimento das plantas implica assumir que, dentro destes limites, não ocorre nenhum outro tipo de limitação ao crescimento das plantas. No entanto, dependendo da condição estrutural do solo, nos limites de potenciais da $A D$ podem ocorrer limitações por excessiva resistência do solo ou aeração deficiente (Letey, 1985), reduzindo o crescimento das plantas.

$\mathrm{Na}$ ausência de limitações térmicas, as condições físicas na interface solo-raiz são controladas pela disponibilidade de água, aeração e resistência à penetração, cujas magnitudes são determinadas pela estrutura do solo (Hamblin, 1985; Letey, 1985; Boone, 1988; Hadas, 1997). A relação de dependência e inter-relação entre estes fatores dificulta o estabelecimento de um nível ótimo destes em relação à produtividade das culturas (Letey, 1985). De maneira geral, condições físicas do solo favoráveis ao crescimento das plantas têm sido associadas com uma porosidade de aeração mínima de $10 \%$ (Grable \& Siemer, 1968; Dexter, 1988; Glinski \& Lipiec, 1990; Bowen et al., 1996), na qual a difusão de oxigênio no solo torna-se limitante ao funcionamento das raízes (Currie, 1984). Um valor de resistência do solo à 
penetração das raízes de $2,0 \mathrm{MPa}$ tem sido comumente associado como impeditivo para o crescimento das raízes (Taylor et al., 1966) e da parte aérea das plantas (Weaich et al., 1996; Tardieu, 1994). No entanto, este valor é muito sensível à condição estrutural do solo (Ehlers et al., 1983; Hamblin, 1985; Stirzaker et al., 1996).

É necessária uma ampla disponibilidade de água para o crescimento do sistema radicular e absorção dos nutrientes. Desta forma, além da resistência à penetração e aeração, a $A D$ é considerada o principal fator físico do solo que controla o crescimento do sistema radicular e a produtividade das culturas. Os níveis destes parâmetros físicos dependem da condição estrutural do solo e das variações dinâmicas do conteúdo de água, de maneira que as alterações nestes fatores implicam modificações nas condições físicas do solo para o crescimento das raízes. Conseqüentemente, os efeitos da estrutura sobre o crescimento das plantas são melhor quantificados por meio do conteúdo de água do solo no qual o potencial mátrico, aeração e resistência do solo à penetração das raízes atingem níveis limitantes.

\subsection{Relações entre umidade do solo, resistência à penetração e crescimento das plantas}

Os resultados de algumas pesquisas relacionando o crescimento das plantas com as condições físicas do solo sugerem que as raízes atuam como sensores do ambiente físico do solo e enviam sinais à parte aérea que controlam o crescimento e a expansão foliar (Masle \& Passioura, 1987; Ludlow et al., 1989; Davies \& Zang, 1991). De forma geral, os efeitos das condições físicas do solo sobre o crescimento das plantas são magnificados com a secagem do solo, a qual as culturas estão freqüentemente expostas. A visão convencional é que com a secagem do solo ocorre, em cadeia, uma redução do potencial da água do solo até as folhas das plantas, afetando a taxa de processos fisiológicos como a fotossíntese e crescimento foliar. Contudo, a 
resposta fisiológica das culturas não é determinada somente pelo potencial total da água na folha (Turner, 1997), e alguns estudos sugerem o envolvimento de outros fatores, resultantes das modificações no conteúdo de água do solo.

Inúmeras pesquisas em fisiologia de plantas são propostas para avaliar o crescimento foliar em relação às mudanças no potencial da água na folha. Entre várias publicadas, as de Passioura (1988) e Saab \& Sharp (1989) demonstraram que o crescimento foliar de plantas de trigo e milho foi reduzido sob baixa disponibilidade de água, embora o potencial da água na folha fosse similar às plantas crescidas sob condições úmidas. Deste comportamento, supõem-se que com a secagem do solo, além das modificações no potencial da água no solo, outros atributos físicos do solo estão sendo alterados e atuam sobre o crescimento das plantas. Estas alterações no solo podem modificar 0 funcionamento bioquímico da planta, gerando sinais que chegam à parte aérea, informando à planta que as condições para o seu funcionamento estão se deteriorando e que reduções no crescimento e na taxa de transpiração são necessárias para manter a hidratação (Turner, 1997). As evidências sugerem também a presença de uma mensagem hormonal (Passioura \& Gardner, 1990), sendo 0 ácido abscísico o principal fitohormônio operativo sob condições de secagem do solo (Sharp et al., 1994; Turner, 1997). Outros hormônios podem estar envolvidos, como citocininas (Richards \& Rowe, 1977) e giberilinas (Carmi \& Heur, 1981), visto que o comportamento de plantas que crescem sob condições de alta resistência equivale ao crescimento sob volumes limitados de solo. Estas constatações têm importantes implicações agronômicas no manejo dos solos e das culturas, uma vez que a área foliar determina a quantidade de luz interceptada pelas plantas e, conseqüentemente, a produção de matéria seca e a produtividade econômica das culturas.

Há indicações de que em solos sob secagem, os sinais inibitórios ocorrem associados com o aumento da resistência do solo à penetração das 
raízes, reduzindo o crescimento do sistema radicular, a expansão e o crescimento foliar (Masle \& Passioura, 1987; Ludlow et al., 1989; Passioura \& Gardner, 1990). A redução no crescimento do sistema radicular com o aumento da resistência do solo é um processo bem documentado na literatura (Taylor et al., 1966; Voorhees et al., 1975; Dexter, 1988; Materechera et al., 1991; Kirkegaard et al., 1992a; Hettiaratchi, 1992; Voorhees, 1992; McMichael \& Quisenberry, 1993). Um aumento da resistência do solo à penetração pode ocorrer com a redução na umidade ou com um aumento da densidade do solo (Ayers \& Perumpral, 1982; Buscher, 1990; Buscher et al., 1997). No entanto, os efeitos da resistência sobre a redução do crescimento radicular independem da causa da elevação da resistência do solo (Masle \& Passioura, 1987). Os resultados obtidos pelos mesmos autores indicam que a elevada resistência do solo à penetração é mais efetiva em reduzir o crescimento da parte aérea do que do sistema radicular das plantas, sugerindo que as plantas podem crescer mais lentamente sob condições de elevada resistência, mesmo com adequada disponibilidade de água e nutrientes. Porém, nestas condições, um reduzido crescimento do sistema radicular implica em não atender a demanda de água e nutrientes das culturas (Barraclough \& Weir, 1988). A resistência à penetração é sensivelmente influenciada pela variação da umidade e pela condição estrutural do solo (Hamblin, 1985), o que demonstra a complexidade das avaliações do crescimento das plantas em relação à resistência do solo

A presença de macroporos, criados mecanicamente ou por vias biológicas, permite que as raízes utilizem-se de zonas de baixa resistência para terem acesso a um maior volume de água e nutrientes disponíveis nas camadas subjacentes. Constatações neste sentido foram feitas por Ehlers et al.(1983), Martino \& Shaykewich (1994) e são discutidas por Passioura (1991) e Boone \& Veen (1994). Há alguns questionamentos neste sentido, como Tardieu (1994), que sugerem que em solos compactados a rápida depleção de água nas zonas de concentração das raízes (macroporos) causa elevação da 
resistência à penetração nas paredes dos poros e/ou alta resistência ao fluxo de água em direção à raiz, ativando os mecanismos para o controle do crescimento da área foliar. Outros estudos indicam que o agrupamento das raízes no interior dos macroporos reduz a eficiência de absorção devido ao menor contato solo-raiz (Smucker \& Aiken, 1992; Passioura, 1991), além da interferência de fatores nutricionais e biológicos (Passioura, 1991). Na maior parte dos estudos, as escalas em que são feitas as avaliações impedem que os macroporos sejam incorporados nas medidas das propriedades físicas do solo, apesar de que as evidências experimentais sugerem que a presença dos macroporos produzem efeitos positivos (Stirzaker et al., 1996). Ainda há necessidade de estudos mais detalhados neste sentido, sob condições de campo, em escalas espaciais e de tempo maiores, visando a identificar os mecanismos atuantes nestas interações.

\subsection{Avaliação dos efeitos do manejo na qualidade física do solo para o crescimento das plantas}

As propriedades físicas do solo, diretamente ligadas ao crescimento das plantas, influenciam o seu crescimento por meio da atuação simultânea e das complexas interações envolvendo resistência, difusão de oxigênio e disponibilidade de água (Hamblin, 1985; Boone, 1988; Glinski \& Lipiec, 1990; Hadas, 1997). A disponibilidade de água é mais freqüentemente utilizada como indicador da qualidade física do solo, mas adiciona apenas o efeito do potencial da água no solo como limitação ao crescimento radicular. Num solo compactado, a taxa de difusão de oxigênio pode limitar o crescimento radicular em potenciais menores ou iguais à capacidade de campo (Eavis, 1972), enquanto que a excessiva resistência à penetração pode limitar o crescimento das raízes sob condições mais secas. As interações entre os atributos físicos do solo têm sido quantificadas em várias pesquisas ( Eavis, 1972; Taylor et al., 1966; Mirreh \& Ketcheson, 1976; Veen \& Boone, 1990). Por exemplo, Boone et 
al. (1987) demonstraram que a compactação do solo em conjunto com as variações da umidade, determinaram as variações na difusão de oxigênio no solo e na resistência à penetração das raízes durante o crescimento da cultura do milho. Também sob condições de campo, Phene \& Beale (1976) utilizaram freqüentes aplicações de água para manter o potencial mátrico numa amplitude de disponibilidade de água, aeração e resistência à penetração favoráveis ao crescimento normal das raizes de milho num solo compactado. 0 reconhecimento da ocorrência destas interações e de que as culturas estão sujeitas às suas interferências implica a necessidade de quantificá-las quando da avaliação da qualidade física do solo para o crescimento das plantas.

Neste contexto, a estrutura é a chave do funcionamento físico do solo para o crescimento e desenvolvimento das plantas (Dexter, 1997). A redução e a estagnação da produtividade das culturas acontecem, muitas vezes, da degradação física do solo devido à erosão e à compactação. As avaliações dos atributos físicos dos solos têm sido feitas utilizando propriedades que descrevem a sua forma estrutural, como a densidade e porosidade do solo (Carter, 1988; Dexter, 1988), a condutividade hidraúlica (Creswell \& Kirkegaard, 1995) e a resistência dos solos à penetração das raízes (Benghough \& Mullins, 1990). Em geral, estas determinações caracterizam bem os efeitos dos sistemas de uso e manejo sobre os atributos físicos do solo, mas demonstram muito pouco da sua funcionalidade física como meio de crescimento e desenvolvimento das plantas. Normalmente, avaliam-se propriedades físicas indiretamente relacionadas com 0 crescimento das plantas, ou não se tem levado em conta as interações entre os atributos físicos do solo diretamente ligados com o crescimento das plantas.

Os resultados de várias pesquisas apresentam coerência quanto às influências dos sistemas de manejo sobre a forma estrutural do solo, mas são pouco conclusivos quanto à qualidade física do solo para o crescimento das culturas (Eltz et al., 1988; Albuquerque et al., 1995; Campos et al., 1995). Por 
exemplo, uma grande parte dos trabalhos sobre o sistema de plantio direto mostra maiores produtividades, apesar de as propriedades físicas do solo, medidas através da densidade, porosidade e resistência do solo à penetração das raízes, serem mais limitantes às culturas em comparação ao preparo convencional do solo. Estas avaliações não permitem obter respostas diretas das condições físicas do solo para o crescimento das culturas, embora a produtividade destas seja função do ambiente físico na zona radicular (Trein et al., 1991). Os resultados obtidos por Lima (1995) demonstram que a redução na produtividade da cultura da cana-de-açúcar com o tempo de cultivo é indicativo da perda da qualidade física do solo. A perda da qualidade física do solo para o crescimento da cultura da cana-de-açúcar foi apenas sugerida nos estudos de Silva \& Ribeiro (1992) e Lima (1995), exigindo uma abordagem diferente nestas avaliações.

O preparo do solo, o tráfego de máquinas e equipamentos, a adição e a decomposição de produtos orgânicos exercem grande influência na forma, na estabilidade estrutural e em várias propriedades físicas do solo. Qualquer mudança significativa na estrutura do solo afeta de forma integrada as propriedades físicas que atuam no crescimento das plantas. Também uma variação no conteúdo de água afeta a taxa de difusão de oxigênio no solo bem como sua resistência à penetração das raízes. A magnitude destas alterações depende da textura e estrutura do solo.

Estas interações são demonstradas nos trabalhos de Boone et al. (1986, 1987), Bar-Yosef \& Lambert (1981), Mirreh \& Ketchenson (1972) e Eavis (1972), ressaltando haver uma interação bem definida entre o crescimento das raízes e o impedimento mecânico, a aeração e o potencial da água do solo. Idealmente, as condições físicas do solo deveriam ser expressas através de parâmetros que fornecessem de forma integrada estas variações nos atributos físicos do solo para avaliar as suas influências no crescimento das plantas (Boone, 1988). Desta forma, é possível caracterizar os efeitos dos sistemas de 
uso e manejo sobre o ambiente físico do solo para o crescimento das plantas. No entanto, isto requer uma abordagem diferente na forma de realizar estas avaliações, exigindo um número mínimo de parâmetros que integrem estas variações (Boone et al., 1986; Boone et al., 1987; Dexter, 1988).

\subsection{O Conceito do Intervalo Hídrico Ótimo (IHO) do solo}

O parâmetro que descreve a faixa de conteúdos de água do solo que incorpora as limitações ao crescimento das plantas por aeração, água disponivel e resistência do solo foi introduzido por Letey (1985). Esta faixa de conteúdos de água foi descrita como "Non-Limiting Water Range" (NLWR) e com exceção da temperatura, é um parâmetro que integra, numa única medida, os efeitos das modificações na estrutura do solo sobre seus atributos físicos diretamente ligados ao crescimento das plantas. Na definição deste conceito, Letey (1985) considerou que a resposta das plantas às modificações físicas do solo é ótima dentro dos limites do NLWR e impedida fora dos seus limites. Recentemente, Silva et al., (1994) aprimoraram e quantificaram este conceito, redefinindo-o como "Least Limiting Water Range" (LLWR). O LLWR é definido como a faixa de conteúdos de água na qual são mínimas as limitações para o crescimento das plantas associadas com o potencial matricial, aeração e resistência mecânica.

O limite superior do LLWR é a umidade do solo na capacidade de campo ou a umidade do solo na qual a porosidade de aeração é de $10 \%$; e o limite inferior é a umidade no ponto de murchamento permanente ou a umidade do solo na qual a resistência à penetração atinge $2,0 \mathrm{MPa}$. Na definição do LLWR, Silva et al. (1994) argumentam que o crescimento das culturas é menos limitado dentro dos limites do LLWR e que as magnitudes dessas limitações aumentam de dentro para fora destes limites. Da maneira como proposto por Letey (1985), o crescimento das plantas é completamente impedido fora dos limites do NLWR, ao passo que no LLWR, as limitações físicas ao crescimento 
das plantas aumentam para fora da faixa de conteúdos de água que determinam o LLWR (Silva et al., 1994). Isto justifica as possibilidades de crescimento das plantas fora dos limites estabelecidos para o potencial, aeração e resistência (Topp et al.1994). O LLWR também pode ser expresso através do potencial mátrico (Boone et al., 1986, 1987) ao invés da umidade. Recentemente, Boone \& Veen (1994) utilizaram a variação do potencial mátrico nos valores limites da porosidade de aeração, água disponivel e resistência do solo para explicar os efeitos da compactação sobre o crescimento das plantas.

O conceito do LLWR foi quantificado por Topp et al. (1994) e Silva et al. (1994) e proposto como um índice da qualidade estrutural do solo para o crescimento das plantas. Orellana et al. (1996) também utilizaram o conceito introduzido por Letey (1985) em avaliações da qualidade física do solo, denominando-o de Intervalo Hídrico Ótimo (IHO) do solo, o qual adotamos como tradução do LLWR, utilizado neste trabalho. O conceito do IHO é descrito na figura 1 , indicando que a degradação da estrutura do solo pode impor reduções no IHO e aumentar as limitações ao crescimento das plantas.

O IHO é considerado um índice da qualidade estrutural do solo para o crescimento das plantas (Silva et al., 1994; Topp et al., 1994). Os resultados obtidos por Silva \& Kay (1997a) e Kay et al. (1997) demonstram que o IHO é positivamente correlacionado com 0 conteúdo de matéria orgânica e negativamente com a densidade e teor de argila dos solos. A degradação da estrutura do solo resulta numa redução do IHO (Letey,1985), aumentando a probabilidade das raízes das culturas serem expostas a condições de insuficiente aeração ou excessiva resistência do solo (Kay, 1989). Isto foi confirmado por Silva \& Kay (1997b). Estes resultados sugerem que a compactação e a redução nos teores de matéria orgânica nos solos de textura argilosa aumentam a probabilidade de ocorrência de condições físicas impróprias para o crescimento das plantas. 0 crescimento de plantas de milho foi negativamente correlacionado com a magnitude do IHO e com a ocorrência 
da umidade do solo fora dos seus limites (Silva \& Kay, 1996). Estes resultados demonstram o potencial do IHO para a avaliação dos efeitos das práticas de manejo sobre a qualidade física do solo.
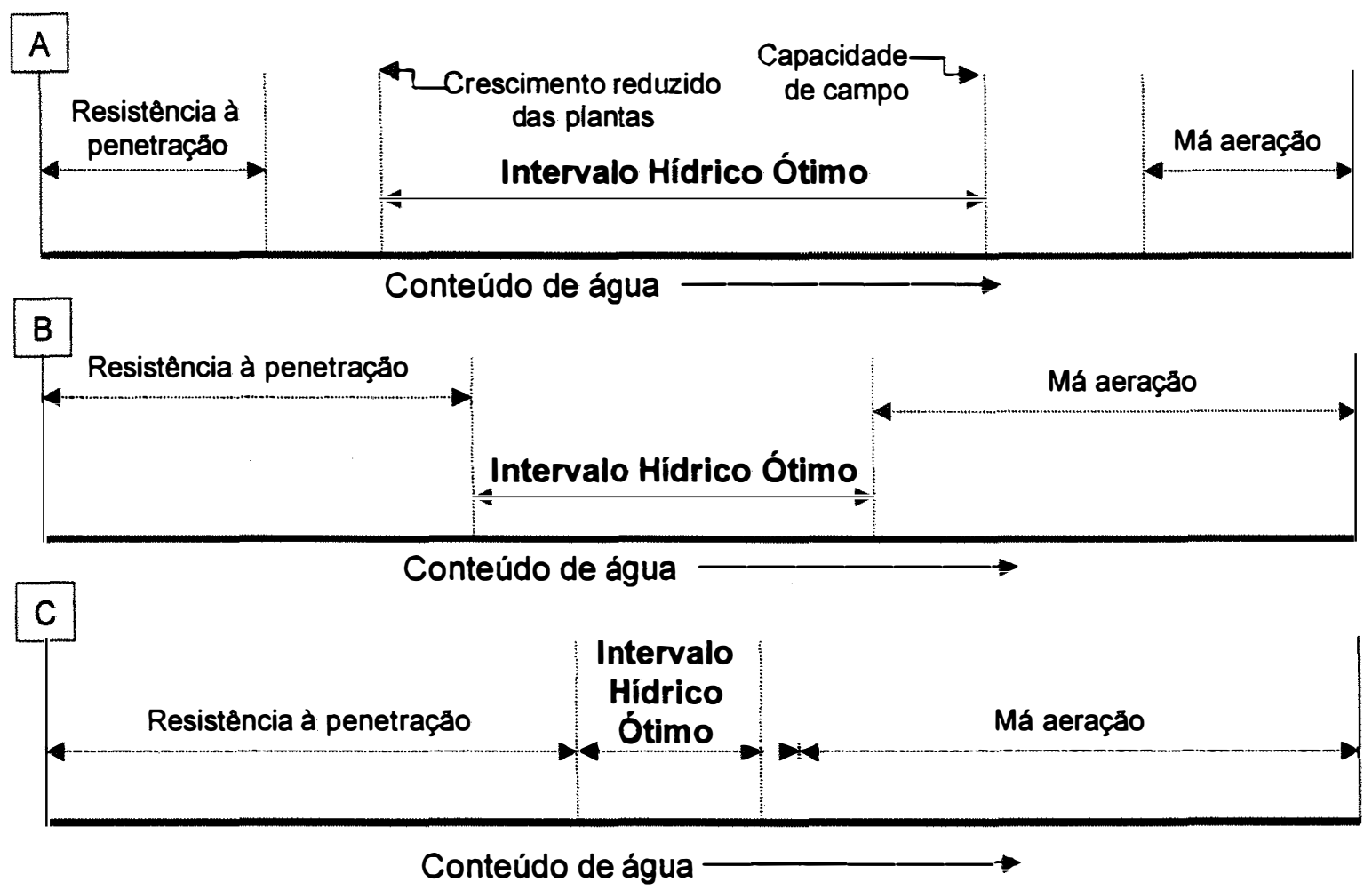

Figura 1. Relação entre 0 teor de água no solo e fatores que limitam o crescimento de plantas. Os fatores limitantes aumentam progressivamente em magnitude, resultando numa diminuição do Intervalo Hídrico Ótimo (IHO) do solo nas condições de $A$ para $C$ (Degradação do solo aumenta de A para $C$ ). [Retirado de Letey (1985).]

Evidências da funcionalidade do conceito do IHO são constatadas no trabalho de Phene \& Beale (1976), os quais demonstraram que o conteúdo de água no solo controla a presença ou não de condições impeditivas para as raízes. Também Jayawardane \& Chan (1994) fizeram uso do conceito do IHO para a avaliação das práticas de manejo em solos sódicos da Austrália. Os autores salientam que quanto mais estreito o IHO, maior é a dificuldade em 
manter o conteúdo de água do solo dentro dos limites da faixa de umidade ótima para o crescimento das plantas. Mais recentemente, Stirzaker (1997) demonstrou que com o aumento da compactação do solo, i.e aumento da densidade do solo, ocorreu redução do $\mathrm{IHO}$ e do crescimento vegetativo de plantas de tomate. A principal vantagem da utilização do IHO na avaliação da qualidade física do solo deve-se à integração, num único parâmetro, dos seus fatores físicos diretamente relacionados com o crescimento das plantas. Desta forma, práticas de manejo que modificam a estrutura do solo, ampliando o IHO e/ou mantendo a umidade dentro dos seus limites, são potencialmente menos restritivas para o crescimento e produtividade das culturas.

No contexto da abordagem feita por Boone (1988), o IHO se enquadra como um indice que fornece de forma integrada as manifestações funcionais da estrutura do solo para o crescimento e desenvolvimento das plantas. Isto é de grande importância para a distinção dos efeitos da condição estrutural do solo de outros que também influenciam a produtividade das culturas (Cresswell e Kirkegaard, 1995). Nos trabalhos de Topp et al. (1994) e Silva et al. (1994), a resistência à penetração foi o fator que mais freqüentemente impôs limitações ou o estreitamento do IHO, em relação à aeração no solo. Também Silva \& Kay (1997b) demonstram a maior freqüência com que o conteúdo de água ultrapassa o limite crítico imposto pela resistência à penetração, sendo dependente da magnitude da faixa de água disponível no solo. Nos solos sódicos, Jayawardane \& Chan (1994)) argumentam que logo após uma chuva ou irrigação, devido aos estreitos limites do $\mathrm{IHO}$, as culturas estão sujeitas a uma aeração deficiente no solo. Em adição aos resultados obtidos por Silva \& Kay (1996), estes estudos confirmam a hipótese de que a magnitude do IHO é um indicador da freqüência com que a estrutura do solo determina condições físicas impróprias para o crescimento das plantas. Assim, quanto maior a amplitude do $\mathrm{IHO}$, menor a probabilidade e freqüência de ocorrência de situações críticas às culturas (Kay, 1989). 
O IHO integra processos relacionados com a disponibilidade de água e ar e com parâmetros da resistência do solo num modo que incorpora os processos e mecanismos ligados com o crescimento das plantas e produção agrícola. Topp et al.(1994) utilizou o IHO para demonstrar como as práticas de manejo afetaram a qualidade física do solo de um ponto de vista de produção sustentável. Também Silva \& Kay (1996) demonstraram que o desenvolvimento da cultura do milho foi negativamente correlacionado com a freqüência com que a umidade do solo ocorre fora dos limites do IHO. Desta forma, o IHO apresenta um alto potencial como uma parâmetro da qualidade física do solo, com a vantagem de integrar mecanismos e processos diretamente relacionados ao crescimento e desenvolvimento das plantas, num único parâmetro.

\subsubsection{Quantificação do Intervalo Hídrico Ótimo do solo}

As dificuldades metodológicas e operacionais dificultam a obtenção do IHO diretamente no campo, como aquelas relatadas por Topp et al. (1994). No entanto, estimativas do IHO podem ser obtidas com base na curva de retenção de água, na curva de resistência, na estimativa da umidade do solo na qual a porosidade de aeração é de $10 \%$ e da densidade do solo. Os métodos para obtenção da densidade do solo são amplamente reconhecidos (Blake \& Hartge, 1986). Também, a partir das amostras obtidas para fins de determinação da densidade, podem ser obtidas as curva de resistência e de retenção de água do solo.

O limite superior do NLWR é a capacidade de campo ou o conteúdo de água no solo no qual a porosidade de aeração é $10 \%$ e o limite inferior é o ponto de murchamento permanente ou o conteúdo de água quando a resistência à penetração atinge 2,0 $\mathrm{MPa}$. Esses conteúdos de água são estimados a partir das curvas de resistência do solo e de retenção de água no solo. A porosidade de aeração é um parâmetro indicativo do espaço poroso disponível para o fluxo de oxigênio no solo, o qual aumenta com a secagem do 
solo devido a maior proporção de poros desprovidos de água. Portanto, a aeração do solo é diretamente relacionada com as características de retenção de água do solo. As evidências disponiveis sugerem que a porosidade de aeração de $10 \%$ é o limite inferior para uma adequada aeração para as raízes das culturas (Grable \& Siemer, 1968; Meyer \& Barrs, 1991; Xu et al., 1992)) e este valor foi utilizado por Silva et al. (1994) e Silva \& Kay (1997a) para as estimativas do IHO.

Os conteúdos de água na capacidade de campo (CC), no ponto de murchamento permanente (PMP) e o conteúdo de água disponivel (CC-PMP) podem ser medidos diretamente ou estimados a partir de funções matemáticas que representem a curva de retenção de água no solo. Os métodos para a determinação da curva de retenção de água no solo são bastante conhecidos (Klute, 1986), apesar de demorados, trabalhosos e, portanto, caros. A curva de retenção é obtida através de medidas simultâneas da umidade $(\theta)$ e do potencial $(\psi)$ sob condições, teoricamente, de equilíbrio, com um decréscimo lento e contínuo destas variáveis durante o processo (Topp et al., 1993). Para a utilização da curva de retenção, Perfect et al. (1996) argumentam que é necessário que ela seja funcionalmente descrita, e que seus dados sejam resumidos em um número mínimo de parâmetros que reflitam as influências da textura e da estrutura do solo. Para isto, comumente são utilizados dois modelos, entre os vários descritos na literatura: o de Van Genuchten (1980) e o de Campbell (1974). Se há necessidade da função descrever a curva próximo à saturação, a função de Van Genuchten é preferida em relação à de Campbell (Van Genuchten \& Nielsen, 1985). Embora o modelo de Campbell descreva adequadamente a curva de retenção sob diferentes tipos de solos (Williams et al., 1983; Saxton et al., 1986; Williams et al., 1993), ele tem validade a partir do potencial de entrada de ar no solo. Ainda que mais complexo, o modelo de Van Genuchten (1980), uma função não linear, ajusta melhor os dados experimentais (Cresswell \& Paydar, 1996; Felton \& Nieber, 1991) do que o 
modelo de Campbell, de forma que muitos pesquisadores apresentam os dados $\theta(\psi)$ através desta função (Vereecken et al., 1989; Scheinost et al., 1997; Sinowski et al., 1997).

A obtenção usual da curva de retenção de água é demorada e impede a incorporação da variabilidade da estrutura do solo nas suas estimativas. Desta forma, Silva et al. (1994), utilizando a abordagem sugerida por Williams et al. (1993), obtiveram a curva de retenção agrupando várias amostras para representar um ponto de $\theta(\psi)$. A partir de métodos estatísticos de regressão múltipla, Silva et al. (1994) incorporaram as variações de textura e estrutura do solo na previsão dos conteúdos de água através de uma função da forma potencial. Os métodos utilizados permitiram boas estimativas das umidades na CC e no PMP, contemplando a variação da estrutura por meio da densidade do solo. Estes métodos para modelar a curva de retenção têm sido restritos aos modelos passíveis de serem linearizados.

A resistência do solo à penetração das raízes é outra propriedade física do solo diretamente ligada com o crescimento radicular e sua variação é determinada pela densidade e umidade do solo. A relação funcional entre estas variáveis pode ser identificada como curva de resistência do solo - CRS (Silva \& Kay, 1997a). A obtenção e a modelagem da CRS deve envolver uma ampla variação de umidade na variação natural ou induzida da estrutura do solo. Em geral, estas condições são mais dificilmente obtidas sob condições de campo, uma vez que com a secagem do solo torna-se impraticável fazer as medidas de sua resistência com os penetrômetros projetados para este fim. Por isso, a utilização de penetrômetros de laboratório é mais adequada, permitindo a obtenção dos dados de resistência nos extremos da retenção de água. A curva de resistência pode ser estimada por várias funções (Busscher, 1990). Funcionalmente a resistência à penetração é uma função não linear da umidade e densidade do solo. Este tipo de função foi utilizada por Silva et al. (1994), Silva \& Kay (1997a) e Kay et al. (1997), com excelentes descrições da 
CRS. A incorporação dos efeitos de variáveis qualitativas na descrição da CRS foi feita por Silva et al. (1994) a partir da abordagem sugerida por Williams et al. (1993). A vantagem da obtenção da CRS em laboratório é que ela pode ser feita simultaneamente à obtenção da CRA, de modo que as medidas de resistência são feitas nas mesmas amostras após a aplicação dos diferentes potenciais utilizados. Este procedimento permite simular, sob a variação natural da densidade do solo, uma ampla variação de umidade e, assim, representar as variações da resistência ao longo da secagem do solo.

\subsection{Avaliação da estrutura e da qualidade física em solos tropicais}

Nos solos tropicais e subtropicais a implantação de sistemas agrícolas tem causado um rápido declínio no potencial produtivo dos solos devido as rápidas perdas de matéria orgânica do solo (Matson et al., 1997) e degradação da estrutura do solo (Cassel \& Lal, 1992). Este processo inicia-se, mais fortemente, com a abertura mecanizada das áreas (Lal \& Cummings, 1979; Alegre et al., 1986; Lal, 1986; Ghuman et al., 1991; Ghuman \& Lal, 1992) e é intensificado com a implantação, em larga escala, de sistemas agrícolas mecanizados (Lal, 1986; Kayombo et al., 1991). Há um grande volume de informações científicas a respeito da estrutura e propriedades físicas em solos tropicais (Lal, 1979; Sanchez, 1976; Theng, 1980; Cassel \& Lal, 1992; Kayombo \& Lal, 1993). As respostas das diferentes culturas a estas modificações têm sido traduzidas em modificações na produtividade das culturas em várias regiões tropicais (Kayombo \& Lal, 1994), com a magnitude das respostas dependendo dos diferentes tipos de solos, culturas e sistemas de manejo.

De forma geral, a estrutura e o comportamento físico dos solos tropicais têm sido avaliados por meio de propriedades físicas indiretamente relacionadas com o crescimento das plantas, como a densidade e porosidade do solo, infiltração, condutividade hidráulica, estabilidade e distribuição dos 
tamanhos de agregados. Já os parâmetros físicos com influência direta sobre o crescimento das plantas, ou seja, o potencial da água no solo, a aeração e a resistência do solo à penetração, na maior parte dos estudos, são avaliados individualmente. A disponibilidade de água é considerada a principal limitação à produção agrícola nos solos tropicais (Lal, 1979; Hsiao et al., 1980) e, também um dos fatores físicos mais estudados nestes solos.

As condições de aeração do solo, estimadas pela porosidade de aeração, e a resistência à penetração, devido à facilidade e simplicidade de medidas, são também com freqüência utilizadas em muitas avaliações. A revisão da literatura, até a presente data, demonstra que as relações manejoestrutura-propriedades físicas em solos tropicais não têm sido avaliadas através das alterações conjuntas sobre a disponibilidade de água, resistência à penetração e aeração do solo. No entanto, Lal (1994) sugere a utilização do IHO na avaliação da estrutura e propriedades físicas dos solos tropicais. Desta forma, há necessidade de que avaliações do IHO sejam conduzidas em solo tropicais, para identificar as limitações $e$ as potencialidades do IHO na avaliação da qualidade física destes solos. 


\section{CARACTERIZAÇÃO DO INTERVALO HÍDRICO ÓTIMO DE UM LATOSSOLO ROXO SOB PLANTIO DIRETO}

\subsection{Resumo}

O crescimento do sistema radicular e da parte aérea das plantas é influenciado por vários atributos físicos do solo, com complexas interações envolvendo o potencial da água, o teor de oxigênio e a resistência do solo à penetração das raízes. O Intervalo Hídrico Ótimo (IHO) é um parâmetro físico que incorpora os efeitos do conteúdo de água no solo sobre as variações do potencial mátrico, aeração e resistência mecânica do solo. $\mathrm{O} \mathrm{IHO}$ não tem sido avaliado em solos tropicais, pelo que, o objetivo deste trabalho é 0 de caracterizá-lo num latossolo roxo (Typic Hapludox), cultivado com milho no sistema de plantio direto. Para este fim, foram obtidas, nas posições linha e entrelinha da cultura do milho, 72 amostras de solo com estrutura indeformada, nas quais se determinou a curva de retenção de água, a curva de resistência à penetração e a densidade do solo, necessárias à obtenção dos limites superior e inferior que definem $\circ \mathrm{IHO}$. Os resultados demonstram que $\circ \mathrm{IHO}$ foi positivamente relacionado com a densidade do solo até $1,1 \mathrm{Mg} \mathrm{m}^{-3} \mathrm{e}$ negativamente para maiores valores. A amplitude de variação do $\mathrm{IHO}$ foi de $0,0073 \mathrm{~m}^{3} \mathrm{~m}^{-3}$ até $0,125 \mathrm{~m}^{3} \mathrm{~m}^{-3}$. A umidade na resistência à penetração de 2,0 $\mathrm{MPa}$ foi o limite superior do $\mathrm{IHO}$ em $85 \%$ das amostras, enquanto o limite superior do $\mathrm{IHO}$ foi determinado pela capacidade de campo em $97 \%$ das amostras. Com o aumento da densidade, a qualidade física do solo para o crescimento das plantas é melhor descrita pelo IHO do que pelo conceito de água disponível entre a capacidade de campo e o ponto de murcha 
permanente. Neste solo, a redução nos limites do IHO foi determinada pela variação da umidade na resistência do solo crítica à penetração das raízes e pela umidade na capacidade de campo. Avaliações suplementares do IHO em solos tropicais poderiam ser feitas sob condiçōes de ampla variação de textura e de manejo.

Termos para indexação: propriedades físicas do solo, resistência à penetração, densidade do solo, plantio direto.

\subsection{SUmmary: CHARACTERIZATION OF THE OPTIMUM HYDRIC INTERVAL OF AN OXISOL UNDER NO-TILLAGE}

Soil physical attributes, specifically the soil water potential, soil oxygen, and the soil strength directly affect plant growth. The optimum hydric interval, $\mathrm{OHI}$, is the range of soil water content within which plant growth is least limited by water potential, aeration and mechanical resistance and has not been evaluated in tropical soils. The objective of this research was to characterize the $\mathrm{OHI}$ of a Typic Hapludox cropped to corn under no-tillage. Seventy-two undisturbed soil samples were collected at the crop row and interrow. The soil water retention curve and the soil resistance curve were evaluated in order to compute the $\mathrm{OHI}$. The results indicated that the $\mathrm{OHI}$ varied positively with bulk density up to $1,1 \mathrm{Mg} \mathrm{m}^{-3}$ and negatively for higher densities. The $\mathrm{OHI}$ ranged from 0,0073 to $0,1252 \mathrm{~m}^{3} \mathrm{~m}^{-3}$. Soil penetration resistance was the limiting factor at the dry end of the $\mathrm{OHI}$ in $85 \%$ of the samples while field capacity was the limiting factor at the wet end in $97 \%$. Further studies on the $\mathrm{OHI}$ in tropical soils would be relevant under a wide range in texture and management.

Index terms: soil physical properties, soil density, soil penetration resistance, no-tillage. 


\subsection{Introdução}

A capacidade do solo em prover o sistema radicular de condições físicas adequadas para o crescimento e desenvolvimento das plantas é denominada qualidade física do solo. A estrutura do solo pode ser alterada pelas práticas de manejo, influenciando a produtividade das culturas através das modificações na disponibilidade de água, na difusão de oxigênio e na resistência do solo à penetração das raízes. A quantificação e a compreensão do impacto destas práticas sobre a qualidade física do solo é fundamental no desenvolvimento de sistemas agrícolas sustentáveis (Dexter \& Youngs, 1992). A relação entre a estrutura do solo e a produtividade das culturas ainda é pouco compreendida devido às dificuldades em quantificar os vários atributos físicos do solo ligados a sua estrutura. A variabilidade espacial e temporal da estrutura é um dos fatores que dificulta esta quantificação (Dexter, 1988) e, além disso, alguns atributos físicos do solo variam mutuamente.

As condições físicas na zona radicular, que estão relacionadas com a estrutura do solo, são determinadas pela disponibilidade de água, pela aeração, pela temperatura e pela resistência que o solo oferece à penetração das raízes (Eavis, 1972; Letey, 1985; Hamblin, 1985; Boone et al., 1986). Os atributos físicos do solo diretamente relacionados com o crescimento das plantas são a retenção de água, a aeração e a resistência à penetração das raízes (Letey, 1985). Valores limites destas propriedades em relação ao crescimento das plantas têm sido documentados na literatura. Os resultados obtidos por Grable \& Siemer (1968) sugerem a porosidade de aeração de 10\% como crítica para o crescimento radicular, em função da limitada difusão de oxigênio no solo. Taylor et al. (1966) consideram que valores de resistência à penetração acima de 2,0 $\mathrm{MPa}$ são impeditivos ao crescimento e funcionamento do sistema radicular. Viehmeyer \& Hendrickson (1927) presumiram como água disponivel (AD) a quantidade de água existente entre a capacidade de campo e o ponto de murchamento permanente. $O$ conceito de $A D$ entre os potenciais mátricos de $0,01 \mathrm{MPa}(\mathrm{CC})$ e $-1,5 \mathrm{MPa}$ (PMP), na zona radicular dos solos, tem sido 
utilizado no desenvolvimento de estratégias de manejo do solo (Cassel \& Nielsen, 1986), apesar das críticas (Ritchie, 1981).

A AD incorpora uma ampla variação de tamanhos de poros, e sua utilização como indicador da qualidade do solo para o crescimento das plantas implica em presumir que, dentro desta faixa de potenciais, não ocorrem limitações por aeração e/ou resistência do solo. No entanto, esta condição depende da estrutura do solo (Hamblin, 1985). Em um solo compactado, Boone et al. (1987) demonstraram que a ocorrência de restrições ao crescimento das plantas por excessiva resistência e/ou reduzida difusão de oxigênio foi dependente da variabilidade temporal da umidade devido à distribuição da precipitação. Por outro lado, Phene \& Beale (1976) utilizaram a variação do conteúdo de água no solo para demonstrar que é possível obter condições de abundante desenvolvimento de raízes num solo compactado.

Várias pesquisas sugerem estreita interação entre as condições físicas do solo e o crescimento das plantas, uma vez que as raízes parecem dispor de mecanismos de detecção destas condições, enviando sinais à parte aérea que controlam o crescimento e a expansão foliar (Masle \& Passioura, 1987; Davies \& Zang, 1991; Passioura \& Gardner, 1990). O reconhecimento da ocorrência desta interação e de que as culturas estão sujeitas às suas interferências, implica na necessidade de quantificá-la na avaliação dos efeitos das práticas de manejo sobre as condições físicas do solo, que são quantificadas por vários parâmetros da sua estrutura. Freqüentemente, tem-se enfatizado a necessidade de um número mínimo de parâmetros que integrem estas condições (Boone, 1988; Boone et al., 1987; Dexter, 1988), apesar dos problemas envolvidos na redução de complexas interações para um único parâmetro (Topp et al., 1994).

O conceito de um único parâmetro que descreve as interações entre os atributos físicos relacionados com o crescimento das plantas foi proposto por Letey (1985) - "Non Limiting Water Range" (NLWR) - Faixa de Água Não Limitante. O NLWR é definido como a faixa de conteúdos de água no solo em 
que as limitações para o crescimento das plantas em função do potencial mátrico, aeração e resistência do solo são nulas. O limite superior do NLWR é a capacidade de campo ou o conteúdo de água no solo no qual a porosidade de aeração é $10 \%$; o limite inferior é o ponto de murchamento permanente ou o conteúdo de água quando a resistência à penetração atinge 2,0 $\mathrm{MPa}$. Isto sugere que 0 crescimento radicular ocorre normalmente entre os limites do NLWR e é completamente impedido fora destes. No entanto, o crescimento do sistema radicular varia de uma forma contínua com os fatores físicos acima (Allmaras \& Logsdon, 1990), o que levou Silva et al. (1994) a aprimorarem este conceito. Eles argumentam que o crescimento das raízes é limitado ao mínimo dentro dos limites, enquanto as limitações aumentam fora destes limites, caracterizando o "Least Limiting Water Range" (LLWR) - Faixa de Água Mínima Limitante.

O LLWR foi quantificado por Topp et al. (1994) e Silva et al. (1994) e proposto como índice da qualidade estrutural do solo para o crescimento das plantas. Orellana et al. (1997) também utilizaram o conceito introduzido por Letey (1985) em avaliações da qualidade física do solo, denominando-o de Intervalo Hídrico Ótimo (IHO) do solo, o qual adotamos neste trabalho. O IHO integra três fatores relacionados com o crescimento das plantas determinado pelas propriedades intrínsecas e pela estrutura do solo (Silva et al., 1994). Estas particularidades tornam o IHO um parâmetro útil para avaliar a qualidade estrutural e o impacto das práticas de manejo sobre a qualidade física do solo para o crescimento das plantas, com a vantagem de relacionar as limitações do solo diretamente aos fatores de resposta das culturas.

O estabelecimento dos níveis limitantes de propriedades físicas é bastante complexo, pois envolve a integração de variáveis relacionadas com 0 solo, clima e planta. A capacidade de campo é um processo dinâmico, e a escolha de um potencial para especificar a umidade na CC não tem respaldo teórico, apesar de que para fins práticos, é mais adequado utilizar potenciais mais elevados do que 0 tradicionalmente empregado de $-0,033 \mathrm{MPa}$, 
especificamente entre 0,006 e de $-0,01 \mathrm{MPa}$ (Reichardt, 1988). Em relação ao PMP, Savage et al. (1996) demonstraram que o conteúdo de água no potencial de $-1,5 \mathrm{MPa}$ pode ser considerado o limite inferior de disponibilidade de água às plantas. De acordo com Silva et al. (1994), a sensibilidade de variação do IHO com a densidade está ligada aos limites de resistência e aeração selecionados. A porosidade de aeração de $10 \%$ tem sido adotada como critica para o crescimento radicular das plantas, apesar da variação deste valor entre diferentes espécies de plantas. Topp et al. (1994) argumentam que, em algumas situações, este valor de $10 \%$ pode não ser suficiente para atender a demanda do sistema radicular em oxigênio. Em relação à resistência crítica, o valor de 2,0 $\mathrm{MPa}$ tem sido aceito como o limite crítico, embora diferentes espécies de plantas apresentarem competências distintas para penetrar o solo (Materechera et al., 1991). Algumas pesquisas têm demonstrado que as culturas podem apresentar crescimento radicular sob resistências superiores a 2,0 MPa (Ehlers et al., 1983; Topp et al., 1994), ou restrito sob resistências ainda menores que este valor (Bengough \& Mullins, 1990).

A variabilidade na textura e os impactos dos sistemas de manejo sobre a estrutura dos solos modificam seus atributos físicos na zona radicular, promovendo alterações na amplitude do IHO (Silva et al., 1994; Topp et al., 1994;). As modificações no conteúdo de água no solo magnificam o impacto da estrutura sobre o crescimento das plantas, de forma que, conforme sugerido por Kay (1990), quanto menor o IHO, maior a probabilidade de ocorrência de limitações físicas para o crescimento das raízes. Esta hipótese foi comprovada por Silva \& Kay (1997b), indicando que a freqüência de ocorrência de conteúdos de água fora dos limites do IHO foi negativamente relacionada com sua amplitude. Isto significa que os sistemas de manejo que proporcionam um menor valor de $\mathrm{IHO}$ expõem as culturas a um maior número de situações de estresse, por excesso ou falta de água. Desta forma, a magnitude do IHO pode ser utilizada como diagnóstico da freqüência com que a estrutura do solo determina as umidades que impõem limites ao crescimento das plantas. 
A amplitude do IHO depende da estrutura e da textura do solo. O IHO foi avaliado em solos de clima temperado com diferentes classes texturais e condições de manejo. Os resultados demonstram que ele é negativamente correlacionado com o teor de argila e a densidade dos solos (Topp et al., 1994; Silva et al., 1994; Silva \& Kay, 1997a). Os resultados obtidos por Topp et al. (1994) indicam que freqüentemente ocorrem valores muito baixos e até nulos do $\mathrm{IHO}$ em solos argilosos. Estreitos valores do $\mathrm{IHO}$ sugerem que as culturas podem ser submetidas a restrições por aeração deficiente ou excessiva impedância mecânica durante o seu crescimento, conforme teorizado por Kay (1990). Estas constatações sugerem a necessidade de quantificar o IHO em solos tropicais, especialmente aqueles com elevados teores de argila, com o objetivo de avaliar a sua sensibilidade às modificações na estrutura pelos sistemas de manejo. Entre estes solos, os latossolos de textura argilosa ou muito argilosa apresentam, sob condições naturais, excelentes condições físicas oriundas da microestrutura granular fortemente desenvolvida. Em geral, as boas condições físicas do solo referem-se à infiltração de água e à baixa erodibilidade, sem menção à sua qualidade estrutural. Os objetivos deste trabalho são quantificar o IHO através da metodologia proposta por Silva et al. (1994) e caracterizar o seu comportamento num latossolo roxo muito argiloso, cultivado com milho no sistema de plantio direto.

\subsection{Material e Métodos}

Este estudo foi realizado numa área agrícola comercial situada no município de Guaíra, região nordeste do Estado de São Paulo, situado entre as coordenadas $20^{\circ} 19^{\prime} 13^{\prime \prime}$ de latitude sul e $48^{\circ} 18^{\prime} 03^{\prime \prime}$ de longitude oeste. De acordo com a classificação de Köppen, o clima da região é do tipo Cwa, com temperatura média de $22,7^{\circ} \mathrm{C}$, precipitação média $1420 \mathrm{~mm}$ entre outubro e abril; e um período seco, com precipitações de menos de $220 \mathrm{~mm}$, entre maio e setembro (Saad, 1987). 
Neste estudo foram utilizadas amostras de um latossolo roxo (Typic Hapludox), cuja análise granulométrica revelou valores médios de $800 \mathrm{~g} \mathrm{~kg}^{-1}$ de argila, $150 \mathrm{~g} \mathrm{~kg}^{-1}$ de silte e $50 \mathrm{~g} \mathrm{~kg}^{-1}$ de areia (Classe textural muito argiloso). A amostragem foi realizada num talhão cultivado no sistema de plantio direto $\mathrm{e}$ irrigado por aspersão através de pivô-central, com amostras obtidas na profundidade de $0-10 \mathrm{~cm}$. A rotação de culturas utilizada consiste da cultura de soja no verão, como cultura principal; milho no inverno, como cultura "safrinha"; e, na seqüência, a cultura do feijão. A amostragem foi feita na primeira quinzena de agosto de 1996 e, neste período, a área estava sendo cultivada com milho (Zea mays L.) c.v. Cargill 701. A adubação de base da cultura de milho foi com $330 \mathrm{Kg} \mathrm{ha}^{-1}$ de uma formulação comercial 04-20-20 $+\mathrm{Zn}$. As adubações de cobertura corresponderam a $145 \mathrm{~kg} \mathrm{ha}^{-1}$ da formulação comercial 20-00-20 aplicada 20 dias após a emergência (DAE) das plantas; 70 e $40 \mathrm{~kg} / \mathrm{ha}$ de uréia foram aplicados aos 35 e 50 DAE. O controle de ervas daninhas foi feito através de métodos químicos convencionais.

A amostragem foi realizada na fase de maturação da cultura do milho. Foram retiradas amostras com estrutura indeformada da camada de 0-0,10 m de profundidade, para as determinações físicas necessárias. Os pontos de amostragem foram localizados numa transeção transversal às linhas das culturas, com comprimento de $32,4 \mathrm{~m}$, sendo as amostras retiradas a cada 0,45 $m$, seqüencialmente nas posições linha (L) e entrelinha (EL) da cultura, totalizando 72 amostras, que foram acondicionadas em sacos plásticos e mantidas sob temperatura de $\pm 5^{\circ} \mathrm{C}$ até serem processadas.

Após devidamente preparadas, as amostras foram saturadas através da elevação gradual de uma lâmina de água numa bandeja, até atingir cerca de 2/3 da altura das amostras. Para a determinação da curva de retenção adotouse o procedimento descrito em Silva et al. (1994). As amostras foram divididas em 9 grupos de 8, sendo quatro amostras por posição de amostragem: 4 amostras na linha e 4 amostras na entrelinha. Em cada grupo de amostras foram aplicados os seguintes potenciais: -0,006 e - $-0,008 \mathrm{MPa}$ numa mesa de 
tensão adaptada de Topp \& Zebchuk (1979); $-0,01,-0,03,-0,05,-0,07,-0,1,-0,5$ e -1,5 $\mathrm{MPa}$ através de pressões aplicadas em placas porosas conforme Klute (1986). Após atingir o equilíbrio, as amostras foram utilizadas para determinar a resistência à penetração e, em seguida, secas em estufa a $105-110^{\circ} \mathrm{C}$ para determinação do conteúdo de água e da densidade do solo conforme Blake \& Hartge (1986).

Para a determinação do IHO é necessário o conhecimento das curvas de retenção de água e de resistência do solo. A relação funcional entre potencial mátrico $(\psi)$ e conteúdo volumétrico de água $(\theta)$ foi ajustada utilizando a função empregada por Silva et al. (1994):

$$
\theta=a|\psi|^{b}
$$

ou a transformação para logarítmica

$$
\ln \theta=\ln a+b \ln |\psi|
$$

onde $\theta=$ conteúdo volumétrico de água $\left(\mathrm{cm}^{3} \mathrm{~cm}^{-3}\right), \psi=$ potencial mátrico $(\mathrm{cm})$, e a e b são constantes estimadas no ajuste da função. A influência da posição de amostragem foi descrita como uma variável indicadora, conforme Silva et al. (1994).

A resistência do solo foi determinada em cada amostra após a aplicação dos potenciais já especificados, com o que se estabeleceu um gradiente de umidade entre as amostras. Utilizou-se um penetrômetro desenvolvido no Laboratório de Física de Solos da ESALQ-USP. O penetrômetro é composto por um atuador linear elétrico com motor de passo; um painel para controle da velocidade e direção de deslocamento; uma base metálica para sustentação do conjunto mecânico e da amostra durante o teste; e uma célula de carga com capacidade nominal de $20 \mathrm{~kg}$ acoplada na extremidade do braço mecânico do atuador. Uma haste metálica, com diâmetro de $6 \mathrm{~mm}$ e com um cone na sua extremidade foi utilizada para determinar a resistência do solo à penetração. $O$ cone possui um semi-ângulo de penetração de $30^{\circ}$ e área da base de $0,1256 \mathrm{~cm}^{2}$. As medidas de resistência à penetração 
foram obtidas através de um sistema automatizado de aquisição de dados e armazenadas num arquivo de dados próprio do sistema.

Para a determinação da resistência à penetração foi feita uma medida de resistência no centro geométrico de cada amostra. A velocidade de penetração foi de $1,0 \mathrm{~cm} \mathrm{~min}{ }^{-1}$ até a profundidade de $4,0 \mathrm{~cm}$. As medidas obtidas da superfície da amostra até $1,0 \mathrm{~cm}$ de profundidade foram descartadas, uma vez que a resistência aumenta até uma determinada profundidade, e depois tende a tornar-se constante. Esta profundidade é considerada por Bradford (1986) como profundidade crítica de penetração e na maioria das amostras, ocorreu entre 0,5 e $1,0 \mathrm{~cm}$. $O$ equipamento foi configurado para obter os valores de resistência em $\mathrm{MPa}$, de forma que nenhuma transformação foi requerida no tratamento dos dados. A freqüência de amostragem correspondeu à coleta de um valor de resistência a cada 0,6767 segundos, obtendo-se um total de 266 leituras, das quais um valor médio foi utilizado.

A relação funcional entre a resistência do solo à penetração (RP), densidade (Ds) e o conteúdo de água no solo, identificada como curva de resistência do solo (CRS), foi ajustada por meio do modelo não linear proposto por Buscher (1990), utilizando os procedimentos descritos por Silva et al. (1994).

$$
R P=c \theta^{d} D_{s}^{e}
$$

Ou alternativamente,

$$
\ln R P=\ln c+d \ln \theta+e \ln D_{s}
$$

onde $\mathrm{RP}=$ resistência do solo à penetração $(\mathrm{MPa}), \theta=$ conteúdo volumétrico de água $\left(\mathrm{cm}^{3} \mathrm{~cm}^{-3}\right)$, Ds=densidade do solo $\left(\mathrm{Mg} \mathrm{m}^{-3}\right)$ e $\mathrm{c}, \mathrm{d}$, e são constantes. $A$ influência da posição de amostragem foi avaliada utilizando a mesma abordagem para a curva de retenção de água.

Os ajustes das curvas de resistência e de retenção de água foram feitos através da rotina PROC REG (SAS Institute, 1991). O IHO foi determinado conforme descrito em Silva et al. (1994). Um valor do IHO foi 
calculado para cada amostra, com valor conhecido da densidade do solo. Os valores críticos para o crescimento das culturas associados com o potencial mátrico, resistência do solo e porosidade de aeração foram, respectivamente: a capacidade de campo $\left(\theta_{\mathrm{cc}}\right)$ ou conteúdo de água no potencial de $-0,01 \mathrm{MPa}$ (Haise et al., 1955), o ponto de murchamento permanente ( $\left.\theta_{\mathrm{PMP}}\right)$ ou conteúdo de água no potencial de -1,5 MPa (Richards \& Weaver, 1944; Savage et al., 1996), o conteúdo de água no solo em que a resistência ( $\left.\theta_{R P}\right)$ atinge $2,0 \mathrm{MPa}$ (Taylor et al., 1966) e o conteúdo de água no solo em que a porosidade de aeração $\left(\theta_{\mathrm{PA}}\right)$ é $10 \%$ (Grable \& Siemer, 1968). Os valores de $\theta_{\mathrm{Cc}}$ e $\theta_{\mathrm{PMP}}$ foram obtidos nos potenciais de $-0,01$ e $-1,5 \mathrm{MPa}$ utilizando a curva de retenção, e os valores de $\theta_{R P}$ em que ocorre resistência à penetração de 2,0 $\mathrm{MPa}$ foram obtidos através do modelo de resistência ajustado aos dados. $O$ valor de $\theta_{\mathrm{PA}}$ em que a porosidade de aeração é $10 \%$ foi obtido por [(1-Ds/2,65) - 0,1]. Assumiuse o valor de $2,65 \mathrm{Mg} \mathrm{m}^{-3}$ como a densidade média de sólidos neste solo.

O IHO foi calculado como a diferença entre os limites superior e inferior dos conteúdos de água em que ocorrem os parâmetros físicos considerados. O limite superior é o menor valor de $\theta$ considerado na capacidade de campo ou na porosidade com ar de 10\%, e o limite inferior é o maior valor de $\theta$ na resistência de $2,0 \mathrm{MPa}$ ou no ponto de murchamento permanente.

\subsection{Resultados e Discussão}

Os valores médios e a variação dos parâmetros físicos determinados nas amostras são apresentados na tabela 1. Não foram constatados efeitos estatisticamente significativos $(p<0,05)$ das posições de amostragem nas curvas de retenção de água e resistência do solo. Isto pode ser atribuído ao efeito de homogeneização do solo pelos cultivos sobre a área, em torno de três por ano agrícola.

Os coeficientes do modelo de resistência do solo à penetração são 
apresentados na tabela 2. O modelo ajustado explicou $86 \%$ da variabilidade dos dados de resistência à penetração.

Tabela 1. Distribuição estatística dos parâmetros físicos do solo determinados nas amostras com estrutura indeformada $(n=72)$.

\begin{tabular}{ccccc}
\hline Variável & Média & Desvio Padrão & Mínimo & Máximo \\
\hline RP & 1,609 & 0,908 & 0,401 & 4,680 \\
DS & 1,152 & 0,059 & 1,000 & 1,280 \\
$\theta$ & 0,336 & 0,052 & 0,239 & 0,435 \\
\hline
\end{tabular}

$\mathrm{RP}=$ resistência do solo $(\mathrm{MPa}) ; \theta=$ conteúdo volumétrico de água $\left(\mathrm{m}^{3} \mathrm{~m}^{-3}\right)$;

Ds=densidade do solo $\left(\mathrm{Mg} \mathrm{m}^{-3}\right) ; \mathrm{n}=72$

Os coeficientes demonstram que a resistência variou positivamente com a densidade do solo e negativamente com o conteúdo de água, estando em concordância com os resultados obtidos por vários autores (Mirreh \& Ketchenson, 1972; Ehlers et al., 1983; Stirzaker et al., 1996; Smith et al., 1997). A partir da estimativa dos coeficientes apresentados na tabela 1, obteve-se a eq. (5). $O$ conteúdo de água em que a resistência à penetração atingiu $2,0 \mathrm{MPa}$ foi calculado através da eq. (6) obtida a partir da eq. (5):

$$
\begin{aligned}
\mathrm{RP} & =0,03611 \mathrm{Ds}^{7,9683} \theta^{-2,2940} \\
\theta & =\left(\operatorname{RP} /\left(0,03611 \mathrm{Ds}^{7,9683}\right)\right)^{1 /-2,2940}
\end{aligned}
$$

Tabela 2. Resultados da análise de regressão múltipla linear da curva de resistência do solo: $\ln \mathrm{RP}=\ln a+b \ln \theta+c \ln \mathrm{Ds}$

\begin{tabular}{ccccc}
\hline Variável & Coeficiente & Erro Padrão & $t$ & Prob $>|t|$ \\
\hline a & $-3,3211$ & 0,1991 & $-16,68$ & 0,0001 \\
b & $-2,2940$ & 0,1606 & $-14,29$ & 0,0001 \\
c & 7,9683 & 0,4916 & 16,21 & 0,0001 \\
\hline \multicolumn{5}{c}{$F=208,60 ; P>F=0,0001 ; R^{2}=0,86 ; n=72}$.
\end{tabular}


Os coeficientes do modelo de retenção de água são apresentados na tabela 3. 0 modelo explicou $88 \%$ da variabilidade do conteúdo de água e os coeficientes obtidos estão de acordo com os resultados por Silva et al. (1994) e Silva \& Kay (1997a). O ajuste da curva de retenção através do procedimento descrito em Silva et al. (1994) permite a incorporação dos valores de densidade do solo nas estimativas da umidade. A densidade do solo influencia a retenção de água devido à sua influência na porosidade total e na distribuição dos tamanhos dos poros. 0 sinal positivo do coeficiente $e$ (tabela 3 ) indica que a retenção de água aumentou com a densidade do solo. Efeitos semelhantes da densidade do solo na retenção de água também foram observados por Williams et al. (1993). A equação utilizada para estimar os conteúdos de água na capacidade de campo e no ponto de murchamento permanente é descrita na equação 7:

$$
\theta=\left(\exp ^{(-1,4894+0,7959 D s)}\right)^{\star}\left(|\psi|^{-0.0842}\right)
$$

em que $\theta=$ conteúdo de água $\left(\mathrm{cm}^{3} \mathrm{~cm}^{-3}\right)$; Ds=densidade do solo $\left(\mathrm{Mg} \mathrm{m}^{-3}\right)$ e $\psi=$ potencial mátrico $(\mathrm{cm})$.

Tabela 3. Resultados do ajuste da curva de retenção de água no solo:Ln $\theta=d+$ $e D s+f n \psi_{m}$

\begin{tabular}{ccccc}
\hline Coeficientes & Estimativa & Erro Padrão & $T$ & Prob $>|\mathrm{t}|$ \\
\hline $\mathrm{d}$ & $-1,4894$ & 0,1297 & $-11,477$ & 0,0001 \\
$\mathrm{e}$ & 0,7959 & 0,1146 & 6,943 & 0,0001 \\
$\mathrm{f}$ & $-0,0842$ & 0,0038 & $-22,128$ & 0,0001
\end{tabular}

$\theta=$ conteúdo volumétrico de água $\left(\mathrm{m}^{3} \mathrm{~m}^{-3}\right)$ e $\mathrm{Ds}=$ densidade do solo $\left(\mathrm{Mg} \mathrm{m}^{-3}\right)$; $\psi=$ potencial da água no solo $(\mathrm{cm}) ; \mathrm{F}=248,46 ; \mathrm{P}>\mathrm{F}=0,0001 ; \mathrm{R}^{2}=0,88 ; \mathrm{n}=72$.

O conteúdo de água nos limites críticos do IHO, i.e, $\theta_{\mathrm{cc}}, \theta_{\mathrm{PMP}}, \theta_{\mathrm{RP}}, \mathrm{e}$ $\theta$ PA, bem como o IHO para cada valor da densidade do solo são apresentados 
na figura 2. Para a faixa de densidades obtidas neste trabalho, ocorreu um efeito positivo da densidade sobre a retenção de água nos potenciais de $-0,01$ e

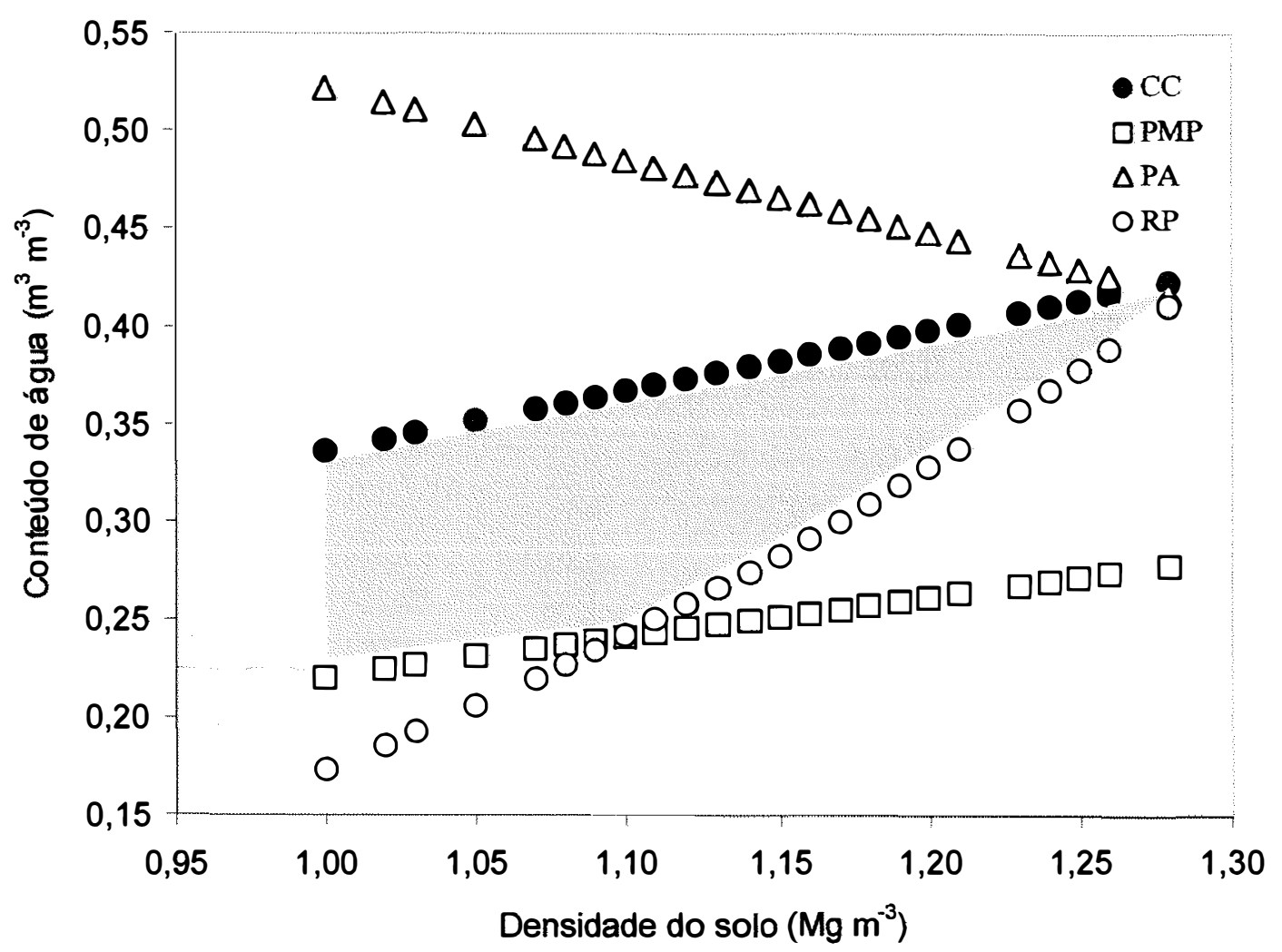

Figura 2 - Variação do conteúdo de água com a densidade nos níveis críticos da capacidade de campo (CC), ponto de murcha (PMP), porosidade de aeração de $10 \%$ (PA) e resistência à penetração de $2,0 \mathrm{MPa}$ (RP). A área hachurada representa o Intervalo Hídrico Ótimo do Solo (IHO).

-1,5 MPa. Em elevados potenciais, estes resultados são contrários aos de Reeve et al. (1973). Já outros autores observaram um efeito negativo da densidade na retenção de água sob elevados potenciais e positivo sob baixos potenciais (Gupta \& Larson, 1979; Smedema, 1993; Silva \& Kay, 1997a). Estes autores argumentam que sob elevados potenciais a retenção é fortemente influenciada pela porosidade total que diminui com o aumento na densidade, enquanto que sob baixos potenciais a retenção é controlada pelo volume de 
microporos, os quais têm correlação positiva com a densidade do solo (Carter 1988).

Sob baixos potenciais ( $\psi=-1,5 \mathrm{MPa}$ ), 0 impacto da densidade sobre a retenção é menor do que sob altos potenciais, uma vez que, nestes solos, a microporosidade é pouco afetada pelo aumento da densidade do solo, como constatado por Kertzman (1996). O aumento na retenção de água no $\psi=-1,5$ MPa com a densidade deve-se a maior quantidade de partículas minerais disponíveis para a adsorção de água (Rawls et al., 1982; Berg et al., 1997). Na capacidade de campo ( $\psi=-0,01 \mathrm{MPa}$ ) (Figura 2$)$, ocorreu um aumento na retenção de água ao longo dos valores de densidade, já que com o aumento da densidade há redução na macroporosidade (Hill et al., 1985) e uma redistribuição dos tamanhos dos poros.

Para maiores valores de densidade, pode ocorrer uma relação inversa entre retenção de água e densidade do solo, uma vez que num solo similar ao desse estudo, a máxima densidade obtida por Kertzman (1996), através do Teste Proctor, foi $1,45 \mathrm{Mg} \mathrm{m}^{-3}$. A máxima densidade obtida neste trabalho foi de $1,28 \mathrm{Mg} \mathrm{m}^{-3}$.

Com o aumento na densidade do solo ocorreu simultaneamente aumento na $\theta_{R P}$ e um decréscimo na $\theta_{P A}$ (Figura 2). Neste solo, a porosidade de aeração $\leq 10 \%$ ocorreu apenas na máxima densidade de $1,28 \mathrm{Mg} \mathrm{m}^{-3}$. Estes resultados contrastam com aqueles de Topp et al. (1994), obtidos em solos de textura muito argilosa, segundo os quais houve com bastante freqüência, condições de estresse por aeração. Os resultados deste estudo demonstram que apenas $3 \%$ das amostras apresentaram porosidade de aeração menor que $10 \%$. A $\theta_{\mathrm{PA}}\left(\theta=0,417 \mathrm{~m}^{3} \mathrm{~m}^{-3}\right)$ substituiu a $\theta_{\mathrm{cc}}\left(0,423 \mathrm{~m}^{3} \mathrm{~m}^{-3}\right)$ apenas na máxima densidade obtida de $1,28 \mathrm{Mg} \mathrm{m}^{-3}$. É possível que para maiores valores de densidade, a difusão de oxigênio no solo seja limitante ao crescimento do sistema radicular. 
A variação da densidade teve grande impacto sobre a resistência à penetração. A $\theta_{\mathrm{RP}}$ foi considerada o limite inferior do $\mathrm{IHO}$ em $89 \%$ das amostras. A $\theta_{R P}$ substituiu $\theta_{P M P}$ nos valores de $D s \geq 1,10 \mathrm{Mg} \mathrm{m}^{-3}$. Estes resultados estão de acordo com os obtidos por Topp et al. (1994) e Silva et al. (1994), nos quais a resistência foi o fator que mais freqüentemente reduziu o IHO em solos sob diferentes condições de textura e manejo. Estas constatações têm um significado especial para o manejo do sistema de plantio direto, pois além da resistência atuar mais freqüentemente como fator limitante ao crescimento do sistema radicular, ela atinge o valor de 2,0 MPa sob baixos valores de densidade do solo. Os resultados obtidos referem-se à camada de 0 $10 \mathrm{~cm}$ (entre 2,5 e $7,5 \mathrm{~cm}$ ). É possível que nas camadas inferiores, com maiores níveis de compactação, o impacto da resistência sobre o limite inferior do IHO seja ainda maior, devido ao forte impacto da densidade sobre a resistência do solo.

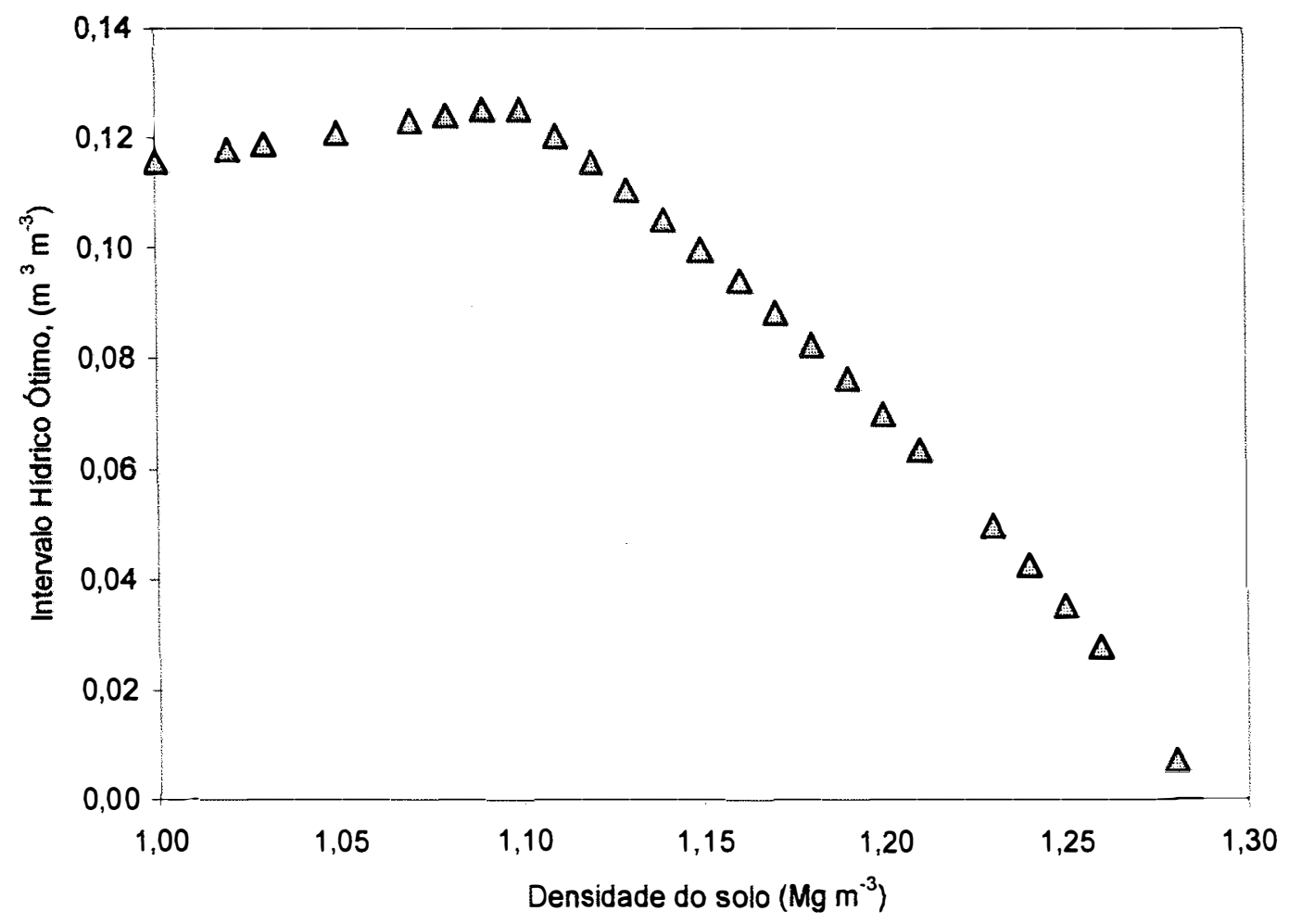

Figura 3 - Variação do Intervalo Hídrico Ótimo em função da densidade do solo. 
A relação funcional entre o $\mathrm{IHO}$ e a densidade do solo é mostrada na figura 3. O IHO é positivamente relacionado com a densidade até valores de $1,10 \mathrm{Mg} \mathrm{m}^{-3}$ e negativamente para densidade superiores. Estes resultados estão de acordo com os obtidos por Silva et al. (1994), em solos de textura arenosa no Canadá. Para a faixa de densidades obtidas, os valores de $\theta_{\mathrm{RP}}, \theta_{\mathrm{PA}}$ e $\theta_{c c}$ foram fortemente influenciados pela densidade, sugerindo que o IHO foi sensivel às modificações na estrutura do solo.

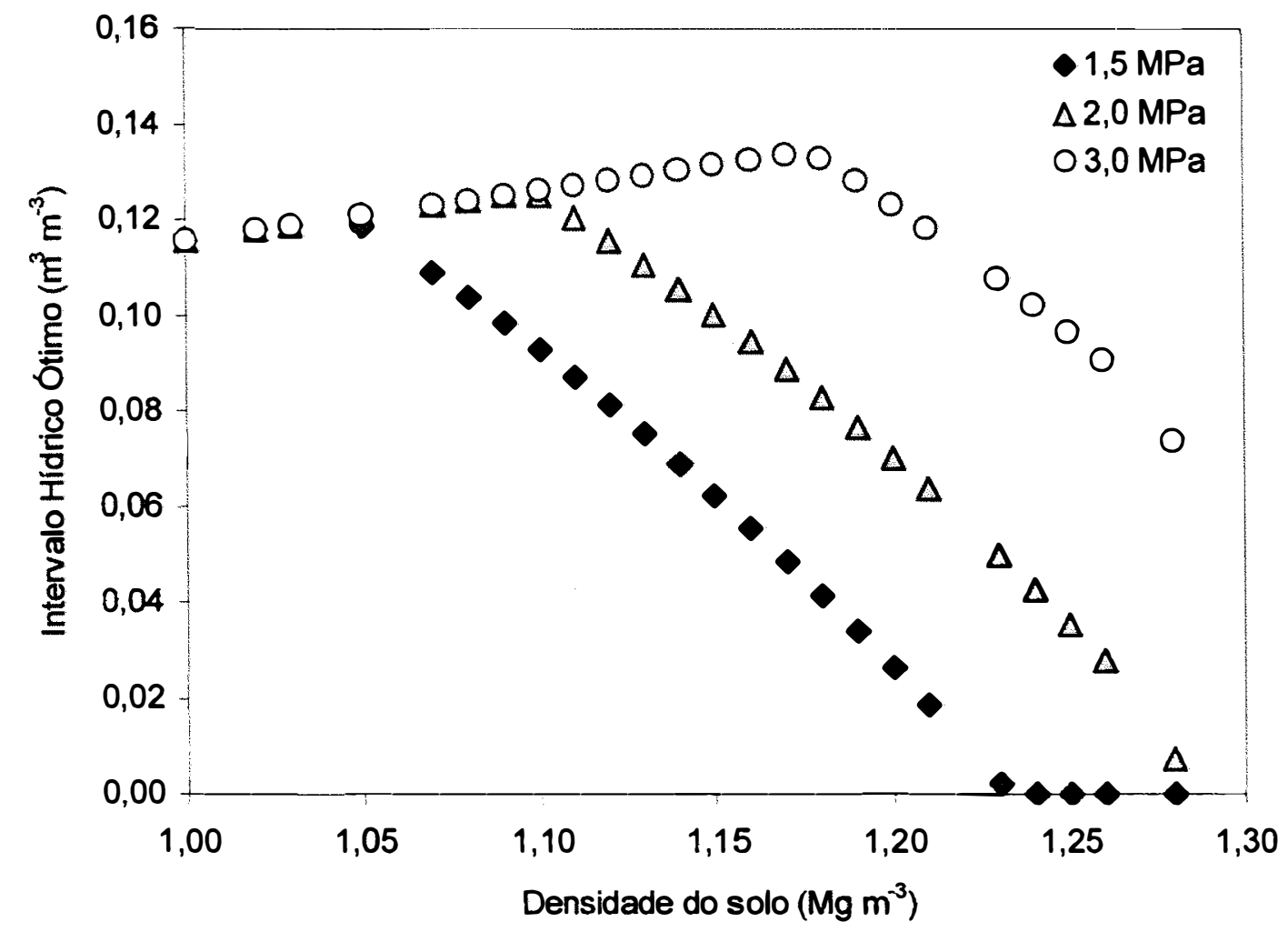

Figura 4 - Variação no Intervalo Hídrico Ótimo com a densidade do solo em diferentes níveis críticos de resistência à penetração.

A utilização de diferentes valores críticos associados com o potencial, aeração e resistência modificam a sensibilidade do $\mathrm{IHO}$, o qual varia com a textura e densidade do solo (Silva et al., 1994), sem alterar a forma e a validade do conceito do IHO. Os mesmos autores constataram que as variações no IHO, adotando diferentes níveis críticos de porosidade de aeração e resistência, foram mais sensiveis sob maiores valores de densidade do solo. Para o solo 
utilizado neste trabalho, a resistência à penetração foi o fator que assumiu maior importância relativa em termos de limitações ao crescimento radicular. A variação do IHO após a adoção de níveis de resistência crítica de 1,5, 2,0 e 3,0 MPa é apresentada na figura 4.

Com o aumento na resistência, a densidade do solo em que o IHO é máximo é alterada, acompanhando a correlação positiva entre as duas variáveis. Os resultados apresentados na figura 4 indicam que com a variação dos limites de resistência, a sensibilidade de variação do IHO foi maior com o aumento da densidade do solo, em conformidade com os resultados obtidos por Silva et al. (1994). Isto sugere que espécies mais sensiveis aos efeitos da resistência podem estar mais sujeitas às variações nas condições físicas do solo em função da variabilidade da densidade no campo, durante a fase de secamento do solo.

Os resultados obtidos demonstram que a variação do IHO foi mais sensivel que a variação da $A D$ (CC - PMP) para descrever e quantificar os efeitos das variações na estrutura do solo sobre as limitações físicas para o crescimento das plantas. A resistência à penetração foi o atributo físico que contribuiu para este comportamento, sugerindo que a avaliação dos limites de resistência para o crescimento de raízes em solos tropicais é fundamental em futuras utilizações do IHO. De forma geral, os resultados indicam que o IHO incorporou as variações da estrutura, representadas pela densidade do solo, sugerindo que ele pode ser utilizada para avaliar a qualidade estrutural do solo para o crescimento das plantas sob solos tropicais.

\subsection{Conclusões}

Os resultados permitem concluir que o conceito do IHO mostrou-se sensivel às variações da estrutura do solo e variou positivamente até a densidade de $1,1 \mathrm{Mg} \mathrm{m}^{-3}$ e negativamente para densidades superiores. A amplitude variação do IHO foi de 0,0073 até $0,125 \mathrm{~m}^{3} \mathrm{~m}^{-3}$. A umidade na resistência à penetração de $2,0 \mathrm{MPa}$ foi o limite superior do $\mathrm{IHO}$ em $85 \%$ das 
amostras, enquanto que a capacidade de campo determinou o limite superior do $\mathrm{IHO}$ em $97 \%$ das amostras. Os resultados obtidos sugerem outros estudos para que o IHO possa ser utilizado na avaliação da qualidade física de solos tropicais sob diferentes condições de textura e manejo. 


\section{AJUSTE DA CURVA DE RETENÇÃO PARA DADOS OBTIDOS COM VARIAÇÃO DE DENSIDADE DO SOLO}

\subsection{Resumo}

A curva de retenção de água no solo é fundamental para o desenvolvimento de estudos relacionados à dinâmica da água no solo, à modelagem de processos físico-hídricos e ao crescimento das plantas. Ela é normalmente obtida através de medidas simultâneas do conteúdo de água $\theta$ e do potencial mátrico da água $\psi$, numa única amostra de solo, envolvendo procedimentos trabalhosos e demorados que limitam a quantidade de amostras a serem analisadas. Um procedimento alternativo é a utilização de várias amostras para a obtenção de uma única curva de retenção, de forma que cada ponto da curva $(\theta, \psi)$ é obtido sob diferentes características e condições do solo, havendo necessidade de incorporar estas variações nos modelos utilizados para ajustar a função $\theta(\psi)$. O objetivo deste trabalho foi 0 de determinar a curva de retenção utilizando esta última sistemática, em amostras apresentando variação de densidade do solo e ajustar um procedimento para incorporar esta variação nas estimativas de $\theta$ da curva de retenção. A curva de retenção de água foi ajustada pela equação utilizada por Van Genuchten (1980). Os resultados demonstraram que a variação da densidade do solo influenciou o ajuste dos dados de $\theta(\psi)$. O parâmetro $n$ do modelo foi sensível à variação da densidade do solo e uma função quadrática entre $\mathrm{n}$ e a densidade do solo substituiu este parâmetro no ajuste dos dados, reduzindo as estimativas dos erros produzidos pelo modelo. A qualidade do ajuste foi avaliada pela 
análise da distribuição dos erros e os resultados indicaram que o procedimento reduziu os erros das estimativas, permitindo estimativas confiáveis de $\theta$ numa ampla faixa de potenciais. Os resultados demonstraram também que a função $\theta(\psi)$ é sensivel às variações da densidade do solo, numa mesma textura. 0 procedimento utilizado tem vantagens de natureza metodológica e proporciona uma redução substancial de tempo para obter os dados de $\theta(\psi)$.

Termos para indexação: curva de retenção, disponibilidade de água, densidade do solo, regressão não linear.

\subsection{SUmmary: FIT OF THE SOIL WATER RETENTION CURVE FOR DATA OBTAINED WITH BULK DENSITY VARIATION}

The soil water retention curve is necessary in the studies related with the soil water dynamics and plant growth. The conventional procedure for water retention curve is realized by simultaneous measures of $\theta(\Psi)$ in a only sample, involving difficult and delayed procedures and limiting the amount of used samples. An alternative procedure is the use of several samples for obtaining of the an only retention curve, having need to incorporate these variations in the models used to fit the soil water retention curve. The objective of this research was determining the soil water retention curve through samples with a variation of bulk density and incorporate this variation in Van Genuchten (1980) function parameters. The function $n$ (Ds) substituted this parameter in the adjustment of data reducing the errors estimates of the model. The quality of the adjustment was evaluated by the analysis of errors distribution and demonstrated that this procedure reduced the errors variance allowing reliable estimates of $\theta$ in a wide range of matric potentials. The results demonstrated that the function $\theta(\psi)$ was sensitive the bulk density and that the used procedure has advantages methodological and promote reduction of the time to obtain the $\theta(\psi)$ data.

Index terms: soil water retention, bulk density, soil water available, non linear regression. 


\subsection{Introdução}

A curva de retenção de água no solo $[\theta(\psi)]$ é muito utilizada em diferentes estudos relacionados ao manejo do solo e da água e ao crescimento das plantas. A variabilidade espacial do solo influencia a relação $\theta(\psi)$, resultando em variação da disponibilidade de água às plantas, no fluxo de água e solutos no solo e na produtividade das culturas. A obtenção da curva de retenção de forma mais simplificada e a utilização de métodos estatísticos que incorporem os fatores ligados à variabilidade são fundamentais para a descrição da curva em escala e precisão maiores.

A curva de retenção é afetada por vários atributos do solo. Variações na geometria e continuidade dos poros, na textura, nos teores de matéria orgânica e na mineralogia influenciam a retenção de água. A variabilidade natural destes fatores, somada àquela oriunda das alterações na estrutura do solo devido ao manejo (Dexter, 1988), aumentam a imprecisão nas estimativas da curva de retenção. Isto tem levado os pesquisadores a desenvolverem métodos para definir as propriedades hidráulicas usando funções matemáticas elou outras propriedades físicas do solo. $O$ reconhecimento da variabilidade da retenção de água no solo (Nielsen et al., 1973; Cameron, 1978; Russo \& Bresler, 1981; Yeh et al., 1986; Kirda et al., 1988; Burd \& Selim, 1989; Shouse et al., 1995) exige que um grande número de medidas sejam feitas para a sua caracterização. No entanto, as dificuldades da amostragem e as particularidades ligadas aos métodos laboratoriais utilizados para a elaboração das curvas de retenção limitam a quantidade de amostras utilizadas. O procedimento comumente utilizado é a elaboração da curva de retenção numa única amostra, de maneira que, quando há necessidade de utilizar uma grande quantidade de amostras, opta-se pelo mínimo possivel de pontos na curva, reduzindo a qualidade e o número de informações nela contidas. Powers et al. (1992) são da opinião de que estas particularidades são algumas das razões de se obter respostas pouco conclusivas da influência de sistemas de preparo sobre as propriedades hidráulicas do solo. 
Os métodos para a determinação da curva de retenção de água no solo são demorados e caros (Klute, 1986). A curva de retenção é obtida através de medidas simultâneas da umidade $(\theta)$ e do potencial $(\psi)$ sob condições, teoricamente, de equilíbrio, com um decréscimo lento e contínuo destas variáveis durante o processo (Topp et al., 1993). Para a utilização da curva de retenção, Perfect et al. (1996) argumentam que é necessário que ela seja funcionalmente descrita e que os parâmetros da equação sejam reduzidos a um número mínimo que reflitam as influências da textura e da estrutura do solo. Para isto, normalmente são utilizados dois modelos, entre os vários descritos na literatura: o de Van Genuchten (1980) e o de Campbell (1974). Se há necessidade da função descrever a curva próxima à saturação, a função de Van Genuchten é preferida à de Campbell (Van Genuchten \& Nielsen, 1985). Embora o modelo de Campbell descreva adequadamente a curva de retenção para diferentes tipos de solos (Williams et al., 1983; Saxton et al., 1986; Willians et al., 1993), ele tem validade a partir do potencial de entrada de ar no solo. Ainda que mais complexo, o modelo de Van Genuchten (1980) é melhor ajustável aos dados experimentais (Felton \& Nieber, 1991; Cresswell \& Paydar, 1996), de forma que muitos pesquisadores apresentam os dados $\theta(\psi)$ através desta função (Vereecken et al., 1989; Scheinost et al., 1997; Sinowski et al., 1997).

Vários estudos têm sido desenvolvidos com o objetivo de descrever a variabilidade da retenção de água no campo e obter estimativas de seus valores a partir de estimativas de propriedades e características do solo como textura, matéria orgânica, estrutura e constituição mineralógica (Gupta \& Larson, 1979; Rawls et al., 1982; Cassel et al., 1983). Além da facilidade de medida, estas propriedades exibem menor variabilidade espacial e temporal do que as propriedades hidráulicas do solo (Cassel \& Bauer, 1975; Courtin et al., 1983). No entanto, a curva de retenção pode ser descrita por funções matemáticas e vários trabalhos têm demonstrado que os parâmetros destas funções estão relacionados com diferentes propriedades do solo (Clapp \& 
Hornberger, 1987; Cosby et al., 1984; Hutson \& Cass, 1987). Neste sentido, pode-se também, estabelecer funçōes relacionando os parâmetros destes modelos com propriedades e características do solo, utilizando-as para estimar a curva de retenção (McQueen et al., 1981; Willians et al., 1983; Cosby et al., 1984; Saxton et al., 1986; Wosten \& Van Genuchten, 1988; Vereecken et al., 1989; Rajkai et al., 1996; Berg et al., 1997). Além da utilização destas abordagens, alguns pesquisadores têm procurado simplificar ainda mais a obtenção da curva de retenção, fazendo uma (Gregson et al., 1987) ou duas medidas (Ahuja et al., 1985) de $\theta(\psi)$ para estimar a curva inteira.

Um procedimento alternativo para a determinação da curva de retenção é a utilização de várias amostras para a obtenção de uma única curva (Silva et al.,1994; Silva \& Kay, 1997a). Desta forma, os pontos da curva $(\theta, \psi)$ são obtidos em amostras com diferentes valores de densidade, porosidade e distribuição dos tamanhos de poros. Isto implica numa variabilidade da retenção ao longo dos valores de $\theta(\psi)$ e a necessidade de incorporá-la nos modelos utilizados para a sua descrição, como demonstrado por Williams et al. (1993), utilizando o modelo de Campbell (1974). A linearização do modelo de Campbell facilita 0 ajuste dos dados de $\theta(\psi)$, e a influência de outras propriedades do solo pode ser incorporada aos valores dos seus parâmetros. Williams et al. (1993) utilizaram métodos de regressão linear múltipla para incorporar os efeitos da textura, estrutura e densidade do solo nos parâmetros da função de Campbell. No ajuste dos dados, as propriedades do solo são tratadas como variáveis independentes. Desta forma, os parâmetros do modelo são obtidos através de métodos de regressão e resultam da somatória dos efeitos, estatisticamente significativos, das diferentes propriedades do solo e/ou de outras variáveis qualitativas. Esta abordagem também foi utilizada por Silva et al. (1994) e Silva \& Kay (1997a), sob diferentes condições de textura, manejo e estrutura do solo, obtendo-se excelentes descrições das suas influências na relação $\theta(\psi)$.

Outra abordagem foi utilizada por Scheinost et al. (1997), que obtiveram estimativas da retenção de água a partir do estabelecimento de 
relações entre algumas propriedades do solo e os parâmetros da equação de Van Genuchten (1980). O procedimento utilizado por Scheinost et al. (1997) envolveu dois passos: 1) estabelecer relações entre os parâmetros do modelo e propriedades do solo através de equações lineares e 2) substituir os parâmetros do modelo por estas equações no ajuste dos dados de $\theta(\psi)$. Estas equações foram estabelecidas com base teórica nas relações entre as características do solo e o comportamento funcional dos parâmetros envolvidos, assumindo que nestas equações as relações entre as variáveis tinham significado físico. $O$ método utilizado por Scheinost et al. (1997) para estimar a curva de retenção de água também foi utilizado em outros tipos de estudos (Scheinost \& Schwertman, 1995), obtendo-se bons resultados nas estimativas por modelos não lineares. A principal vantagem do procedimento proposto é que os dados de $\theta(\psi)$ podem ser ajustados pela função de Van Genuchten com diferentes combinações dos parâmetros do modelo com as propriedades do solo e, assim, verificar qual delas fornece, estatisticamente, o melhor ajuste.

A curva de retenção de água é utilizada nas descrições dos efeitos dos sistemas de manejo nas propriedades físicas e hidráulicas dos solos. As modificações na estrutura proporcionam amplas variações no tamanho de agregados e de poros, que são parcialmente representados pela densidade do solo (Hall et al., 1977) que, por sua vez, influencia a retenção de água no solo (Hill \& Sumner, 1967; Archer \& Smith, 1972; Reeve et al., 1973; Hall et al., 1977; Rajkai et al., 1996), e seus efeitos devem estar representados nos modelos descritivos da curva de retenção. $O$ procedimento convencional de obtenção da curva de retenção impede de, quantitativamente, representar estes efeitos, além de impor restrições ao número de amostras utilizadas e à representatividade da condição estrutural do solo. A densidade do solo é bastante variável espacial e temporalmente e, a curto e médio prazos, é sensivelmente influenciada pelo manejo do solo e das culturas, além de apresentar variação cíclica durante o crescimento das plantas, principalmente após o preparo do solo e a semeadura. 
A influência da densidade sobre a função $\theta(\psi)$ é importante em relação à compactação e à adoção de sistemas de preparo do solo. A adoção de sistemas de preparo com mínima mobilização do solo tem sido motivada por várias razōes, mas eles invariavelmente aumentam a densidade do solo, principalmente na superfície. Assim, procedimentos para prever a função $\theta(\psi)$ deveriam levar em conta as influências dos sistemas de manejo na estrutura do solo. Desta forma, os objetivos deste trabalho foram descrever um procedimento simplificado para estimar a curva de retenção e ajustar os dados à função de Van Genuchten (1980), incorporando a variação da densidade do solo nas estimativas da curva de retenção.

\subsection{Material e Métodos}

Este estudo foi conduzido numa área agrícola comercial situada no município de Guaíra, região nordeste do Estado de São Paulo, entre as coordenadas $20^{\circ} 19^{\prime} 13^{\prime \prime}$ de latitude sul e $48^{\circ} 18^{\prime} 03^{\prime \prime}$ de longitude oeste. De acordo com a classificação de Köppen, o clima da região é do tipo Cwa, com temperatura média de $22,7^{\circ} \mathrm{C}$, precipitação média de $1420 \mathrm{~mm}$ entre outubro e abril e um período seco com precipitações de menos de $220 \mathrm{~mm}$ entre maio e setembro (Saad, 1987).

As amostras foram obtidas num Latossolo Roxo (Typic Hapludox), com granulometria composta por $800 \mathrm{~g} \mathrm{~kg}^{-1}$ de argila, $150 \mathrm{~g} \mathrm{~kg}^{-1}$ de silte e $50 \mathrm{~g}$ $\mathrm{kg}^{-1}$ de areia. A amostragem foi realizada em dois talhões contígüos, cultivados em sistema de plantio direto (PD) e preparo convencional (PC), irrigados por aspersão por meio de pivô-central. A área sob PD vinha sendo cultivada neste sistema por quatro anos, enquanto que a área sob preparo convencional, por cerca de 10 anos. Na área sob PC o preparo primário do solo era realizado com grade aradora tipo Rome e o preparo secundário com grade niveladora de discos. Um sistema de rotação de culturas foi utilizado na área consistindo da cultura de soja no verão, como cultura principal; milho no inverno como cultura "safrinha" e, na seqüência, a cultura do feijão. A amostragem foi realizada na 
primeira quinzena de agosto de 1996, quando a área estava sendo cultivada com milho (Zea mays L.) c.v. Cargill 701, com espaçamento de entrelinhas de $0,90 \mathrm{~m}$. A adubação de base da cultura de milho foi realizada com $330 \mathrm{Kg} \mathrm{ha}^{-1}$ de uma formulação comercial 04-20-20 $+\mathrm{Zn}$. As adubações de cobertura corresponderam a $145 \mathrm{~kg} \mathrm{ha}^{-1}$ da formulação comercial 20-00-20 aplicada vinte dias após a emergência (DAE) das plantas; 70 e $40 \mathrm{~kg} / \mathrm{ha}$ de uréia foram aplicados aos 35 e 50 DAE. O controle de ervas daninhas e pragas foram feitos através de métodos químicos convencionais.

$\mathrm{Na}$ fase de maturação da cultura do milho a amostragem foi realizada no talhão sob PD e na fase de enchimento de grãos, na área sob PC. Foram retiradas amostras com estrutura indeformada $(5 \mathrm{~cm}$ de diâmetro e $5 \mathrm{~cm}$ de altura) no centro da camada de 2,5 a $7,5 \mathrm{~cm}$ de profundidade, conforme Blake \& Hartge (1986). Os pontos de amostragem foram localizados numa transeção transversal às linhas das culturas, com as amostras sendo retiradas a cada 0,45 $m$, seqüencialmente nas posições linha $(L)$ e entrelinha $(E L)$ da cultura, totalizando 192 amostras (2 sistemas de preparo $\times 2$ posições de amostragem $x$ 12 potenciais $\times 4$ repetições por potencial). As amostras foram acondicionadas em sacos plásticos e mantidas sob temperatura de $\pm 5^{\circ} \mathrm{C}$ até serem processadas. Saturou-se as amostras por elevação gradual de uma lâmina de água numa bandeja, até atingir cerca de $2 / 3$ da sua altura.

Para a determinação da curva de retenção foi adotado o procedimento descrito em da Silva et al. (1994). As amostras foram divididas em 12 grupos de 16, sendo quatro amostras por posição em cada sistema de preparo. Em cada grupo de amostras foram aplicados os seguintes potenciais: $-0,001,-0,003$, $0,005,-0,006$, e $-0,008 \mathrm{MPa}$ numa mesa de tensão descrita por Topp \& Zebchuck (1979) e os potenciais de $-0,01,-0,03,-0,05,-0,07,-0,1,-0,5$ e $-1,5$ $\mathrm{MPa}$, através de câmaras de pressão com placas porosas, conforme Klute (1986). Em seguida, as amostras foram secas em estufas a $105-110^{\circ} \mathrm{C}$ para determinação do conteúdo de água e da densidade do solo. 
A equação utilizada por Van Genuchten (1980) foi utilizada para ajustar os dados de potencial mátrico $[\psi(\mathrm{cm})]$ e conteúdo volumétrico de água [ $\left.\theta\left(\mathrm{m}^{3} \mathrm{~m}^{-3}\right)\right]$. O modelo de Van Genuchten (1980) é descrito na equação 8.

$$
\theta=\left[\theta r+(\theta s-\theta r) /\left[(1+\alpha \cdot \psi)^{\eta}\right]^{1-1 / n}\right],
$$

sendo $\theta=$ conteúdo de água do solo $\left(\mathrm{m}^{3} \mathrm{~m}^{-3}\right) ; \theta r=$ conteúdo de água residual $\left(\mathrm{m}^{3}\right.$ $\left.\mathrm{m}^{-3}\right) ; \theta s=$ conteúdo de água na saturação $\left(\mathrm{m}^{3} \mathrm{~m}^{-3}\right) ; \alpha\left(\mathrm{cm}^{-1}\right)$ e $\mathrm{n}$ são parâmetros do modelo.

A eq. (8) apresenta quatro parâmetros independentes: $\theta r, \theta s, \alpha$ e n. $O$ valor de $\theta s$ foi obtido como $\theta s=(1-D s / 2,65)$, a partir da densidade do solo e assumindo a densidade de partículas igual a $2,65 \mathrm{Mg} \mathrm{m}^{-3}$. Os parâmetros $\alpha$, n e $\theta \mathrm{r}$ foram determinados iterativamente no ajuste do modelo.

A incorporação da variação de densidade na equação Van Genuchten (1980) foi feita a partir do comportamento dos resíduos ( $\theta$ medido - $\theta$ estimado) produzidos no ajuste do modelo em relação à densidade do solo. Os dados foram inicialmente ajustados pelo modelo, utilizando estimativas iniciais dos parâmetros $\theta r, \mathrm{n}$ e $\alpha$. Como cada amostra tinha um valor de $\theta$ s e potencial, o modelo inicialmente ajustado permitiu fazer estimativas do conteúdo de água para cada potencial e amostra. Assim, os resíduos produzidos ( $\theta$ medido - $\theta$ previsto) foram plotados contra a densidade do solo obtida nas amostras e adotou-se uma função polinomial quadrática. Estabeleceram-se, então, relações funcionais, de modo quadrático, entre os parâmetros independentes do modelo e a densidade do solo. Estas funções substituíram estes parâmetros no ajuste dos dados, utilizando métodos de regressão não linear. Os parâmetros do modelo foram estimados através do método de Gauss-Newton (SAS Institute, 1991).

\subsection{Resultados e Discussão}

Os dados de retenção de água foram obtidos em amostras com uma 
ampla variação da densidade do solo. A densidade média foi $1,14 \mathrm{Mg} \mathrm{m}^{-3}$ e variou de $0,93 \mathrm{Mg} \mathrm{m}^{-3}$ a $1,33 \mathrm{Mg} \mathrm{m}^{-3}$, com um CV de 6,3\%. Conforme o teste de Shapiro (SAS Institute, 1991) a densidade do solo apresentou distribuição normal $(W=0,99 ; P<W=0,77)$.

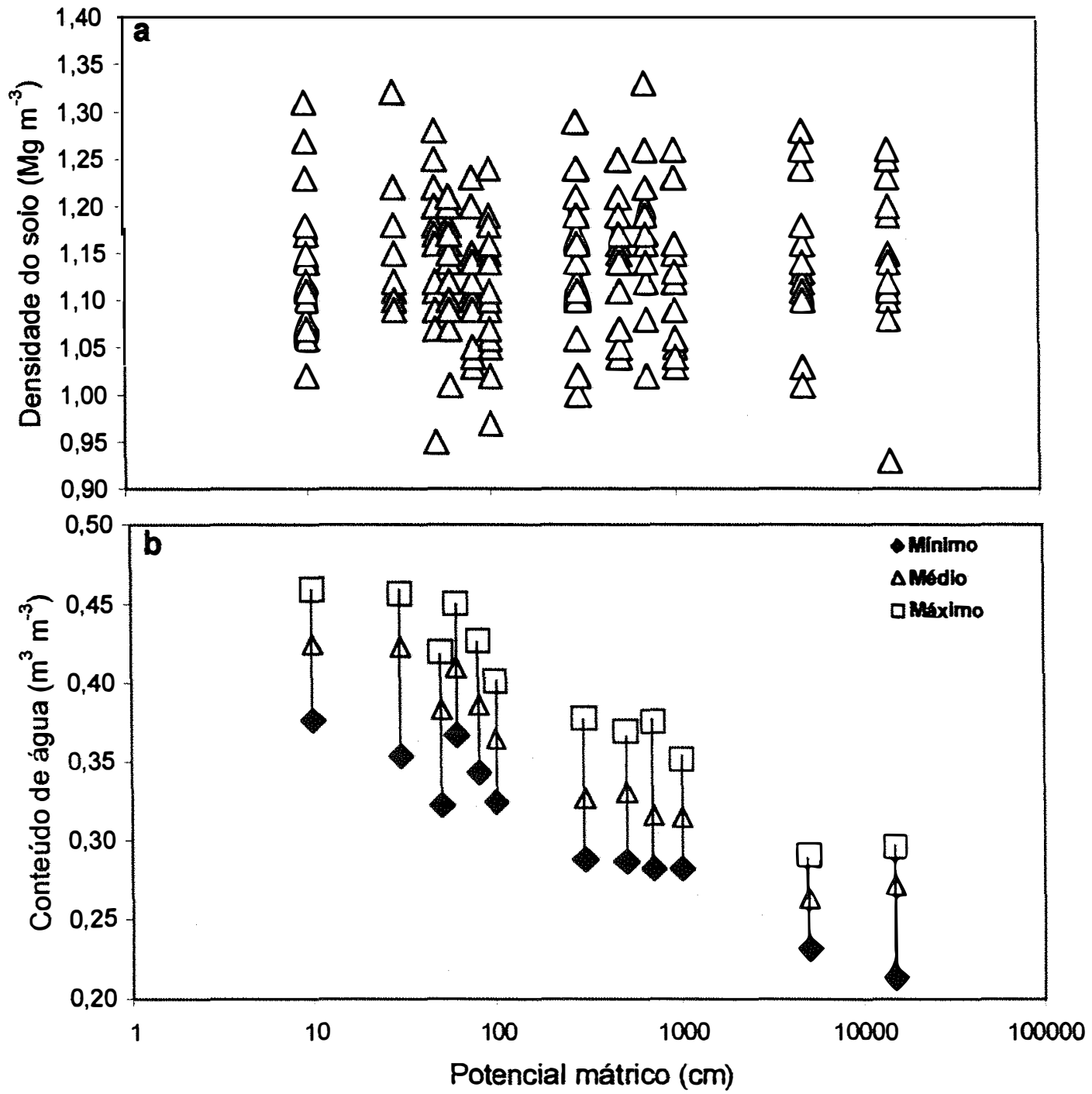

Figura 5 - Distribuição da densidade do solo nos diferentes potenciais aplicados (a) e dos valores máximos e mínimos dos conteúdos de água $(\theta)$ medidos em cada potencial aplicado às amostras (b).

A variação da densidade das amostras nos respectivos potenciais 
aplicados é apresentada na figura $5 a$. A casualização na tomada das amostras para a aplicação dos potenciais especificados implicou numa variação da densidade do solo para cada potencial. As amplitudes das variações dos dados de $\theta(|\psi|)$ obtidos estão resumidos na figura $5 \mathrm{~b}$. As maiores amplitudes do conteúdo de água foram observadas nos potenciais de $-0,003,-0,005,-0,03$, 0,07 e -1,5 MPa, correspondendo a variação da densidade do solo apresentada na figura 1a. Os maiores valores de umidade ocorrem nos potenciais de $-0,05$ e -1,5 MPa comparados aos potenciais de -0,03 e -0,5 MPa e ocorreu a redução da umidade no potencial de -0,005 $\mathrm{MPa}$ em relação aos potenciais de $-0,006 \mathrm{e}$ $0,008 \mathrm{MPa}$. Os efeitos das práticas de manejo sobre as variações de $\theta(\psi)$, num mesmo solo também foram demonstrados por Hill et al. (1985) e Powers et al. (1992).

Tabela 4. Estimativas dos parâmetros da função de Van Genuchten (1980) ajustada aos dados de $\theta(\psi)$.

\begin{tabular}{cccc}
\hline Parâmetro & Estimativa & Erro Padrão & Intervalo de Confiança \\
\hline$\theta \mathrm{r}\left(\mathrm{m}^{3} \mathrm{~m}^{-3}\right)$ & 0,25 & 0,017 & $0,218-0,285$ \\
$\alpha\left(\mathrm{cm}^{-1}\right)$ & 0,51 & 0,191 & $0,140-0,897$ \\
$N$ & 1,27 & 0,051 & $1,167-1,367$ \\
\hline
\end{tabular}

$N=192 ; S Q$ erro $=0,2261 ; S Q$ corrigido total $=0,6476 ; R^{2}=0,65[1-(S Q$ erro)/[SQ corrigido total)].

Os dados de $\theta(\psi)$ foram ajustados através da equação (8). Os valores estimados dos parâmetros são apresentados na tabela 4 e o intervalo de confiança destes parâmetros não inclui o valor zero, de modo que todos são estatisticamente significativos (Glantz \& Slinker, 1990). O valor de $R^{2}$ foi 0,65 , indicando que grande proporção da variância $(0,35)$ dos dados de $\theta(\psi)$ ainda deve-se aos erros presentes nas estimativas dos parâmetros da equação. A melhoria do valor do $R^{2}$, ou seja, a redução da variância do erro, pode ser feita 
através da redução dos efeitos das prováveis fontes de erro presentes no processo. A magnitude do $\mathrm{R}^{2}$ indica que, possivelmente, outra variável além do potencial, está determinando a variabilidade do conteúdo de água no solo.
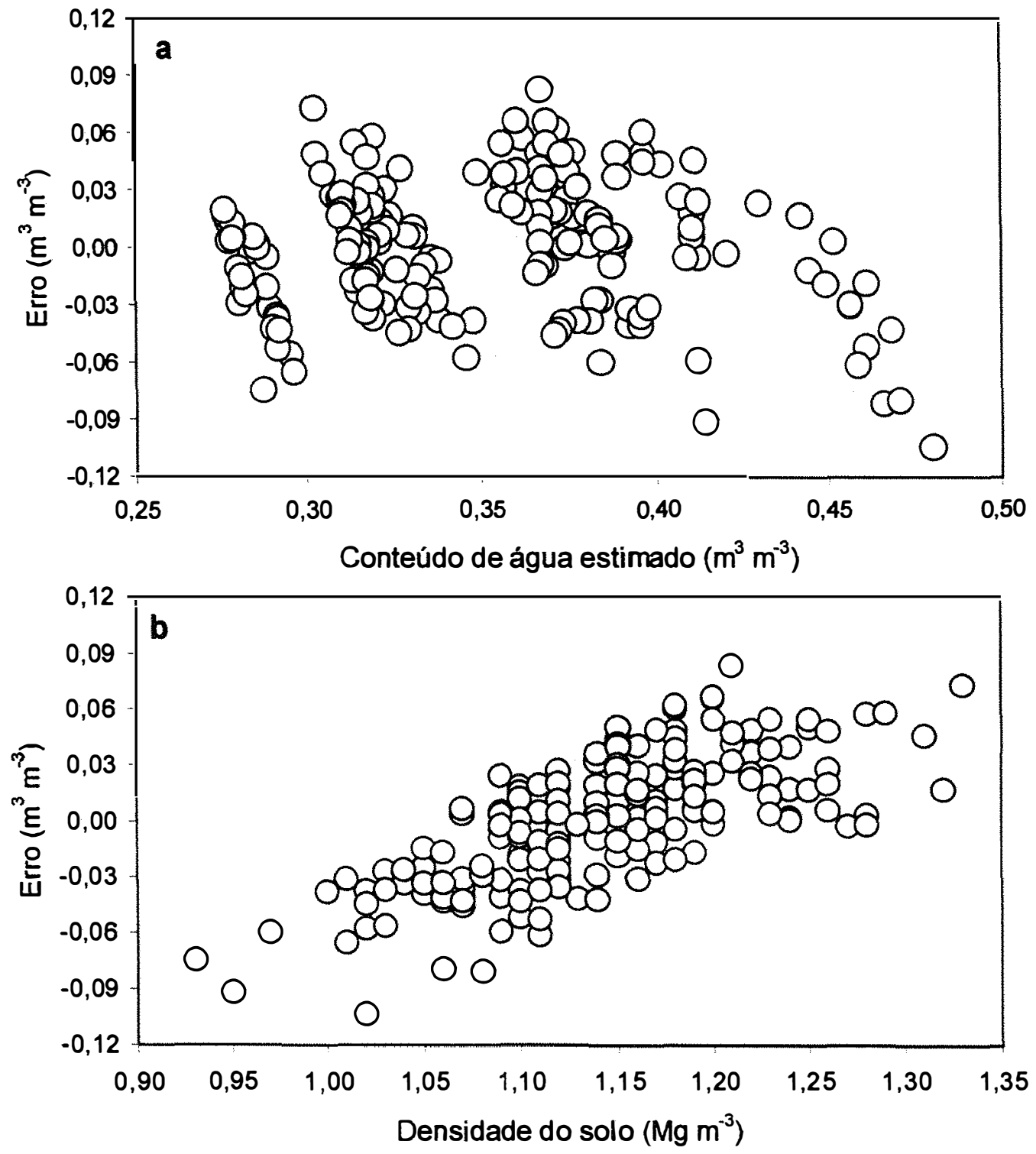

Figura 6 - Distribuição dos erros ( $\theta$ medido - $\theta$ estimado) de $\theta$ em relação ao conteúdo de água previsto pelo modelo (a) e em relação à densidade do solo (b).

$O$ ajuste dos dados de $\theta(\psi)$ através de diferentes funções tem como base fundamental a minimização da soma dos quadrados dos resíduos de $\theta$. 
Baseado nesta fundamentação teórica, Glantz \& Slinker (1990) sugerem que a análise qualitativa dos resíduos, em relação às variáveis independentes ou estimadas pelo modelo, constitui um diagnóstico dos possíveis problemas envolvidos no ajuste dos dados. Neste contexto, Netter et al. (1989) sugerem que os resíduos ( $\theta$ observado - $\theta$ estimado) podem também ser analisados em relação às variáveis independentes omitidas no modelo para verificar possiveis interferências destas no ajuste dos dados experimentais. Estas verificações foram feitas avaliando o comportamento dos resíduos ( $\theta$ observado - $\theta$ estimado) em relação à densidade do solo e aos valores de umidade previstos pelo modelo (Figura 6a e 6b).

Analisando-se as figuras $6 a$ e $6 \mathrm{~b}$ constata-se que os resíduos variam sistematicamente com a densidade e com os valores de $\theta$ previsto, sugerindo que a densidade do solo é, além do potencial, a outra variável que determina a variabilidade da retenção de água no solo. A densidade do solo influencia retenção devido à incorporação de fatores diretamente relacionados com a retenção de água numa ampla faixa de potenciais: a distribuição dos tamanhos dos poros e a superfície ativa para a adsorção de moléculas de água (Rawls et al., 1991).

Em estudos de pedotransferência os parâmetros dos modelos são estimados a partir de equações de regressão entre eles e diferentes propriedades do solo, e estas relações são utilizadas para fazer as estimativas do conteúdo de água do solo através das equações ajustadas. Scheinost et al., (1997) estabeleceu relações entre os parâmetros da equação de Van Genuchten (1980) e várias propriedades do solo, as quais explicitadas através de equações lineares, substituíram os parâmetros do modelo. Desta forma, baseando-se no comportamento dos resíduos em relação à densidade do solo, - qual constituiu um diagnóstico para avaliar a ocorrência sistemática de erros no ajuste do modelo, estabeleceu-se relações quantitativas entre a densidade do solo e os parâmetros da equação 8.

A variação dos resíduos com a densidade do solo (Figura 6b) sugere 
um comportamento não linear, de modo que uma função polinomial quadrática foi utilizada para relacionar funcionalmente os parâmetros do modelo com a densidade do solo. A função quadrática foi utilizada porque permite uma interpretação física mais adequada das relações entre as variáveis, em comparação a uma função linear, como poderia sugerir a Figura $6 \mathrm{~b}$. As equações entre os parâmetros do modelo e a densidade do solo foram inseridas na função de Van Genuchten (1980), substituindo os parâmetros do modelo.

Os resultados indicaram que apenas o parâmetro $n$ apresentou em relação à densidade do solo, coeficientes estatisticamente diferentes de zero e eliminou a tendência de variação dos resíduos com a densidade do solo. Os coeficientes dos parâmetros obtidos no ajuste do modelo com o parâmetro n(Ds) são apresentados na tabela 5. Conforme o critério de Glantz \& Slinker (1990), todos os coeficientes são estatisticamente significativos. A função relacionando o parâmetro $n$ e Ds (eq. 9) eliminou a tendência de variação dos resíduos com à densidade do solo (Figura $7 b$ ), bem como os resíduos se distribuíram aleatoriamente em relação aos valores de $\theta$ estimados (Figura 7a).

$$
n=2,5181-2,064 D s+0,7373 D s^{2}
$$

Tabela 5. Resultados do ajuste da curva de retenção de água pelo modelo de Van Genuchten (1980) com inserção da eq. (9):n=2,5181-2,064Ds+ $0,7373 D s^{2}$ na eq. (8): $\theta=\left[\theta r+(\theta s-\theta r) /\left[(1+\alpha \cdot \psi)^{n}\right]^{1-1 / n}\right]$.

\begin{tabular}{ccc}
\hline Coeficientes & Valor & Intervalo de Confiança \\
\hline$\theta r$ & 0,1342 & $0,0666-0,2018$ \\
$\alpha$ & 1,3355 & $0,5119-2,1591$ \\
$a_{0}$ & 2,5181 & $1,6269-3,4094$ \\
$a_{1}$ & $-2,064$ & $-3,4480--0,601$ \\
$a_{2}$ & 0,7373 & $0,1816-1,2928$
\end{tabular}

$N=192 ; S Q$ erro=0,0789; $S Q$ corrigido total $=0,6476 ; R^{2}=0,89$ (1-SQ erro/SQ corrigido total). 
Os resultados demonstraram que houve substancial redução nas estimativas do erro com este procedimento, elevando o $R^{2}$ para 0,89 , além de eliminar a variação sistemática dos resíduos com a densidade do solo. A eq. 9 indica que quanto maior a densidade, menor o valor de $n$, corroborando os resultados de Rasiah \& Aylmore (1998). Quanto maior o valor de $n$ (baixas densidades), menor a retenção de água no solo, indicando que, sob baixas densidades, a retenção de água neste solo é semelhante a de um solo de textura arenosa (Rajkai et al., 1996; Rasiah \& Aylmore, 1998).

O parâmetro $n$ é fortemente relacionado com a distribuição dos tamanhos de poros (Gupta et al., 1989) e, portanto, diretamente ligado com a variação da densidade do solo. De maneira geral, os resultados estão de acordo com os obtidos por Rasiah \& Aylmore (1998), os quais demonstraram que apenas o parâmetro $n$ foi influenciado pela variação da densidade do solo. Para os valores medidos de densidade, o parâmetro $n$ não foi inferior a 1 , atendendo o critério proposto por Van Genuchten \& Nielsen (1985). Ainda conforme Vereecken et al. (1989), a ocorrência de valores de $n$ menores do que 1 em solos de textura argilosa pode estar relacionada com problemas metodológicos na obtenção da curva de retenção. Em solos argilosos, o modelo de Van Genuchten parece ser mais sensivel às variações neste parâmetro (Vereecken et al., 1989) e, nesta condição, sua variação com a densidade do solo permite melhor descrição da curva de retenção de água. Os resultados estão de acordo com os obtidos por Shouse et al. (1995).

A inserção da eq. (9) na eq. (8) para 0 ajuste dos dados de $\theta(\psi)$ permitiu ao modelo explicar uma proporção da variabilidade da umidade que depende da variação da densidade do solo e, portanto, de variações em atributos do sistema poroso que estavam omitidos no modelo. Com a introdução da densidade no modelo, em torno de $89 \%$ da variabilidade dos dados de $\theta(\psi)$ foi explicada no ajuste dos dados, além de os resíduos terem suas amplitudes reduzidas e tornaram-se aleatoriamente distribuídos com a umidade estimada e com a densidade do solo (Figura 7a e 7b). 

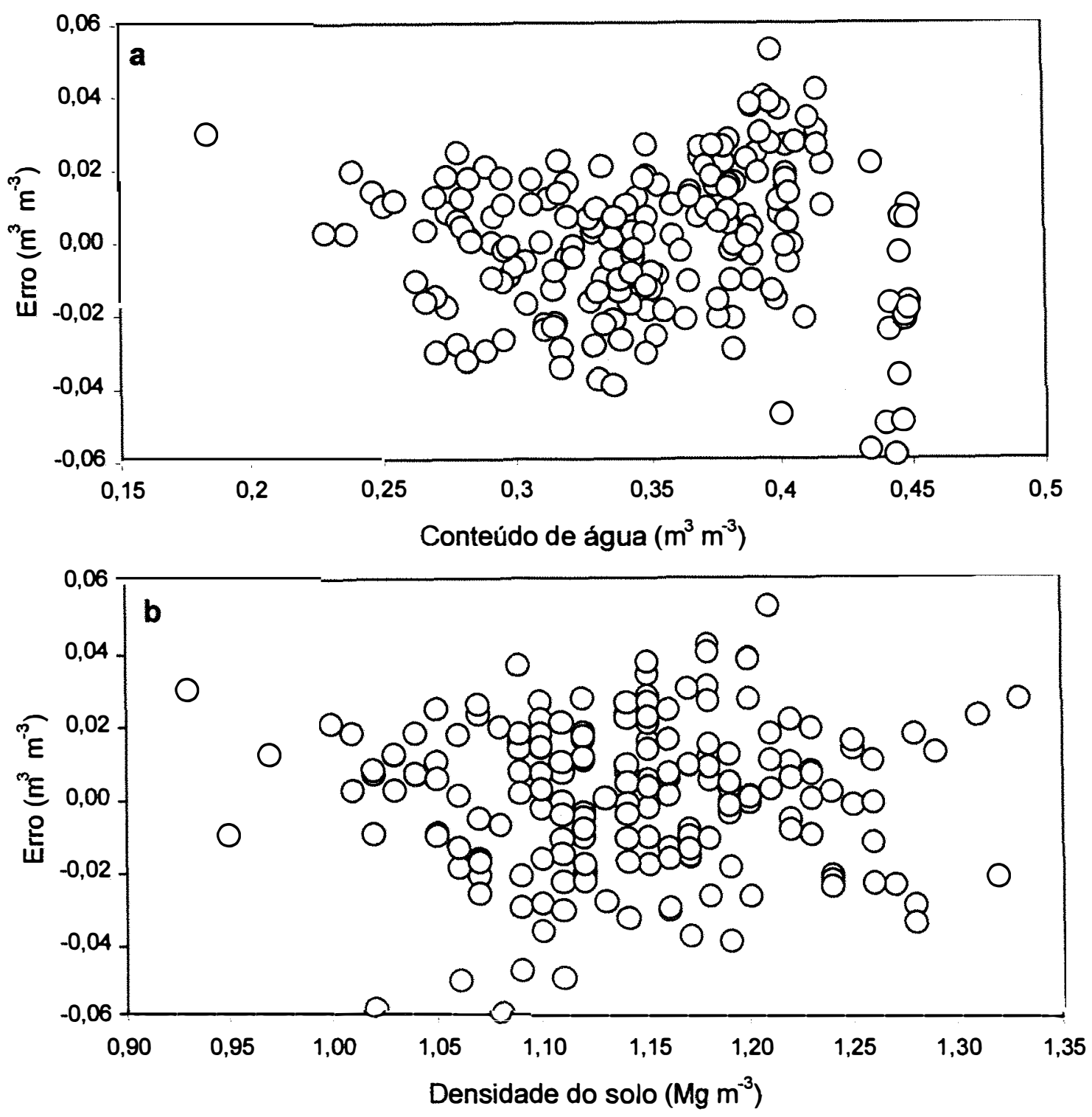

Figura 7 - Distribuição dos resíduos de $\theta$ ( $\theta$ medido - $\theta$ estimado) em relação ao conteúdo de água previsto pelo modelo (a) e em relação à densidade do solo (b).

O procedimento utilizado permitiu aumentar a precisão das estimativas dos conteúdos de água numa ampla faixa de potenciais. Isto é confirmado pelo aumento na soma dos quadrados do modelo e redução do erro através da eq. 9. Também os outros parâmetros da equação utilizada podem ser relacionados através de regressão, em relação às propriedades do solo e incorporados no 
modelo, da mesma forma que 0 parâmetro $n$. Os valores de $\theta$ medidos e estimados pelo modelos são apresentados na figura 8 . Observa-se que 0 ajuste utilizando o procedimento descrito produz boas correlações entre os valores medidos e estimados de $\theta$, em praticamente todos os potenciais.

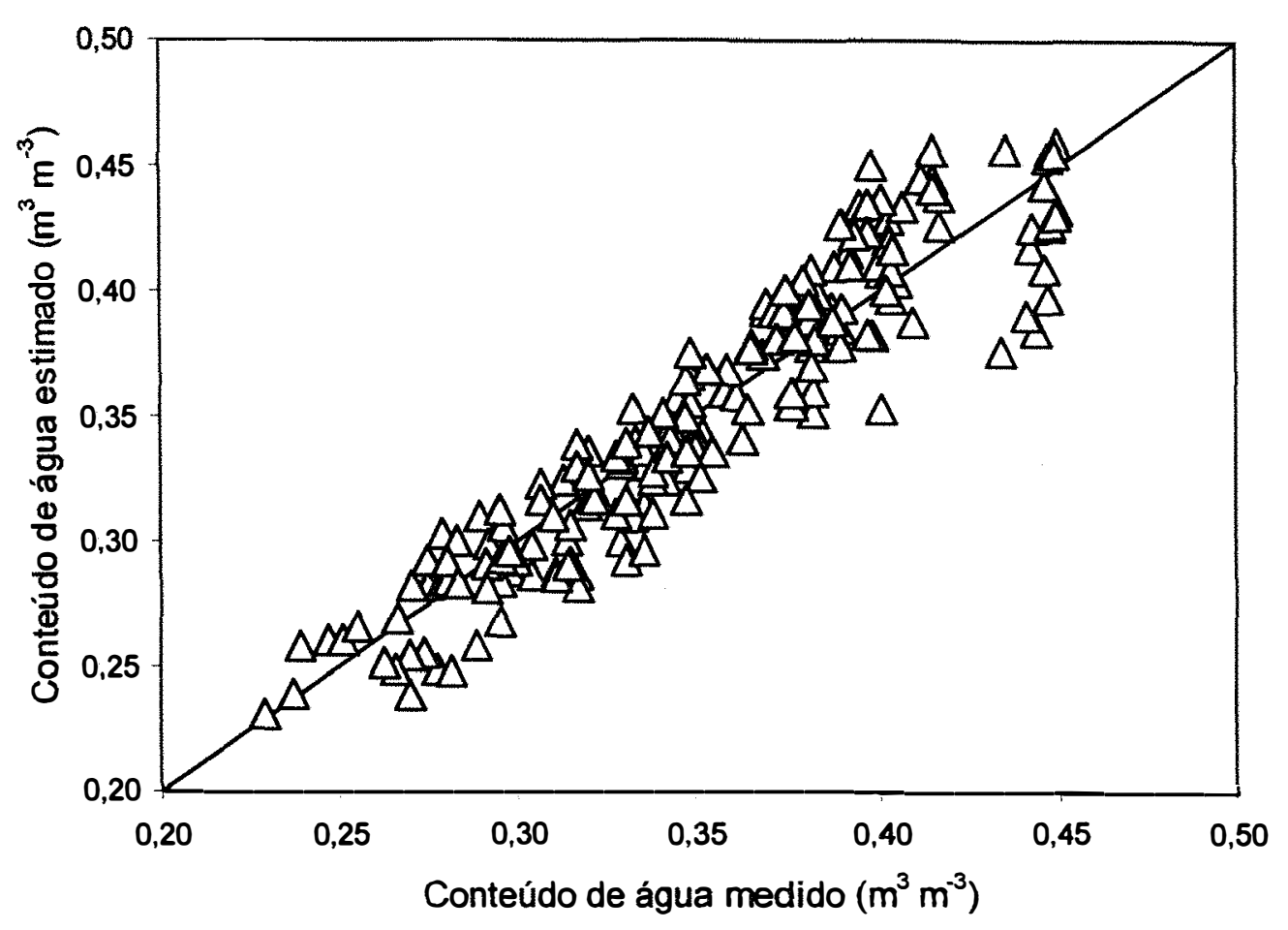

Figura 8 - Conteúdos de água medidos e estimados pelo modelo de Van Genuchten ajustado através da equação (8) com inserção da equação (9).

Os resultados obtidos neste estudo demonstram que a abordagem utilizada permite estimar a retenção de água no solo com razoável nível de precisão. A principal vantagem deste procedimento é que um maior número de amostras pode ser utilizado, representando melhor os fatores que determinam a variabilidade espacial das propriedades do solo, permitindo que estes efeitos sobre a curva de retenção sejam explorados. Neste sentido, é também possível utilizar procedimentos estatísticos para incorporar os efeitos de diferentes 
variáveis ligadas à variação de $\theta(\psi)$, a partir da parametrização de $\theta(\psi)$ através de um modelo matemático.

Os resultados obtidos indicam, ainda, que a variação da densidade do solo pode ser incorporada nas estimativas da retenção de água do solo por meio da função de Van Genuchten (1980), com a vantagem de se poder utilizar as amostras para fins de determinação da densidade do solo. A possibilidade de aumentar o número de amostras, utilizando-se várias delas por potencial, permite introduzir nas estimativas da retenção os efeitos de uma amostragem composta, inviável de se conseguir quando da confecção de curvas de retenção completas numa única amostra. Os critérios de separação de áreas homogêneas e amostragem composta, utilizados rotineiramente no estudo da fertilidade do solo, podem ser implementados em estudos de retenção de água para fins de manejo do solo.

O procedimento utilizado também permite economia de tempo e de recursos na confecção da curva de retenção de água no solo. Este fato é de fundamental importância para a pesquisa em física do solo nos países em desenvolvimento, onde a escassez de recursos e equipamentos tem sido considerada a principal limitação neste sentido. Os equipamentos utilizados para extração de água das amostras têm limitações quanto ao número de amostras utilizadas simultaneamente: geralmente são duas placas porosas por panela de pressão e cerca de $16-18$ amostras de $100 \mathrm{~cm}^{3}$ por placa porosa. 0 tempo para equilíbrio da umidade nos potenciais aplicados impõe limitações ainda maiores à realização da curva de retenção. Adotando os critérios sugeridos por Topp \& Zebchuck (1979) e por Castro Filho (1988) num solo similar e considerando a disponibilidade de um único conjunto extrator de água (duas panelas para aplicação de potenciais até $0,1 \mathrm{MPa}$ e uma panela para aplicação de potenciais entre $0,1 \mathrm{MPa}$ e $1,5 \mathrm{MPa}$ ), o tempo necessário para determinar a curva de retenção de água completa nas 192 amostras podem ser estimados. Para os potenciais de $-0,001,-0,003,-0,005,-0,006$, e $-0,008 \mathrm{MPa}$ a utilização de uma mesa de tensão descrita por Topp \& Zebchuck (1979) é 
bastante viável. A mesa de tensão disponível no laboratório de física de solos da ESALQ permite a utilização simultânea de 86 amostras. Para completar estes potenciais seriam necessários vinte e seis dias efetivos de trabalho. Para os potenciais de $-0,01,-0,03,-0,05,-0,07,-0,1,-0,5$ e $-1,5 \mathrm{MPa}$ os cálculos baseados nos tempos de equilíbrio recomendados totalizariam 570 dias efetivos. O tempo necessário para estabelecer a curva completa seria 596 dias. A adoção do procedimento descrito neste trabalho exigiria cerca de 78 dias para se obter os dados de $\theta(\Psi)$.

São inúmeras as outras vantagens do procedimento utilizado: a) evita os problemas relativos à histerese e contato hidráulico da amostra, que certamente ocorre no procedimento convencional; b) permite utilizar maior número de amostras, aumentando o número de pontos na curva, bem como mais repetições por ponto individual; c) em caso de acidentes com a amostra, perdese apenas um ponto da curva e não uma curva inteira ou uma repetição do tratamento; d) reduz as alterações na estrutura da amostra por excessiva manipulação desta no laboratório; f) as amostras são submetidas a um menor número de ciclos de secagem e molhamento, reduzindo a probabilidade de destruição dos agregados e alteração do sistema poroso; g) uma vez os dados ajustados a um modelo e as propriedades variáveis entre as amostras nele incorporadas, as estimativas do conteúdo de água nos potenciais de interesse podem ser feitas individualmente para cada amostra.

Com o desenvolvimento de sistemas de agricultura de precisão, são necessárias informações contemplando as variações da retenção de água que ocorrem no campo para alocação e manejo eficiente dos recursos. A possibilidade de fazer as estimativas da retenção de água, levando em conta sua variabilidade no campo, é fundamental para a adoção de tecnologias de alta precisão. A variabilidade na disponibilidade de água no solo é uma das principais causas da variabilidade da produtividade das culturas, de forma que 0 manejo de água e nutrientes com elevada precisão pode ser feito utilizando equipamentos que apliquem as lâminas de água na escala de variação da 
retenção e disponibilidade de água no solo (Camp et al., 1998). A rapidez para obtenção da curva de retenção e das outras propriedades do solo, bem como a facilidade e disponibilidade de computadores e programas para a modelagem destes fatores, favorecem a sua inclusão nesta área de desenvolvimento. Os resultados deste estudo mostram que, em solos com textura pouco variável, a densidade é o fator que controla a retenção de água, a qual pode ser monitorada temporalmente em função das manipulações a que o solo é submetido. Assim, durante os diferentes estágios das culturas, o simples monitoramento da densidade permite o ajustamento dos fatores de manejo para atender as necessidades de água das plantas, através da aplicação de taxas mais precisas de água e nutrientes no solo, com vantagens econômicas e ambientais.

\subsection{Conclusões}

Os resultados obtidos indicam que a determinação da curva de retenção, utilizando várias amostras por potencial, em consonância com a incorporação da variação da densidade do solo na função utilizada para o ajuste dos dados, permitiu fazer estimativas confiáveis da umidade do solo ao longo dos potenciais utilizados, com economia de tempo e de recursos laboratoriais. Para as condições em que foi feita a amostragem, a densidade do solo influenciou significativamente o parâmetro $n$ da equação de Van Genuchten (1980) utilizada apara o ajuste da curva de retenção. A substituição do parâmetro $n$ por uma função quadrática da densidade do solo proporcionou uma redução nos erros das estimativas pelo modelo e melhorou a qualidade das suas estimativas. A proposta permite descrever o parâmetro $n$ em termos de $\theta$ s, reduzindo o número de parâmetros empíricos da função utilizada. 


\section{EFEITOS DO SISTEMA DE PLANTIO DIRETO E DO PREPARO CONVENCIONAL NO INTERVALO HÍDRICO ÓTIMO DE UM LATOSSOLO ROXO}

\subsection{Resumo}

Os atributos físicos do solo, especificamente o potencial mátrico, a aeração e a resistência do solo à penetração das raízes influenciam diretamente o crescimento das plantas. O Intervalo Hídrico Ótimo (IHO) é a amplitude de conteúdos de água no solo em que as limitações ao crescimento das plantas por potencial mátrico, aeração e resistência à penetração são mínimas. O IHO não tem sido avaliado em solos tropicais e a sua avaliação como índice da qualidade estrutural é de especial importância nos latossolos, aos quais são atribuídas excelentes propriedades físicas. $O$ objetivo deste trabalho é avaliar os efeitos dos sistemas de plantio direto e preparo convencional sobre o IHO num latossolo roxo. Nestes sistemas de preparo foram obtidas, nas posições linha e entrelinha da cultura do milho, 96 amostras de solo com estrutura indeformada, nas quais se determinou a curva de retenção de água, a curva de resistência e a densidade do solo. O IHO foi significativamente alterado pelos sistemas de preparo e negativamente correlacionado com a densidade do solo para valores acima de $1,02 \mathrm{Mg} \mathrm{m}^{-3}$. A amplitude de variação do $\mathrm{IHO}$ foi de 0 até $0,1184 \mathrm{~m}^{3} \mathrm{~m}^{-3} \mathrm{em}$ ambos sistemas de preparo, com valores médios de 0,0776 e $0,0957 \mathrm{~m}^{3} \mathrm{~m}^{-3}$ no sistema de plantio direto e preparo convencional, respectivamente. A resistência à penetração foi o limite inferior do $\mathrm{IHO}$ em $89 \%$ das amostras no plantio direto e $46 \%$ das amostras no preparo convencional do solo. Prováveis mecanismos 
determinantes da maior resistência no plantio direto são discutidos. Para a faixa de densidades obtidas, na capacidade de campo, a porosidade de aeração foi maior do que $10 \%$ em ambos sistemas de preparo. A resistência à penetração $e$ a porosidade de aeração foram fortemente influenciadas pela densidade do solo. As modificações na estrutura do solo, refletidas pela variação na densidade, foram mais sensivelmente descritas pelo IHO do que pela água disponivel entre a capacidade de campo e ponto de murcha permanente. Avaliações suplementares do IHO são necessárias sob outras condições de textura e de manejo nos solos tropicais.

Termos de indexação: Densidade do solo, preparo do solo, propriedades físicas do solo, resistência do solo à penetração.

\subsection{Summary: EFFECTS OF NO-TILLAGE AND CONVENTIONAL TILLAGE ON THE OPTIMUM HYDRIC INTERVAL OF A OXISOL.}

Soil physical attributes, specifically the soil water potential, soil oxygen, and the soil strength directly affect plant growth. The Optimum Hydric Interval, $\mathrm{OHI}$, is the range of soil water content within which plant growth is least limited by water potential, aeration and mechanical resistance and has not been evaluated in tropical soils. The objective of this research was to evaluate the $\mathrm{OHI}$ of a Typic Hapludox cropped to corn under no-tillage and conventional tillage. Ninety-six undisturbed soil samples were collected at the crop row and interrow. The soil water retention curve and the soil resistance curve were evaluated in order to compute the $\mathrm{OHI}$. The results indicated that the $\mathrm{OHI}$ was influenced by tillage systems and varied positively with bulk density up to 1,02 $\mathrm{Mg} \mathrm{m}^{-3}$ and negatively for higher densities. The $\mathrm{OHI}$ ranged from 0 to $0,1184 \mathrm{~m}^{3}$ $\mathrm{m}^{-3}$ with mean values of 0.0776 and 0.0957 for no-tillage and conventional tillage, respectively. Soil penetration resistance was the limiting factor at the dry end of the $\mathrm{OHI}$ in $89 \%$ of the samples to no-tillage and $46 \%$ for conventional tillage. The air-filled porosity was not limiting to $\mathrm{OHI}$ in the tillage systems. 
Further studies on the $\mathrm{OHI}$ in tropical soils would be relevant under a wide range in texture and management.

Index terms: Bulk density; soil tillage, water retention, soil penetrometer resistance.

\subsection{Introdução}

As práticas de manejo do solo e das culturas influenciam a estrutura e a qualidade do solo para o crescimento das plantas. As respostas das culturas às alterações na estrutura do solo ocorrem devido às modificações dos fatores físicos diretamente ligados ao crescimento das plantas. Neste contexto, os impactos das práticas de manejo deveriam ser avaliados por meio das suas influências sobre a habilidade do solo em prover o sistema radicular com condições físicas favoráveis para o crescimento das culturas. Vários estudos demonstraram que as raízes atuam como sensores das condições físicas do solo e enviam sinais à parte aérea, que controlam o seu crescimento (Masle \& Passioura, 1987; Passioura, 1988; Davies \& Zang, 1991; Dodd et al., 1996). Sob condições físicas restritivas ao crescimento radicular, estes mecanismos parecem atuar mesmo com suficiência de água e nutrientes no solo (Passioura, 1991), afetando principalmente o crescimento da parte aérea (Masle \& Passioura, 1987), com redução na produtividade física (Vyn \& Raimbault, 1993) e econômica das culturas.

Nos solos tropicais e subtropicais, a implantação de sistemas agrícolas tem causado um rápido declínio no potencial produtivo dos solos devido às rápidas perdas de matéria orgânica (Matson et al., 1997) e degradação da estrutura do solo (Cassel \& Lal, 1992). Este processo inicia-se mais fortemente com a abertura mecanizada das áreas (Lal \& Cummings, 1979; Alegre et al., 1986; Lal, 1986; Ghuman et al., 1991; Ghuman \& Lal, 1992) e é intensificado com a implantação, em larga escala, de sistemas agrícolas mecanizados (Lal, 1986; Kayombo et al., 1991). Há um grande volume de 
informações cientificas a respeito da estrutura e propriedades físicas em solos tropicais (Lal, 1979; Sanchez, 1976; Theng, 1980; Cassel \& Lal, 1992; Kayombo \& Lal, 1993). As respostas das diferentes culturas a estas modificações têm sido traduzidas em reduções na produtividade das culturas em várias regiões tropicais (Kayombo \& Lal, 1994), com a magnitude das respostas dependendo dos diferentes tipos de solos, culturas e sistemas de manejo.

De forma geral, a estrutura e o comportamento físico dos solos tropicais têm sido avaliados por meio de propriedades físicas indiretamente relacionadas com o crescimento das plantas, como a densidade e porosidade do solo, infiltração, condutividade hidráulica, estabilidade e distribuição dos tamanhos de agregados. Entre os parâmetros físicos com influência direta sobre o crescimento das plantas, i.e. a disponibilidade de água, aeração e resistência à penetração, a maior parte dos estudos avaliam estes parâmetros através de suas respostas individuais. Dentre estes, a retenção e disponibilidade de água afetam $42 \%$ dos solos tropicais (Sanchez \& Salinas, 1981) e, é considerada a principal limitação à produção agrícola nos solos tropicais (Lal, 1979; Hsiao et al., 1980) e também um dos fatores físicos mais estudados nestes solos. A revisão da literatura, até a presente data, indica que as relações manejo-estrutura-propriedades físicas em solos tropicais não têm sido avaliadas através de alterações conjuntas sobre a disponibilidade de água, resistência à penetração e aeração do solo. Um maior entendimento dos processos e propriedades físicas é um dos pré-requisitos para o desenvolvimento de sistemas sustentáveis de manejo dos solos e das culturas em solos tropicais.

Os Latossolos representam $22,5 \%$ dos solos agrícolas tropicais e cerca de $8,5 \%$ da superfície da terra (Van Wambeke, 1992), nos quais a maior parte da agricultura intensiva é praticada. A fração argila destes solos é composta, predominantemente, por argilas caoliníticas e sesquióxidos de ferro e alumínio, resultando uma microagregação estável, elevada friabilidade e permeabilidade (Sanchez, 1976; Trapneli \& Webster, 1986; Cassel \& Lal, 1992). 
A excelente condição física nos latossolos sempre foi relacionada com a estabilidade da estrutura, de forma geral associadas com a infiltração de água no solo e resistência à erosão. Vários estudos demonstram que em termos de retenção de água, estes solos comportam-se como arenosos sob elevados potenciais e argilosos sob baixos potenciais (Tsuji et al., 1975; Wolf, 1975). Também têm sido constatadas elevações bruscas de resistência com a rápida drenagem destes solos e redução na porosidade de aeração com a compactação do solo (Kirkegaard et al., 1992, 1993). No Brasil, os Oxissolos de textura argilosa e muito argilosa, sob relevo favorável à mecanização, são utilizados em sistemas de agricultura intensiva, com evidências de compactação e degradação da estrutura destes solos (Kemper \& Derpsch, 1981; Roth et al., 1988). Embora a microagregação seja muito estável, a baixa estabilidade da macroestrutura (El-Swaify, 1980) torna os latossolos suscetíveis aos efeitos dos estresses aplicados pelas práticas de manejo.

O Intervalo Hídrico Ótimo (IHO) é a faixa de conteúdos de água do solo na qual o crescimento das plantas é limitado, em grau mínimo, pelo potencial mátrico, aeração e resistência do solo à penetração (Silva et al., 1994). O IHO foi proposto como um índice da qualidade estrutural do solo para o crescimento das plantas (Silva et al., 1994; Topp et al., 1994). Jawayardane \& Chan (1994) destacaram a utilização do conceito do IHO no manejo da estrutura de solos sódicos da Austrália. Os resultados de avaliações feitas em solos de clima temperado têm demonstrado que o IHO é influenciado pelo conteúdo de matéria orgânica (Silva \& Kay, 1997a), pelas condições estruturais (Silva et al., 1994; Silva \& Kay, 1997a; Stirzaker, 1997) e pela textura do solo (Silva et al., 1994; Silva \& Kay, 1997a). De acordo com Letey (1985), a degradação da estrutura do solo resulta numa redução do $1 \mathrm{HO}$, a qual, conforme Kay (1989), aumenta a probabilidade das raizes das culturas serem expostas à ocorrência de limitações físicas no solo. A ocorrência de umidade do solo fora dos limites do IHO depende da sua magnitude e da variabilidade do clima (Silva \& Kay, 1997b). O crescimento de plantas de milho foi 
negativamente correlacionado com a freqüência de ocorrência de umidades do solo fora dos limites do IHO (Silva \& Kay, 1996).

Os resultados destas pesquisas demonstram o potencial do IHO para a avaliação dos impactos das práticas de manejo sobre a qualidade física do solo. Entre os solos tropicais, os Oxissolos são especialmente importantes para avaliação do IHO, uma vez que as excelentes produtividades obtidas são atribuídas às boas condições físicas do solo para as culturas. A vantagem da utilização do $\mathrm{IHO}$ deve-se à integração, num único parâmetro, dos fatores físicos do solo diretamente relacionados com o crescimento das plantas. $O$ objetivo deste trabalho foi quantificar os efeitos do sistema de plantio direto e preparo convencional sobre o IHO num Latossolo Roxo.

\subsection{Material e Métodos}

Amostras com estrutura indeformada foram obtidas numa fazenda comercial situada na região nordeste do Estado de São Paulo, entre as coordenadas $20^{\circ} 19^{\prime} 13^{\prime \prime}$ de latitude sul e $48^{\circ} 18^{\prime} 03^{\prime \prime}$ de longitude oeste. $O$ clima da região caracteriza-se por temperaturas e precipitações médias anuais de $22,7^{\circ} \mathrm{C}$ e $1420 \mathrm{~mm}$, respectivamente. O solo é classificado como Latossolo Roxo (Typic Hapludox), com granulometria composta por $800 \mathrm{~g} \mathrm{~kg}^{-1}$ de argila, $150 \mathrm{~g} \mathrm{~kg}^{-1}$ de silte e $50 \mathrm{~g} \mathrm{~kg}^{-1}$ de areia.

A amostragem foi realizada em agosto de 1996, em dois talhões contíguos cultivados com o sistema de plantio direto e preparo convencional do solo. $\mathrm{Na}$ área sob plantio direto, o sistema tinha sido implantado há quatro anos, enquanto que o preparo convencional era utilizado por dez anos. Ambas as áreas eram irrigadas por aspersão com pivô-central. A rotação utilizada em ambos sistemas consistia da cultura de soja, milho e feijão. No periodo da amostragem as duas áreas estavam sendo cultivadas com milho (Zea mays L. c.v. Cargill 701), na fase final de produção. A adubação de base da cultura foi feita com a aplicação de $330 \mathrm{Kg} \mathrm{ha}{ }^{-1}$ de 04-20-20 $+\mathrm{Zn}$. As adubações de cobertura foram feitas aos vinte dias após a emergência (DAE) das plantas com 
$145 \mathrm{~kg} \mathrm{ha}^{-1}$ de 20-00-20 e aos 35 e 50 DAE com $40 \mathrm{~kg} \mathrm{ha}^{-1}$ de uréia. O controle de pragas e ervas daninhas foi feito através de métodos químicos convencionais.

Foram retiradas amostras com estrutura indeformada através de amostrador e anéis de $100 \mathrm{~cm}^{3}$, no centro da camada de 0-0,10 m de profundidade. Os pontos de amostragem foram localizados numa transeção de 43,2 m, transversal às linhas das culturas, em ambos os sistemas de preparo. Foram retiradas amostras a cada $0,45 \mathrm{~m}$, resultando 96 amostras por sistema de preparo, seqüencialmente nas posições linha $(L)$ e entrelinha $(E L)$ da cultura. As amostras indeformadas foram acondicionados em sacos plásticos e mantidas sob temperatura de $\pm 5^{\circ} \mathrm{C}$ até serem processadas. Depois, foram saturadas por elevação gradual de uma lâmina de água, durante 48 horas. Para a determinação da curva de retenção adotou-se o procedimento descrito em Silva et al. (1994). As amostras foram divididas em 12 grupos de 16 amostras, sendo quatro amostras por posição e potencial em cada sistema de preparo. Os seguintes potenciais foram aplicados: $-0,001,-0,003,-0,005,-0,006$, e $-0,008$ MPa numa mesa de tensão adaptada de Topp \& Zebchuk (1979) e, $-0,01,-0,03$, $-0,05,-0,07,-0,1,-0,5$ e $-1,5 \mathrm{MPa}$ através de pressões aplicadas em placas porosas (Klute, 1986). Após atingirem o equilíbrio, as amostras foram utilizadas para determinar a resistência à penetração e, em seguida, secas em estufas a 105-110 ${ }^{\circ} \mathrm{C}$ para determinação do conteúdo de água e densidade do solo. $\mathrm{O}$ ajuste da curva de retenção foi feito através do procedimento descrito no capítulo 4 e os efeitos do preparo e posição incorporados como variáveis qualitativas no modelo. $O$ efeito dos sistemas de manejo sobre a estrutura do solo foi incorporado na função $\theta(\psi)$ através de uma função quadrática relacionando o parâmetro $n$ do modelo de Van Genuchten (1980) com a densidade do solo, a qual foi inserida no modelo para o ajuste dos dados. A curva de retenção ajustada foi utilizada para estimar os conteúdos de água nos potenciais de -0,01 $\mathrm{MPa}$ ou capacidade de campo e -1,5 $\mathrm{MPa}$ ou ponto de murchamento permanente. 
Para a obtenção da curva de resistência do solo à penetração, a resistência foi determinada nas amostras distribuídas em grupos por potencial, nas quais obteve-se um gradiente de umidade sob a variação natural da densidade do solo nos sistemas de preparo. A determinação da resistência foi feita através de um penetrômetro composto por um atuador linear elétrico, com motor de passo, montado numa base metálica para sustentação do conjunto mecânico e da amostra durante o teste. $\mathrm{Na}$ extremidade do atuador foi acoplada uma célula de carga com capacidade nominal de $20 \mathrm{~kg}$, na qual ajustou-se uma haste metálica com ponta cônica de $4 \mathrm{~mm}$ de diâmetro e semiângulo de penetração de $30^{\circ}$. Os valores de resistência à penetração foram obtidos por meio de um sistema automatizado de aquisição de dados. Os dados de resistência foram obtidos até a profundidade de $4,0 \mathrm{~cm}$ no centro geométrico de cada amostra, com velocidade de penetração de $1,0 \mathrm{~cm} \mathrm{~min}^{-1}$. A freqüência de amostragem correspondeu à coleta de um valor de resistência a cada 0,6767 segundos, obtendo-se um total de 266 leituras, das quais um valor médio foi utilizado. As medidas obtidas da superfície da amostra até $1,0 \mathrm{~cm}$ de profundidade foram desprezadas pelas razões descritas em Smith et al., (1997).

A resistência do solo (RP) é influenciada pela densidade (Ds) e conteúdo de água do solo $(\theta)$, de forma que uma relação funcional entre RP, Ds e $\theta$ pode ser identificada como curva de resistência do solo (CRS). A CRS foi ajustada através de um modelo não linear proposto por Busscher (1990) adotando os procedimentos utilizados por Silva et al. (1994). O modelo utilizado é descrito na equação 10.

$$
\mathrm{RP}=a \theta^{b} D s^{c}
$$

ou, a transformação logarítmica do mesmo,

$$
\ln \mathrm{RP}=\ln a+b \ln \theta+c \ln \mathrm{Ds}
$$

em que RP é a resistência do solo à penetração ( $\mathrm{MPa}), \theta$ representa a umidade volumétrica do solo $\left(\mathrm{m}^{3} \mathrm{~m}^{-3}\right)$, Ds corresponde à densidade do solo $\left(\mathrm{Mg} \mathrm{m}^{-3}\right)$, sendo $a, b, c$ os coeficientes do modelo. Os efeitos do sistema de preparo e da 
posiçáo da amostragem e suas interações foram incorporados no modelo conforme Silva et al. (1994):

$$
\begin{aligned}
\ln R P= & \left(a_{0}+a_{1} x_{1}+a_{2} x_{2}+a_{3} x_{1} x_{2}\right)+\left(b_{0}+b_{1} x_{1}+b_{2} x_{2}+b_{3} x_{1} x_{2}\right) \ln \theta \\
& +\left(c_{0}+c_{1} x_{1}+c_{2} x_{2}+c_{3} x_{1} x_{2}\right) \ln D s
\end{aligned}
$$

em que $a_{i}, b_{i}$ e $c_{i}$ são os coeficientes da regressão, e $x_{1}, x_{2}, x_{1} x_{2}$ são respectivamente preparo, posição e suas interações. $O$ ajuste foi feito através de modelos de regressão linear múltipla (SAS Institute, 1991), e os termos significantes do modelo foram selecionados.

O IHO foi determinado conforme Silva et al. (1994). Um valor do IHO foi calculado para cada amostra, com um valor conhecido da densidade do solo. Os valores críticos do conteúdo de água do solo, em que o crescimento das culturas é influenciado pelo potencial mátrico, resistência do solo e porosidade de aeração, foram obtidos na capacidade de campo $\left(\theta_{c c}\right)$ ou umidade no potencial de -0,01 $\mathrm{MPa}$ (Haise et al., 1955); no ponto de murchamento permanente ( $\theta_{\mathrm{PMP}}$ ) ou umidade no potencial de $-1,5 \mathrm{MPa}$ (Savage et al., 1996); na resistência à penetração $\left(\theta_{\mathrm{RP}}\right)$ de $2,0 \mathrm{MPa}$ (Taylor et al., 1966) e na porosidade de aeração $\left(\theta_{\mathrm{PA}}\right)$ de $10 \%$ (Grable \& Siemer, 1968). Os valores de Өcc e OpMP foram obtidos nos potenciais de $-0,01$ e $-1,5 \mathrm{MPa}$ utilizando a curva de retenção de água. $O$ valor da umidade do solo em que a resistência atinge 2,0 MPa foi obtido através da equação (12), explicitando o valor de $\theta$. $O$ valor de $\theta$ em que a porosidade de aeração é de $10 \%$ foi obtido como [(1-Ds/2,65) 0,1 , presumindo a densidade de partículas igual a $2,65 \mathrm{Mg} \mathrm{m}^{-3}$. O IHO foi calculado como a diferença entre os limites superior e inferior dos conteúdos de água em que ocorrem os parâmetros físicos considerados. $O$ limite superior é o menor valor de $\theta$ considerado na capacidade de campo ou na porosidade de aeração de $10 \%$ e o limite inferior é o maior valor de $\theta$ na resistência de 2,0 $\mathrm{MPa}$ ou no ponto de murcha permanente. A normalização do $\mathrm{IHO}$ em relação à água disponível (CC-PMP), IHO/AD, foi feita conforme Topp et al. (1994). 


\subsection{Resultados e Discussão}

A distribuição dos parâmetros determinados nas amostras é apresentada na tabela 6 . Menores valores da densidade do solo no preparo convencional podem ser atribuídos ao revolvimento do solo e à incorporação dos resíduos culturais (Hill, 1990). Valores semelhantes de densidade do solo, em solos similares, sob plantio direto e convencional, também foram obtidos por Kemper \& Derpsch (1981), Derpsch et al. (1986) e Roth et al., 1988).

Tabela 6. Valores dos parâmetros físicos do solo determinados nas amostras com estrutura indeformada.

\begin{tabular}{ccccc}
\hline Parâmetro & Média & Desvio Padrão & Mínimo & Máximo \\
\hline \multicolumn{5}{c}{ Plantio Direto } \\
\hline RP & 1,426 & 0,936 & 0,306 & 5,082 \\
Ds & 1,153 & 0,065 & 0,950 & 1,320 \\
$\theta$ & 0,356 & 0,059 & 0,239 & 0,459 \\
\hline RP & 1,116 & Preparo Convencional \\
Ds & 1,129 & 0,745 & 0,312 & 3,603 \\
$\theta$ & 0,346 & 0,075 & 0,930 & 1,330 \\
& 0,058 & 0,213 & 0,457
\end{tabular}

$\mathrm{RP}=$ resistência à penetração $(\mathrm{MPa}) ; \mathrm{Ds}=$ densidade do solo $\left(\mathrm{Mg} \mathrm{m}^{-3}\right) ; \theta=$ conteúdo de água $\left(\mathrm{m}^{3} \mathrm{~m}^{-3}\right) ; \mathrm{N}=96$.

Não foram constatados efeitos dos sistemas de preparo e posição de amostragem $(p<0,001)$ sobre a curva de retenção de água no solo. Os coeficientes do modelo descritivo da curva de resistência do solo são apresentados na tabela 7 . O modelo ajustado explicou $88 \%$ da variabilidade da resistência à penetração com as variáveis utilizadas. Os coeficientes do modelo demonstram que a resistência à penetração variou positivamente com a densidade do solo e negativamente com o conteúdo de água. Estes resultados estão de acordo com os obtidos por outros autores (Smith et al., 1997; Stirzaker 
et al., 1996). O aumento da resistência à penetração com o decréscimo da umidade é um processo bem conhecido e deve-se a um aumento na coesão entre as partículas do solo, o qual é magnificado pelo aumento na densidade do solo. Não houve influência da posição de amostragem nos coeficientes do modelo da curva de resistência do solo. $O$ efeito relativo ao sistema de preparo foi incorporado no modelo através de uma variável qualitativa (plantio direto $=0 \mathrm{e}$ preparo convencional=1), diferenciando significativamente a resistência do solo à penetração nos dois sistemas de preparo.

Tabela 7. Resultados da análise de regressão múltipla linear da curva de resistência do solo: $\ln R P=\left(a_{0}+a_{1}\right.$ preparo $)+b_{0} \ln \theta+c_{0} \ln D s$.

\begin{tabular}{ccccc}
\hline Variável & Coeficiente & Erro Padrão & $t$ & Prob> $|t|$ \\
\hline$a_{0}$ & $-3,8065$ & 0,1211 & $-31,446$ & 0,0001 \\
$a_{1}$ & $-0,1341$ & 0,0331 & $-4,050$ & 0,0001 \\
$b_{0}$ & $-2,6908$ & 0,0987 & $-27,248$ & 0,0001 \\
$c_{0}$ & 8,2080 & 0,2721 & 30,165 & 0,0001 \\
\hline
\end{tabular}

$\mathrm{RP}=$ resistência à penetração $(\mathrm{MPa})$; Preparo=variável qualitativa $(\mathrm{PD}=0$ e $P C=1) ; \theta=$ conteúdo volumétrico de água $\left(\mathrm{m}^{3} \mathrm{~m}^{-3}\right)$ e $D s=$ densidade do solo $(\mathrm{Mg}$ $\left.m^{-3}\right) . F=462,29 ; R^{2}=0,88 ; P>F=0,0001 ; N=192$.

Os modelos para as estimativas da resistência em ambos sistemas de preparo são:

$$
\begin{aligned}
& \text { Plantio Direto: RP=0.02223 } \theta^{-2.6908} \mathrm{Ds}^{8.2080} \\
& \text { Preparo Convencional: } \mathrm{RP}=0.01944 \theta^{-2.6908} \mathrm{Ds}^{8.2080}
\end{aligned}
$$

Vários estudos têm demonstrado maior resistência à penetração no PD em comparação ao PC (Pidgeon \& Soane, 1976; Cornish \& Lymbery, 1987; Hill, 1990; McCoy \& Cardina, 1997; Opoku et al., 1997), o que se justifica pelas variações de densidade e umidade do solo. Os modelos ajustados demonstram que, sob mesmas condições de umidade e densidade, a resistência do solo à 
penetração é maior no sistema de plantio direto. Estes resultados assemelhamse àqueles obtidos no estudo de Cornish (1993). No plantio convencional, o revolvimento do solo resulta em quebra de ligações entre partículas e/ou agregados, reduzindo a resistência do solo em comparação com o plantio direto (Dexter et al., 1988). A maior resistência no plantio direto pode estar relacionada com a ocorrência do processo de "envelhecimento" dos agregados ("age-hardening"), por meio do qual os agregados readquirem e mantêm a resistência ao longo do tempo, após o revolvimento inicial do solo (Utomo \& Dexter, 1981; Kemper \& Rosenau, 1984). De acordo com Dexter et al. (1988), esta aquisição de resistência após a mobilização do solo é determinada principalmente por dois processos: a) rearranjamento das partículas e orientações destas em novas posições de menor energia livre e, b) através do reforço das ligações existentes por mecanismos de cimentação entre as partículas do solo.

Estes dois mecanismos não são mutuamente excludentes, mas Dexter et al. (1988) sugerem que o segundo mecanismo pode ser inibido pelo aumento nos teores de matéria orgânica do solo. De acordo com Grant et al. (1985) e Semmel et al. (1990), a persistência dos efeitos dos ciclos de secagem e umidecimento e do tráfego resulta em agregados cujas características motivam a maior resistência no sistema de plantio direto. As diferenças de resistência entre plantio direto e convencional também foram descritas por McCoy \& Cardina (1997). De acordo com Cornish (1993), a densidade do solo numa microescala é maior num solo com estrutura não mobilizada, o que também pode justificar a maior resistência do solo no PD, detectada pelo penetrômetro, sob mesmos valores de umidade e densidade, em comparação com o PC.

A variação do conteúdo de água nos limites críticos de disponibilidade, i.e, $\theta_{\mathrm{Cc}}, \theta_{\mathrm{PMP}}, \theta_{\mathrm{RP}}, \mathrm{e} \theta_{\mathrm{PA}}$, nos sistemas de plantio direto e preparo convencional, é apresentada, respectivamente, nas figuras $9 \mathrm{a}$ e $9 \mathrm{~b}$. A densidade teve um impacto positivo na $\theta \mathrm{cc}$ até densidades limites de $1,27 \mathrm{Mg} \mathrm{m}^{-3}$ no plantio direto, $1,26 \mathrm{Mg} \mathrm{m}^{-3}$ no preparo convencional e negativo a partir destes valores. 

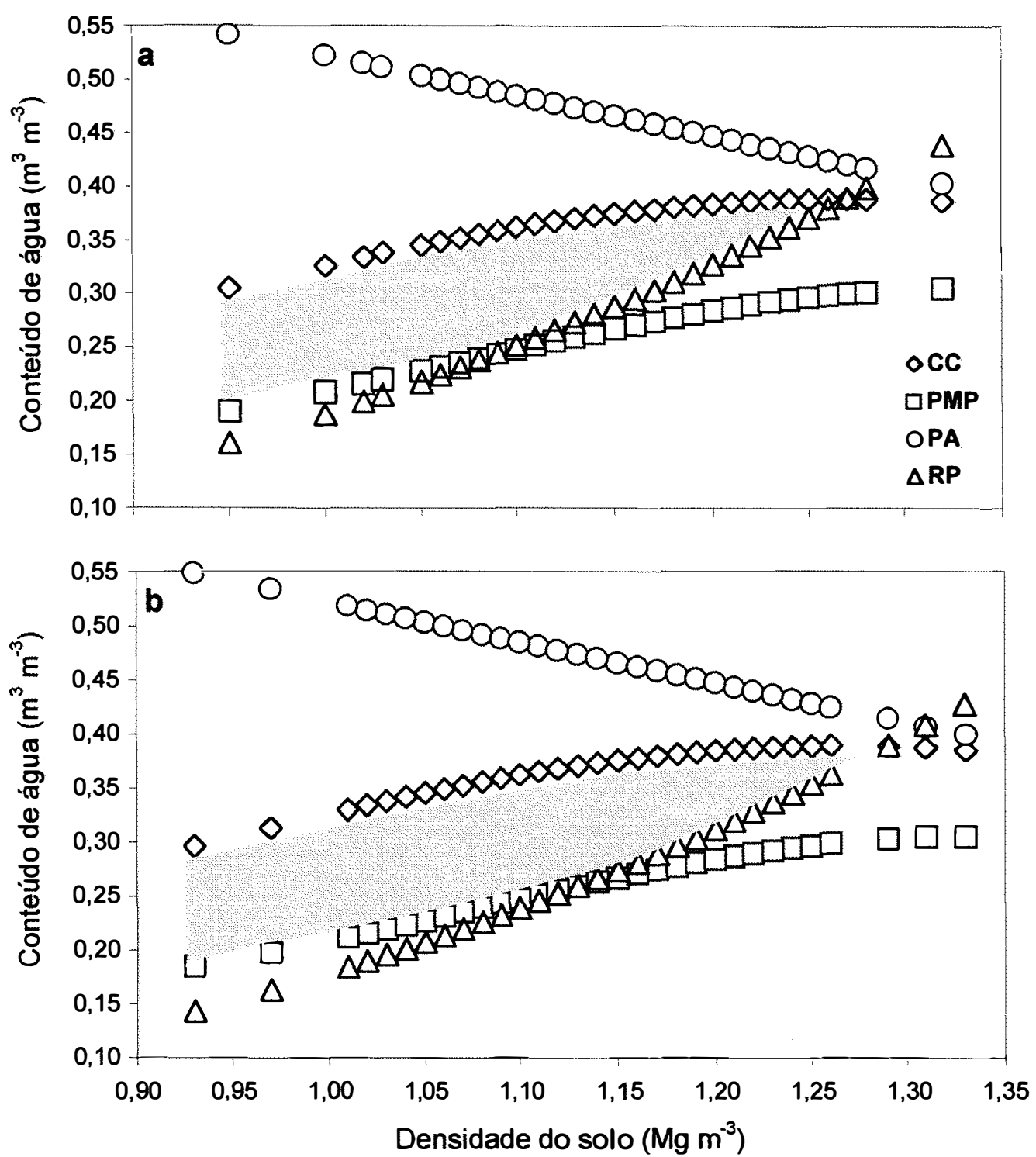

Figura 9 - Variação do conteúdo de água com a densidade do solo nos níveis críticos da capacidade de campo (CC), ponto de murcha permanente $(P M P)$, porosidade de aeração (PA) e resistência à penetração (RP) no sistema de plantio direto (a) e preparo convencional do solo (b). A área hachurada representa o Intervalo Hídrico Ótimo do Solo (IHO).

O aumento da retenção de água com a densidade do solo, sob elevados potenciais, ocorre às expensas da redução na macroporosidade (Hill et al., 1985) e uma redistribuição para poros de menor tamanho. Ainda que 
parcialmente, estes resultados contrastam os de Reeve et al. (1973), os quais argumentam que sob elevados potenciais, a maior retenção de água ocorre em menores valores de Ds devido à maior porosidade do solo nestas condições. Já a $\theta_{\text {PMP }}$ foi positivamente influenciada em toda faixa de densidades descritas em ambos sistemas de preparo. De acordo com Berg et al. (1997), em solos tropicais com estrutura fortemente microagregada, a maior retenção de água sob os menores potenciais com o aumento na densidade do solo deve-se à maior quantidade de partículas disponíveis para a adsorção de água, aliado a um aumento na microporosidade do solo. Outros autores tem demonstrado o efeito negativo da densidade na retenção de água sob elevados potenciais e positivo sobre baixos potenciais (Gupta \& Larson, 1979; Smedema, 1993). Estes autores argumentam que, em elevados potenciais, a retenção é fortemente influenciada pela porosidade total que é reduzida com o aumento na densidade, enquanto que sob baixos potenciais a retenção é controlada pelo volume de microporos, os quais têm correlação positiva com a densidade do solo, conforme demonstrado por Carter (1988). O conteúdo de água disponível $(A D)$ variou positivamente até a densidade de $1,02 \mathrm{Mg} \mathrm{m}^{-3} \mathrm{em}$ ambos sistemas de preparo. A maior redução na $A D$ no plantio direto deve-se aos maiores valores de densidade em comparação com o preparo convencional do solo.

Com o aumento na densidade do solo ocorre, simultaneamente, um aumento na $\theta_{\mathrm{RP}}$ e um decréscimo na $\theta_{\mathrm{PA}}$ em ambos sistemas de preparo (Figuras 9a e 9b). A porosidade de aeração é progressivamente reduzida com o aumento da densidade, conforme constatado por Archer \& Smith (1972), Carter (1990) e Silva et al. (1994). Neste solo, na capacidade de campo, a porosidade de aeração foi maior do que $10 \%$ em ambos sistemas de preparo. Os resultados sugerem que a microestrutura com elevada estabilidade preserva 0 espaço poroso necessário para a troca de gases no solo, mesmo sob os maiores valores de densidade do solo. Estes resultados contrastam com os obtidos por Topp et al. (1994), em solos argilosos do Canadá, nos quais a porosidade de aeração atingiu, com bastante freqüência, valores menores do 
que $10 \%$. No sistema de PD e PC, as máximas densidades obtidas foram de 1,32 e $1,33 \mathrm{Mg} \mathrm{m}^{-3}$ e os valores de $\theta_{c c}$ e $\theta_{P A}$ foram respectivamente $0,385 \mathrm{~m}^{3}$ $\mathrm{m}^{-3}$ e $0,402 \mathrm{~m}^{3} \mathrm{~m}^{-3}$ no PD e $0,38 \mathrm{~m}^{3} \mathrm{~m}^{-3}$ e $0,39 \mathrm{~m}^{3} \mathrm{~m}^{-3}$ no PC. É possível que para maiores valores de Ds, a $\theta_{\mathrm{PA}}$ possa constituir numa limitação como sugerem os resultados obtidos por Kirkegaard et al. (1992), principalmente sob condições de elevada demanda de oxigênio no solo que ocorrem com o aumento da temperatura, da densidade radicular e da atividade microbiológica do solo (Hadas, 1997). Hamblin (1985) sugere que em solos argilosos as limitações por aeração podem ocorrer com freqüência, uma vez que com o aumento na densidade do solo as raízes ocupam poros de menor tamanho, cuja drenagem é mais lenta. Além disso, a compressão do solo durante o crescimento das raízes concorre para redução na proporção da superfície das raízes expostas ao fluxo livre de oxigênio no solo.

A variação da densidade teve forte impacto na resistência do solo à penetração nos dois sistemas de manejo, com maior magnitude no sistema de plantio direto. No PD a $\theta_{R P}$ foi considerada o limite inferior em $89 \%$ das amostras e, substituiu $\theta_{P M P}$ nos valores de $D s \geq 1,06 \mathrm{Mg} \mathrm{m}^{-3}$. Já no $\mathrm{PC}, \theta_{R P}$ ocorreu como limite inferior em $46 \%$ dos valores de Ds e substituiu $\theta_{\mathrm{PMP}}$ para Ds $\geq 1,13 \mathrm{Mg} \mathrm{m}^{-3}$. Também Topp et al. (1994) e Silva et al. (1994) obtiveram resultados semelhantes em diferentes solos canadenses, nos quais a resistência foi o fator que mais freqüentemente reduziu o $\mathrm{IHO}$.

A elevada resistência à penetração é considerada a principal restrição física para a emergência das plântulas, para o estabelecimento das culturas e para o desenvolvimento do sistema radicular (Cornish \& Lymbery, 1987; Bathke et al., 1992). Na literatura há vários exemplos de impedimento ao crescimento radicular sob potenciais maiores que o PMP (Boone et al., 1986, 1987). Sob plantio direto, a resistência à penetração além de ser o principal fator limitante ao crescimento das raízes, substitui o ponto de murcha permanente em densidades muito próximas da máxima disponibilidade de água, o que implica 
num estreitamento das condições estruturais favoráveis para o crescimento das plantas. Os resultados obtidos referem-se à profundidade de $10 \mathrm{~cm}$ (entre 2,5 e $7,5 \mathrm{~cm}$ ) e é possível que nas camadas subsuperficiais o comportamento seja diferente do descrito nestas amostras localizadas.
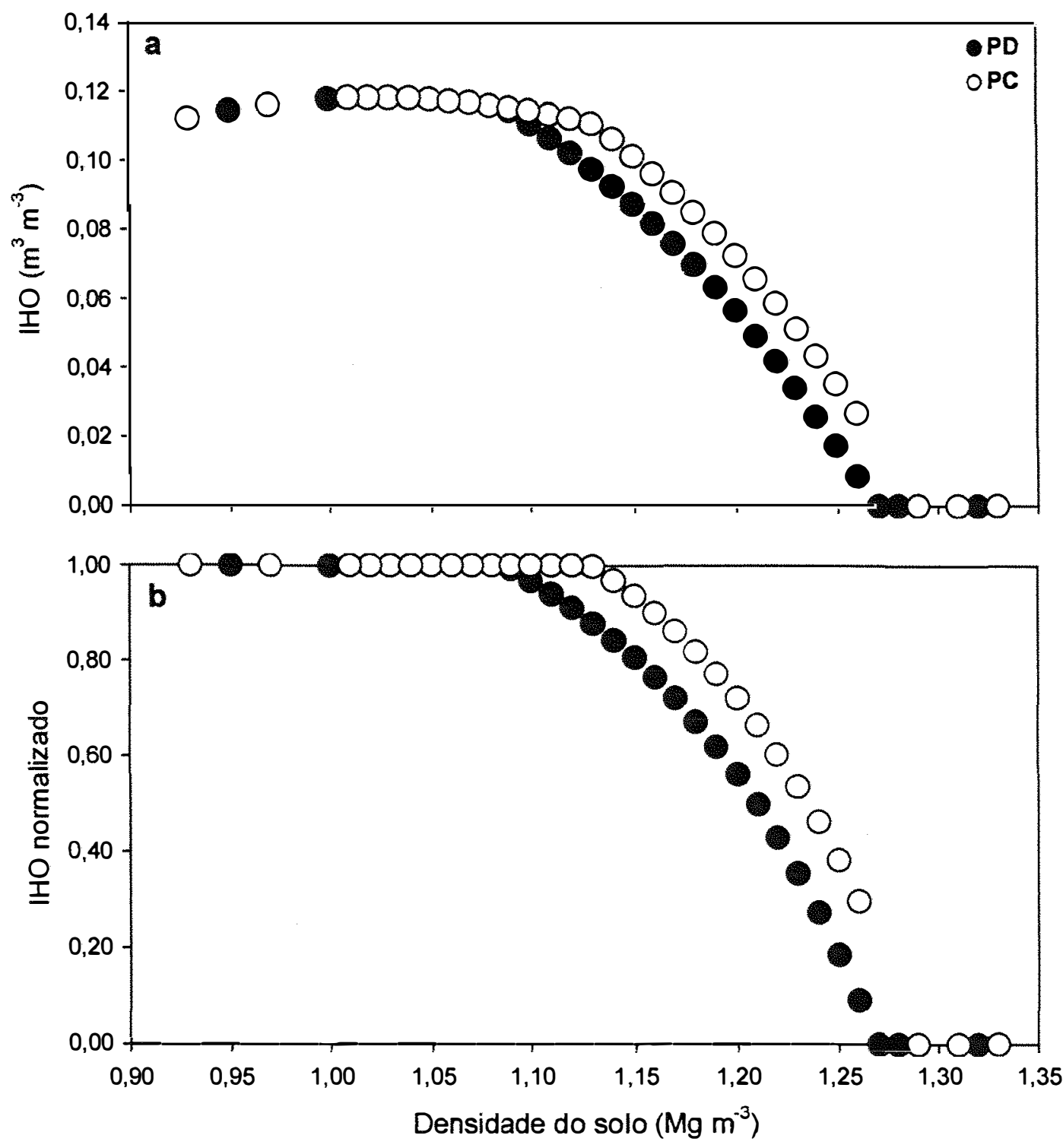

Figura 10 - Variação do $\mathrm{IHO}$ com a densidade do solo nos sistemas de preparo convencional e plantio direto (a) e do $\mathrm{IHO}$ normalizado com a densidade em ambos sistemas de preparo (b). 
A densidade do solo teve forte impacto no IHO em ambos sistemas de preparo do solo (Figura 10a), diferenciando ambos os sistemas de manejo com o aumento na densidade do solo pelas razões antes consideradas. De forma geral, com o aumento na densidade ocorreu redução no $\mathrm{IHO}$, concordando com os resultados obtidos por Topp et al. (1994), Silva et al. (1994) e Stirzaker (1997). Para mesmos valores de densidade do solo, o IHO foi menor no sistema de plantio direto em função das menores amplitudes de retenção de água entre a CC e o PMP e devido ao maior impacto da resistência, em comparação com o preparo convencional do solo. O IHO variou de 0 até $0,1184 \mathrm{~m}^{3} \mathrm{~m}^{-3}$ em ambos sistemas de preparo, com valores médios de $0,0776 \mathrm{~m}^{3} \mathrm{~m}^{-3}$ no plantio direto e $0,0957 \mathrm{~m}^{3} \mathrm{~m}^{-3}$ no preparo convencional. O IHO foi positivamente relacionado com a densidade até $1,02 \mathrm{Mg} \mathrm{m}^{-3}$, com pequeno impacto negativo até densidades de $1,09 \mathrm{Mg} \mathrm{m}^{-3}$ no PD e 1,13 $\mathrm{Mg} \mathrm{m}^{-3}$ no PC. A partir destes valores, o IHO foi fortemente reduzido pelo aumento na densidade do solo nos dois sistemas de preparo do solo.

A normalização do IHO (IHO/AD) é sugerida por Topp et al. (1994) para avaliar os efeitos dos sistemas de manejo sobre a proporção da AD que é mantida no IHO, em solos de diferentes texturas. O IHO normalizado (IHO/AD) é apresentado na figura $10 \mathrm{~b}$ para os dois sistemas de preparo. O IHO normalizado demonstra claramente que no preparo convencional, comparado ao plantio direto, ocorre uma maior faixa de densidades com condições físicas do solo menos limitantes ao crescimento das plantas. Estes resultados sugerem que a normalização do IHO pode ser também utilizada para a avaliação dos efeitos dos sistemas de manejo sobre a disponibilidade de água em solos com textura pouco variável.

$O$ efeito do aumento da densidade foi mais pronunciado sobre a $\theta_{R P}$, sugerindo que neste solo o IHO é mais sensivel aos efeitos das modificações da estrutura sobre a resistência do solo à penetração do que sobre a disponibilidade de água. Conforme estabelecido por Silva et al. (1994), a sensibilidade das variações no $\mathrm{IHO}$ estão sujeitas aos limites de resistência 
adotados. Silva et al., (1994) incluíram vários limites de CC e porosidade de aeração para testar a sensibilidade do IHO. Já os resultados obtidos neste estudo indicam que a resistência à penetração é o principal fator envolvido na redução do IHO. Assim, valores limites para a resistência do solo à penetração selecionados para esta análise foram $1,2,3$ e $4 \mathrm{MPa}$, sendo a faixa de resistências mais freqüentemente indicadas, na literatura, como limitantes ao crescimento do sistema radicular das diferentes culturas.
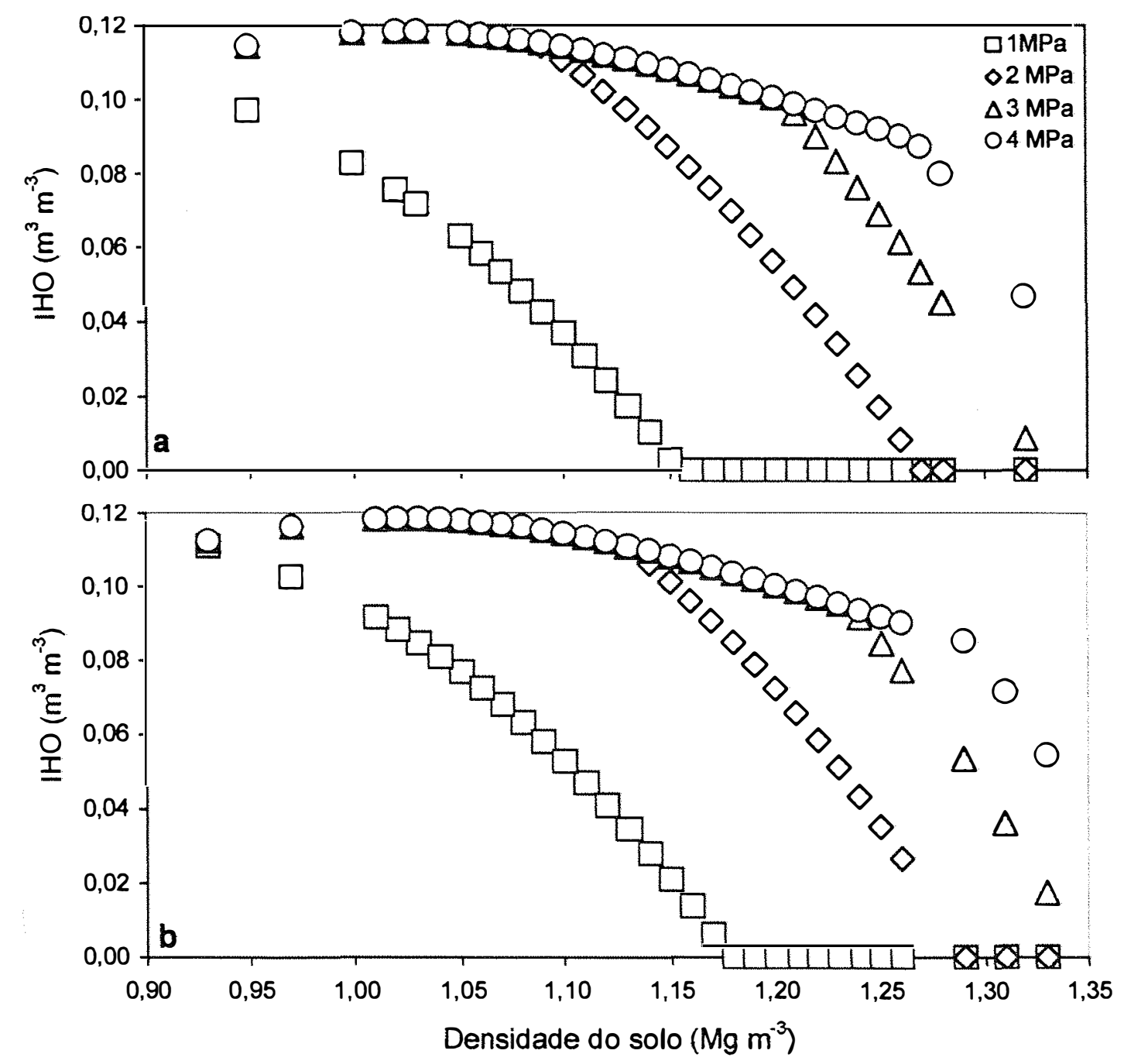

Figura 11 - Variação do $\mathrm{IHO}$ com a densidade do solo sob diferentes níveis críticos de resistência à penetração no sistema de plantio direto (a) e preparo convencional do solo (b). 
A sensibilidade de variação no $\mathrm{IHO}$ modificou-se com os sistemas de preparo (Figura 11), sendo maior no plantio direto devido aos maiores valores de densidade do solo. A resistência à penetração, sendo o principal atributo físico potencialmente impeditivo ao crescimento radicular, condiciona a resposta das culturas a uma distribuição mais uniforme da umidade no solo para manter condições físicas favoráveis ao crescimento das plantas.

Os resultados obtidos sugerem que sob baixas densidades não há restrições hídricas às plantas, apesar de que Kirkegaard et al., (1992) indicam que nestas condições o crescimento das plantas pode ser afetado por uma reduzida disponibilidade de água, em função da rápida drenagem do solo. Considerando a magnitude do $\mathrm{IHO}$, constata-se pela figura 10 que a faixa de densidades ótimas deste solo é muito estreita (entre 1,0 e 1,1 $\mathrm{Mg} \mathrm{m}^{-3}$ ), a partir da qual ocorre uma brusca redução do IHO com o aumento da densidade do solo. Em oxissolos, a densidade do solo de $1,20 \mathrm{Mg} \mathrm{m}^{-3}$ foi considerada ótima para o crescimento das culturas de milho (Onwualu \& Anazodo,1989) e cana (Trouse \& Hubert, 1961).

Em geral, os efeitos da resistência sobre o crescimento das raízes têm sido estudados sob condições controladas, em solos com matriz homogênea. Já sob condições de campo, as raizes podem crescer em macroporos formados pela mesofauna e pelas raizes das culturas, apesar que a eficiência destas raízes em absorver água e nutrientes é questionada (Passioura, 1991; Smucker \& Aiken, 1992). Em plantio direto, a utilização destes bioporos possibilita o crescimento das raízes sob condições de maior resistência (Ehlers et al., 1983; Cornish, 1993; Martino \& Shaykewich, 1994; Stirzaker et al., 1996). Ehlers et al. (1983) constataram que as resistências limites para o crescimento das raizes de milho foram de 3,6 e 4,9 $\mathrm{MPa}$, respectivamente sob preparo convencional e plantio direto. Esta diferença é atribuída à presença de bioporos que permitem o crescimento em extensão do sistema radicular, mas que não são detectados pelos penetrômetros (Mullins et al., 1992).

Adotando os niveis de resistências críticas estabelecidas por Ehlers et 
al. (1983), O IHO foi recalculado. O IHO foi semelhante em ambos os sistemas de preparo (Figura 12), indicando que, nestas condições, as raízes integram de forma comparável as diferentes condições estruturais do solo. Os resultados também sugerem que, com o aumento na densidade do solo, o plantio direto pode oferecer condições estruturais mais favoráveis para o crescimento das raízes do que o preparo convencional. De acórdo com Stirzaker et al. (1996), a presença de bioporos permite às raízes obterem água e nutrientes de um maior volume do solo, resultando em maior crescimento das plantas, principalmente em períodos prolongados de secamento do solo. Esta é uma das vantagens do sistema de plantio direto que compensa a maior densidade e resistência do solo (Kemper \& Derspch, 1981), mantendo a produtividade das culturas em níveis comparáveis e até superiores ao plantio convencional.

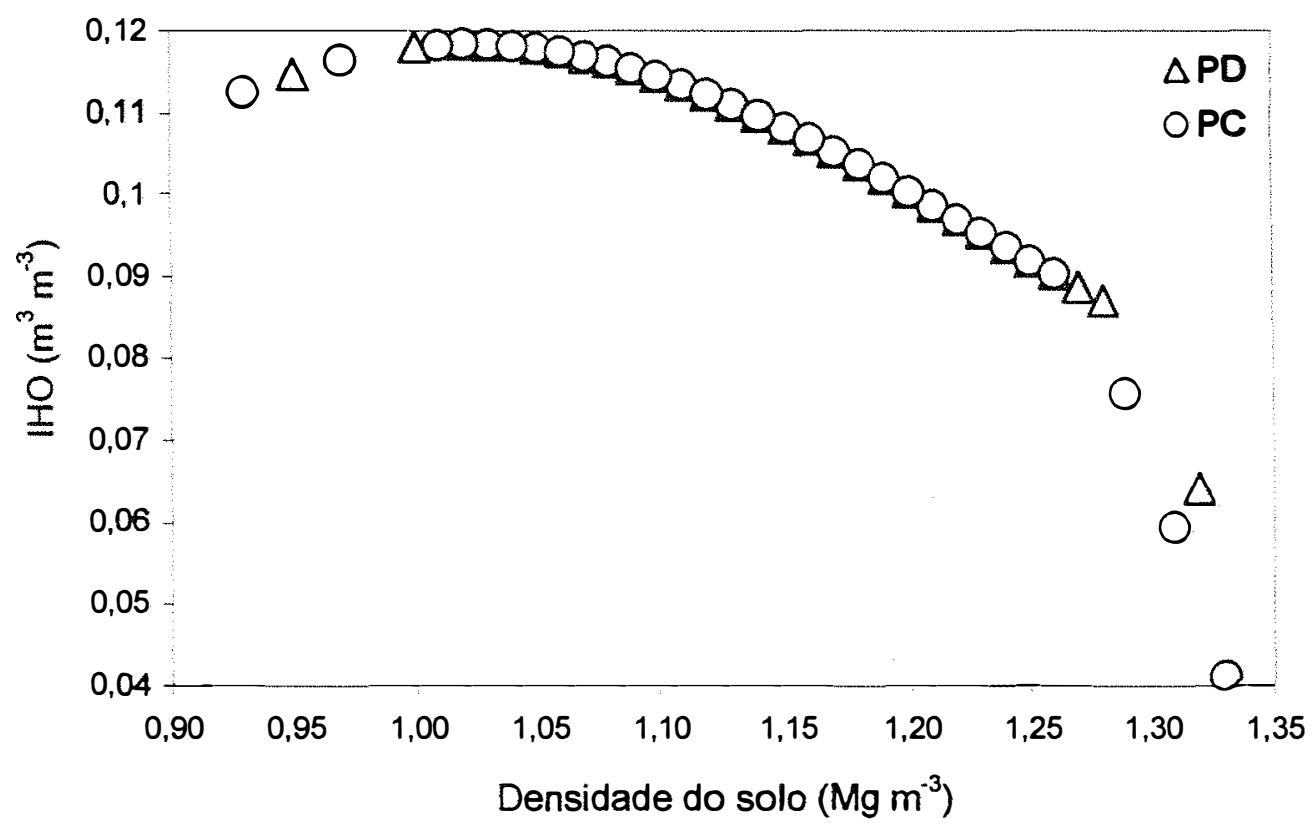

Figura 12 - Variação do $\mathrm{IHO}$ com a densidade do solo nas resistências críticas de 4,9 MPa no plantio direto e de 3,6 MPa no preparo convencional do solo .

O preparo excessivo e a ausência de cobertura podem expor estes 
solos a elevadas taxas de secamento e aumentar bruscamente a resistência como sugerem os resultados obtidos por Weaich et al. (1992) e Townend et al. (1996). Já sob plantio direto, a presença de resíduos mantém maiores conteúdos de água no solo contribuindo para manter as propriedades físicas numa faixa ótima para o crescimento das culturas (Kladviko, 1994). De forma geral, os resultados indicaram que os sistemas de plantio direto e preparo convencional promoveram diferentes alterações na estrutura do solo, que foram traduzidas pelas diferenças nos valores do IHO.

Estudos em solos brasileiros com amplas variações de mineralogia, textura e condições de manejo, são necessários em futuras avaliações do IHO como parâmetro da qualidade estrutural destes solos para o crescimento das plantas. A utilização de funções de pedotransferência pode ser uma alternativa para facilitar a sua obtenção a partir de outras propriedades do solo, mais facilmente mensuráveis, obtidas nos trabalhos de levantamento e mapeamento do solo, como sugerem os trabalhos de Silva \& Kay (1997a) e Kay et al. (1997). Estudos detalhados para estabelecer os limites de resistência do solo para o crescimento das plantas também devem ser tomados como prioridade em solos tropicais, visando o estabelecimento dos limites inferiores do IHO. Avaliações das influências dos sistemas de manejo nas variações espaciais e temporais do conteúdo de água de água do solo, também são necessárias para estabelecer os impactos dos sistemas de manejo sobre as condições físicas do solo. Isto permite avaliar a habilidade dos diferentes sistemas de manejo em manter as condições físicas do solo em situações favoráveis para o crescimento e produtividade das culturas.

\subsection{Conclusões}

A utilização do conceito do IHO permitiu identificar os fatores físicos que controlam a qualidade do solo estudado para o crescimento das plantas. $A$ amplitude de variação do $\mathrm{IHO}$ foi de 0 até $0,1184 \mathrm{~m}^{3} \mathrm{~m}^{-3}$ para ambos os sistemas de preparo, com valores médios de $0,0776 \mathrm{~m}^{3} \mathrm{~m}^{-3}$ no plantio direto e 
de $0,0957 \mathrm{~m}^{3} \mathrm{~m}^{-3}$ no preparo convencional. A umidade do solo na resistência à penetração de $2,0 \mathrm{MPa}$ determinou o limite inferior do $\mathrm{IHO}$ em $89 \%$ das amostras no plantio direto e em $46 \%$ das amostras no preparo convencional. A umidade do solo na capacidade de campo foi o limite superior do $\mathrm{IHO}$ em ambos os sistemas de preparo, em relação à umidade do solo, na qual a porosidade de aeração é de $10 \%$. 


\section{CONCLUSÕES GERAIS}

Os resultados obtidos no solo utilizado para este estudo indicaram que:

- a resistência à penetração de 2,0 $\mathrm{MPa}$ determinou o conteúdo de água do solo no limite inferior do $\mathrm{IHO}$, enquanto que a umidade na capacidade de campo $(\psi=-0,01 \mathrm{MPa})$ foi o limite superior do IHO.

- a determinação da curva de retenção, utilizando várias amostras por potencial, e a incorporação da variação da densidade do solo, nos parâmetros da função utilizada para 0 ajuste dos dados, permitiram fazer estimativas confiáveis do conteúdo de água do solo, para a determinação do IHO, com economia de tempo, de recursos econômicos e laboratoriais.

- na avaliação e comparação do IHO entre os sistemas de plantio direto e preparo convencional do solo, constatou-se que o $\mathrm{IHO}$ foi significativamente influenciado pelos sistemas de preparo do solo e negativamente correlacionado com a densidade do solo, para valores acima de $1,02 \mathrm{Mg} \mathrm{m}^{-3}$. Nos dois sistemas de preparo, a resistência à penetração foi considerada a principal limitação física do solo, contribuindo para reduzir a amplitude do $\mathrm{IHO}$, enquanto que a porosidade de aeração de $10 \%$ não limitou o seu valor. A adoção de diferentes limites de resistência, em função do sistema de manejo utilizado, permite incorporar a macroestrutura criada pelos sistemas de preparo nas estimativas do IHO.

Em solos tropicais, são necessários estudos mais detalhados para a avaliação do IHO. Especificamente, avaliações contemplando amplas variações 
de textura e manejo, são necessárias. É necessário, também, neste contexto, o desenvolvimento de funções de pedotransferência para facilitar as estimativas da retenção de água e resistência do solo. Estudos visando a determinação dos limites críticos de resistência e aeração para o crescimento das plantas, em solos tropicais, deverão ser priorizados. 


\section{REFERÊNCIAS BIBLIOGRÁFICAS}

AHUJA, L.R.; NANEY, J.W.; WILLIANS, R.D. Estimating soil water characteristics from simpler properties or limited data. Soil Science Society of America Journal, v.49, n.4, p.1100-1105, 1985.

ALBUQUERQUE, J.A.; REINERT, D.J.; FIORIN, J.E. et al. Rotação de culturas e sistemas de manejo: efeitos sobre a forma estrutural do solo ao final de sete anos. Revista Brasileira de Ciência do Solo, v.19, n.1, p.115-119, 1995.

ALEGRE, J.C.; CASSEL, D.K.; BANDY, D.E. Effects of land clearing and subsequent management on soil physical properties. Soil Science Society of America Journal, v.50, n.6, p.1379-1384, 1986.

ALLMARAS, R.R.; LOGSDON, S.D. Soil structural influences on root zone and rizosphere. In:BOX Jr., J.E.; HAMMOND, L.C. (Ed.). Rhizosphere dynamics. Washington:Westview Press, 1990. p.8-54. (AAAS Selected Symposium, 113).

ARCHER, J.R.; SMITH, P.D. The relation between bulk density, available water capacity and air capacity of soils. Journal of Soil Science, v.23, n.4, p.475480, 1972.

AYERS, P.D.; PERUMPRAL, J.V. Moisture and density effect on cone index. Transactions of the ASAE, v.25, n.5, p.1169-1172, 1982. 
BARRACLOUGH, P.B.; WEIR, A.H. Effects of a compacted subsoil layer on root and shoot growth, water use and nutrient uptake of winter wheat. Journal of Agricultural Science, v.110, n.3, p.207-216, 1988.

BAR-YOSEF, B.; LAMBERT, J.R. Corn and cotton root growth in response to soil impedance and water potential. Soil Science Society of America Journal, v.45, n.3, p.930-935, 1981.

BATHKE, G.R.; CASSEL, D.K.;HARGROVE, W.L.. et al. Modification of soil physical properties and root growth response. Soil Science, v.154, n.4, p.316-329, 1992.

BENGHOUGH, A.G.; MULLINS, C.E. Mechanical impedance to root growth: a review of experimental techniques and root growth responses. Journal of Soil Science, v. 41, n.1, p.341-358, 1990.

BERG, M. van den; KLAMT, E.; REUWIJK, L.P. van et al. Pedotransfers functions for the estimation of moisture retention characteristics of Ferralsols and related soils. Geoderma, v.78, n.3/4, p.161-180, 1997.

BLAKE, G.R.; HARTGE, K.H. Bulk density. In: KLUTE, A. (Ed.) Methods of soil analysis:(physical and mineralogical methods). 2. ed. Madison: American Society of Agronomy, 1986. cap.13, p.363-375.

BOONE, F.R. Wheater and other enviromental factors influencing crop responses to tillage and traffic. Soil and Tillage Research, v.11, n.3/4, p.283-324, 1988.

BOONE, F.R.; VEEN, B.W. Mechanisms of crop responses to soil compaction. In: SOANE, B.D.; OUWERKERK, C. van (Ed.) Soil compaction in crop production. Amsterdam: Elsevier, 1994. cap.11, p.237-264.

BOONE, F.R.; WERF, H.M.G van der; KROESBERGEN, B. et al. The effect of compaction of arable layer in a sandy soils on the growth of maize for silage. I. Critical potentials in relation to soil aeration and mechanical impedance. Netherlands Journal of Agricultural Research, v.34, n.2, p.155-171, 1986. 
BOONE, F.R.; WERF, H.M.G van der; KROESBERGEN, B. et al. The effect of compaction of the arable layer in sandy soils on the growth of maize for silage. II. Soil conditions and plant growth. Netherlands Journal of Agricultural Research, v.35, n.2, p.113-128, 1987.

BOWEN, H.D.; GARNER, T.H.; VAUGHN, D.H. Advances in soil-plant dynamics. In.UPADHYAYA, S.K.; CHANCELLOR, W.J.; PERUMPRAL, J.V. et al. (Ed.). Advances in soil dynamics. St. Paul: ASAE, 1996. cap. 3, p.256-274. (ASAE. Monograph, 12).

BRADFORD, J.M. Penetrability. In A. KLUTE (Ed). Methods of soil analysis: physical and mineralogical methods. 2. ed. Madison: American Society of Agronomy, 1986. cap.11, p.463-478.

BURDEN, D.S.; SELIM, H.M. Correlation of spatially variable soil water retention for a surface soil. Soil Science, v.148, n.6, p.436-447, 1989.

BUSSCHER, W.J. Adjustment of flat-tipped penetrometer resistance data to a common water content. Transactions of ASAE, v.33, n.2, p.519-524, 1990.

BUSSCHER, W.J.;BAUER, P.J.; CAMP, C.R. et al. Correction of cone index for soil water content differences in a coastal plain soil. Soil and Tillage Research, v.43, n.3/4, p.205-217, 1997.

CAMERON, D.R. Variability of soil curves retention and predict hydraulic condutivities on a small plot. Soil Science, v.126, n.6, p.364-371, 1978.

CAMP, C.R.; SADLER, E.J.; EVANS, D.E. et al. Modified center pivot system for precision management of water and nutrients. Transactions of ASAE, v.14, n.1, p.23-31, 1998.

CAMPBELL, G.S. A simple method for determining unsatured conductivity from moisture retention data. Soil Science, v.117, n.6, p.311-314, 1974. 
CAMPOS, B.C.D.; REINERT, D.J.; NICOLODI, R. et al. Estabilidade estrutural de um Latossolo Vermelho escuro após sete anos de rotação de culturas e sistemas de manejo do solo. Revista Brasileira de Ciência do Solo, v.19, n. 1, p.121-126, 1995.

CARMI, .A.; HEUR, B. The role of roots in control bean shoot growth. Annals of Botany, v.48, n.4, p.519-522, 1981.

CARTER, M.R. Relative measures of soil bulk density to characterize compaction in tillage studies on fine loam sands. Canadian Journal of Soil Science, v.70, n.3, p.425-433, 1990.

CARTER, M.R. Temporal variability of soil macroporosity in a fine sandy loam under mouldboard ploughing and direct drilling. Soil and Tillage Research, v.12, n.1, p.37-51, 1988.

CASSEL, D.K.; BAUER, A. Spatial variability in soils below depth of tillage: bulk density and fifteen atmosphere percentage. Soil Science Society of America Journal, v.39, n.2, p.247-250, 1975.

CASSEL, D.K.; LAL, R. Soil physical properties of the tropics:Commons beliefs and management restraints. In: Myths and science of soils of the tropics. Madison:Soil Science Society of America, 1992. p.61-89 (SSSA. Special Publication, 29).

CASSEL, D.K.; NIELSEN, D.R. Field capacity and available water capacity. In. KLUTE, A. (Ed.) Methods of soil analysis:physical and mineralogical methods. 2. ed. Madison: American Society of Agronomy, 1986. cap.11, p.901-926.

CASSEL, D.K.; RATLIFF, L.F.; RITCHIE, J.T. Models for estimating in-situ potential extractable water using soil physical and chemical properties. Soil Science Society of America Journal, v.47, n.3, p.764-769, 1983. 
CASTRO FILHO, C. Effects of liming on characteristics of a Brazilian oxisol at three levels of organic matter as related to erosion. Columbus, 1988. 261p. Thesis (PhD) Ohio State University

CLAPP, R.B.; HORNBERGER, G.M. Empirical equations for some hydraulic properties. Water Resources Research, v.15, n.2, p.601-604, 1987.

CORNISH, P.S. Soil macrostructure and root growth of establishing seedlings. Plant and Soil, v.151, n.1, p.119-126, 1993.

CORNISH, P.S.; LYMBERY, J.R. Reduced early growth of direct drilled wheat in southern New South Wales: Causes and consequences. Australian Journal of Experimental Agriculture, v.27, p.869-880, 1987.

COSBY, B.J.; HORNBERGER, G.M.; CLAPP, R.B. et al. A statistical exploration of soil moisture characteristics to the physical properties of soils. Water Resources Research, v.20, n.6, p.682-690, 1984.

COURTIN, P.; FELLER, M.C.; KLINKA, K. Internal variability in some properties of disturbed soils in S.W. British Columbia, Canada. Journal of Soil Science, v.63, n.2, p.529-539, 1983.

CRESSWELL, H.P.; KIRKEGAARD, J.A. Subsoil amelioration by plant roots the process and the evidence. Australian Journal of Soil Research, v.32, n.2, p.221-239, 1995.

CRESSWELL, H.P.; PAYDAR, Z. Water retention in Australian soils. I. Description and prediction using parametric functions. Australian Journal of Soil Research, v.35, n.4, p.195-212, 1996.

CURRIE, J.A. Gas diffusion through soil crumbs: the effect of wetting and compaction. Journal of Soil Science, v.35, n.1, p.1-10, 1984.

DAVIES, W.J.; ZANGH, J. Root signals and the regulation of growth and development of plants in drying soil. Annual Review of Plant Physiology and Plant Molecular Biology, v.42, p.55-76, 1991. 
DERPSCH, R.; SIDIRAS, N.; ROTH, C.H. Results of studies made from 1977 to 1984 to control erosion by cover crops and no-tillage techniques in Paraná, Brazil. Soil and Tillage Research, v.8, n.1/4, p.253-263, 1986.

DEXTER, A.R. Advances in characterization of soil structure. Soil and Tillage Research, v.11, n.3/4, p.199-238, 1988.

DEXTER, A.R. Physical properties of tilled soils. Soil and Tillage Research, v.43, n.1/2, p.41-63, 1997.

DEXTER, A.R.; YOUNGS, I.M. Soil physic toward 2000. Soil and Tillage Research, v.24, n.2, p.101-106, 1992.

DEXTER, A.R.;HORN, R.; KEMPER, W.D. Two mechanism for age-hardening of soil. Journal of Soil Science, v.39, n.2, p.163-175, 1988.

DODD, I.C.; STIKIC, R.; DAVIES, W.J. Chemical regulation of a gas exchange and growth of plants in drying soil in the field. Journal of Experimental Botany, v.47, n.303, p.1475-1490, 1996.

EAVIS, B.W. Soil physical condition affecting seedling root growth. I. Mechanical impedance, aeration and moisture availability and moisture levels in a sandy loam soil. Plant and Soil, v.36, n.1/4, p.613-622, 1972.

EHLERS, W.W.; KOPKE, F.; HESSE, F. et al. Penetration resistance and growth root of oats in tilled and untiled loess soil. Soil and Tillage Research, v.3, n.3, p.261-275, 1983.

EI-SWAIFY, S.A. Physical and mechanical properties of oxisols. In. THENG, B.K.G. (Ed.). Soils with variable charge. Lower Hutt:New Zealand Society of Soil Science, 1980. cap.15, p.303-325.

ELTZ, F.L.F.; PEIXOTO, R.T.G.;JASTER, F. Efeitos de sistemas de preparo do solo em propriedades físicas e químicas de um Latossolo Roxo álico. Revista Brasileira de Ciência do Solo, v.13, n.2, p.259-267, 1989. 
FELTON, G.K.; NIEBER, J.L. Four soil moisture characteristics curve functions evaluated for numerical modeling of sand. Transactions of ASAE, v.34, n.2, p.417-422, 1991.

GHUMAN, B.S.; LAL, R. Effects of soil wetness at the time of land clearing on physical properties and crop response on a ultisol in southern Nigeria. Soil and Tillage Research, v.22, n.1/2, p.1-11, 1992.

GHUMAN, B.S.; LAL, R.; SHEARER, W. Land clearing and use in the humid Nigerian tropics: I. Soil physical properties. Soil Science Society of America Journal, v.55, n.1, p.178-183, 1991.

GLANTZ, S.A.; SLINKER, B.K. Primer of applied regression and analysis of variance. New York: McGraw-Hill, 1990. 777p.

GLINSKI, J.; LIPIEC, J. Soil physical conditions and plant roots. Boca Raton: CRC Press, 1990. 250p.

GRABLE, A.R.; SIEMER, E.G. Effects of bulk density, aggregate size, and soil water suction on oxygen diffusion, redox potential and elongation of corn roots. Soil Science Society of America Journal, v.32, n.2, p.180-186, 1968.

GRANT, C.D.; KAY, B.D.; GROENEVELT, P.H. et al. Spectral analysis of micropenetrometer data to characterize soil structure. Canadian Journal of Soil Science, v.65, n.4, p.789-804, 1985.

GREGSON, K.;HECTOR, D.J.; McGOWAN, M. A one-parameter model for the soil water characteristic. Journal of Soil Science, v.38, n.3, p.483-486, 1987.

GUPTA, S.C.; LARSON, W.E. Estimating soil water characteristics from size distribution, organic carbon and bulk density. Water Resource Research, v.15, n.6, p.1633-1635, 1979. 
GUPTA, S.C.; SHARMA, P.P.; De FRANCHI, S.A. Compaction effects on soil structure. Advances in Agronomy, v.42, p.331-338, 1989.

HADAS, A. Soil tilth - the desired soil structural state obtained through proper soil fragmentation and reorientation processes. Soil and Tillage Research, v.43, n.1/2, p.7-40, 1997.

HAISE, H.R.; HAAS, H.J.; JENSEN, L.R. Soil moisture studies of some great plains soils. II. Field capacity as related to 1/3-atmosphere percentage, and "minimum point" as related to 15- and 26- atmosphere percentage. Soil Science Society of America Proceedings, v.34, n.1, p.20-25, 1955.

HALL, D.G.M.; REEVE, M.J.; THOMASSON, A.J. et al. Water retention, porosity and density of field soils. Harpenden:Soil Survey, 1977. 67p. (Technician Monograph, 9).

HAMBLIN, A.P. The influence of soil structure on water movement, crop root growth and water uptake. Advances in Agronomy, v.38, p.95-158, 1985.

HETTIARATCHI, D.R.P. The mechanics of soil-root interactions. In: WAGENET, R.J.; BAVEYE, P.; STEWART, B.A. (Ed.) Interacting processes in soil science. Boca Raton: Lewis Publishers, 1992. p.255-288.

HILL, J.N.S.L.; SUMNER, M.E. Effect of bulk density on moisture characteristics of soils. Soil Science, v.103, n.4, p.234-238, 1967.

HILL, R. L. Long-term conventional and no-till effects on selected soil physical properties. Soil Science Society of America Journal, v.54, p.161-166, 1990.

HILL, R.L.; HORTON, R.; CRUSE, R.M. Tillage effects on soil water retention and pore size distribution of two mollisols. Soil Science Society of America Journal, v.49, n.5, p.1264-1270, 1985. 
HSIAO, T.C.; O'TOOLE, J.C.; TOMAR, V.S. Water stress as a constraint to crop production in the tropics. In:INTERNATIONAL RICE RESEARCH INSTITUTE. Priorities for alleviating soil-related constraints to food production in the tropics. Los Baños, 1980. p.339-371.

HUTSON, J.L.; CASS, A. A retentivity function for use in soil-water simulation models. Journal of Soil Science, v.38, n.1, p.105-113, 1987.

JAYAWARDANE, N.S.; CHAN, K.Y. The management of soil physical properties limiting crop production in Australian sodic soils - A Review. Australian Journal of Soil Science, v.32, n.6, p.13-44, 1994.

JONES, C.A.; BLAND, W.L.; RITCHIE, J.R.; WILLIAMS, J.R. Simulation of root growth. In:HANKS, J.; RITCHIE, J.T. (Ed.) Modeling plant and soil system. ASA; CSSA; SSSA, Madison: 1991. 545p. (ASA. CSSA.SSSA. Agronomy Series, 13).

KAY, B.D. Assessing the suitability of different soils for new cropping systems in terms of rates of change in soil structure. In: LARSON, W.E.; BLAKE, G.R.; ALLMARAS, R.R. et al. (Ed.). Mechanics and related processes in structured agricultural soils. Dordrecht: Elsevier, 1989. cap.17, p.223-232. (NATO Series Applied Sciences).

KAY, B.D. Rates of changes of soil structure under different cropping systems. Advances in Soil Science, v.12, p.1-51, 1990.

KAY, B.D.; SILVA, A.P.; BALDOCK, J.A. Sensitivity of soil structure to changes in organic carbon content: Predictions using pedotransfer functions. Canadian Journal of Soil Science, v.77, n.4, p.655-667, 1997

KAYOMBO, B.; LAL, R. Responses of tropical crops to soil compaction. In: SOANE, B.D.; OUWERKERK, C. van. (Ed.) Soil compaction in crop production. Amsterdan:Elsevier, 1994.cap.13, p.287-316. (Developments in Agricultural Engineering, 11). 
KAYOMBO, B.; LAL, R. Tillage systems and soil compaction in Africa. Soil and Tillage Research, v.27, n.1/4, p.35-72, 1993.

KAYOMBO, B.; LAL, R.; MREMA, G.C. et al. Characterizing compaction effects on soil properties and crop growth in southern Nigeria. Soil and Tillage Research, v.21, n.3/4, p.325-345, 1991.

KEMPER, B.; DERPSCH, R. Soil compaction and root growth in Parana. In RUSSEL, R.S; IGUE, K.; MEHTA, Y.R. (Ed.). The soil/root system in relation to Brazilian agriculture. Londrina:IAPAR, 1981. cap 2, p.62-81.

KEMPER, W.D.; ROSENAU, R.C. Soil cohesion as affected by time and water content. Soil Science Society of America Journal, v.48, n.5, p.1001-1006, 1984.

KERTZMAN, F.F. Modificações na estrutura e no comportamento de um latossolo roxo provocadas pela compactação do solo. São Paulo, 1996. 176p. Tese (Doutorado) - Faculdade de Filosofia, Letras e Ciências Humanas, Universidade de São Paulo.

KIRDA, C.; HARDARSON, G., ZAPATA. et al. Spatial variability of root zone soil water status and of fertilizer $\mathbf{N}$ uptake by forage crops. Soil Technology, v.1, n.1, p.223-234, 1988.

KIRKEGAARD, J.A.; TROEDSON, R.J.; SO, H.B. et al. The effect of compaction on the growth of pigeonpea on clay soils: III. Effect of soil type and water regime on plant response. Soil and Tillage Research, v.26, n.2, p.163-178, 1993.

KIRKEGAARD, J.A.; TROEDSON, R.J.; SO, H.B.et al. The effect of compaction on the growth of pigeonpea on clay soils: II. Mechanisms of crop response and seasonal effects on a oxissol in a humid coastal environment. Soil and Tillage Research, v.24, n.2, p.129-147, 1992. 
KLADIVKO, E.J. Residue effects on soil physical properties. In. UNGER, P.W. (Ed.) Managing agricultural residues. Boca Raton: Lewis Publisher, 1994. cap.7, p.123-141.

KLUTE, A. Water retention: laboratory methods. In KLUTE, A. (Ed.) Methods of soil analysis: physical and mineralogical methods. Madison:America Society of Agronomy, 1986. cap.26, p. 635-660.

KOPI, A.J.; DOUGLAS, J.T. A rapid inexpensive and quantitative procedure for assessing soil structure with respect to cropping. Soil Use and Management, v.7, n.1, p.52-56, 1991.

LAL, R. Methods and guidelines for assessing sustainable use of soil and water resources in the tropics. Washington: Soil Management Support Services, 1994. 78p. (SMSS. Technician Monograph, 21).

LAL, R. Physical characteristics of soils of the tropics: Determination and management. In: LAL, R.; GREENLAND, D.J. (Ed.) Soil physical properties and crop production in the tropics. New York: John Wiley, 1979. p.7-44.

LAL, R. Soil surface management in the tropics for intensive landuse and high and sustained production. Advances in Soil Science, v.5, p.1-109, 1986.

LAL, R.; CUMMINGS, D.J. Clearing of a tropical forest. I. Effects on soil and microclimate. Field Crops Research, v.2, n.1, p.91-97, 1979.

LAL, R.; STEWART, B.A. Managing soils for enhancing and sustain agricultural production. Advances in Soil Science, v.1, p.1-9, 1995.

LETEY, J. Relationship between soil physical properties and crop production. Advances in Soil Science, v.1, p.277-294, 1985.

LIMA, J.M.J.C. Alterações de propriedades de solos cultivados com cana-deaçúcar. Piracicaba, 1995. 173p. Tese (Doutorado) - Escola Superior de Agricultura Luiz de Queiroz, Universidade de São Paulo. 
LUDLOW, M.M.; SOMMER, K.J.; FLOWER, D.J. et al. Influence of root signals resulting from soil dehydration and high soil strength on the growth of crop plants. Current Topics in Plant Biochemistry and Physiology, v.8, n.2, p.81-99, 1989.

MARTINO, D.L.; SHAYKEWICH, C.F. Root penetration profiles of wheat and barley as affected by soil penetration resistance in field conditions. Canadian Journal of Soil Science, v.74, n.2, p.193-200, 1994.

MASLE, A.; PASSIOURA, J.B. Effect of soil strength on the growth of young wheat plants. Australian Journal of Plant Physiology, v.14, n.6, p.634656, 1987.

MATERECHERA, S.A.; DEXTER, A.R.; ALSTON, .A.M. Penetration of very strong soils by seedling of different plant species. Plant and Soil, v.135, n.1, p.31-41, 1991.

MATSON, P.A; PARTON, W.J., POWER, A.G. et al. Agricultural intensification and ecosystem properties. Science, v.277, p.504-509, 1997.

McCOY, E.L.; CARDINA, J. Characterizing the structure of undisturbed soils. Soil Science Society of America Journal, v.61, n.1, p.280-286, 1997.

MCMICHEL, B.L.; QUISENBERRY, J.E. The impact of the soil environment on the growth of root systems. Environmental and Experimental Botany, v.33, n.1, p.53-61, 1993.

McQUEEN, R.H.; RAWLS, W.H.; BRAKENSIEK, D.L. Statistical analysis of Brooks-Corey and Green-Ampt parameters across soil textures. Water Resources Research, v.17, n.3, p.1005-1013, 1981.

MEYER, W.S.; BARRS, H.D. Roots in irrigated clay soils: measurement techniques and responses to rootzones conditions. Irrigation Science, v.12, n.2, p.125-134, 1991. 
MIRREH, H.F.; KETCHENSON, J.W. Influence of soil bulk density and matric pressure on soil resistance to penetration. Canadian Journal of Soil Science, v.52, n.4, p.477-483, 1972.

MULLINS, C.E.; BLACKWELL, P.S.; TISDALL, J.M. Strength development during drying of a cultivated, flood-irrigated hardsetting soil. I. Comparison with a structurally stable soil. Soil and Tillage Research, v.25, n.2, p.113128, 1992.

NETTER, J.; WASSERMAN, W.; KUTNER, M.H. Applied linear regression models. 2.ed. Homewwod: R.D.Imwin, 1989. 245p.

NIELSEN, D.R.; BIGGAR, J.W.; ERH, K.T. Spatial variability of field-measured soil-water properties. Hilgardia, v.42, n.7, p.215-260, 1973.

ONWUALU, A.P.; ANAZODO, U.G.N. Soil compaction effects on maize production under various tillage methods in a derived Savannah zone Nigeria. Soil and Tillage Research, v.14, n.2, p.99-114, 1989.

OPOKU, G.; VYN, T.J.; SWANTON, C.J. Modified no-tillage systems for corn following wheat on clay soils. Agronomy Journal, v.89, n.4, p.549-556, 1997.

ORELLANA, J.A. de; PILATTI, M.A.; GRENÓN, D.A. Soil quality: an approach to physical state assessment. Journal of Sustainable Agriculture, v.9, n.2, p.91-108, 1997.

PASSIOURA, J.B. Soil structure and plant growth. Australian Journal of Soil Research, v.29, n.6, p.717-728, 1991.

PASSIOURA, J.B. Root signals control leaf expansion in wheat seedlings growing in drying soil. Australian Journal of Plant Physiology, v.15, n.5, p.687-693, 1988. 
PASSIOURA, J.B.; GARDNER, P.A. Control of leaf expansion in wheat seedlings growing in drying soil. Australian Journal of Plant Physiology, v.17, p.149-157, 1990.

PERFECT, E.; MCLAUGHLIN, N.B.; KAY, B.D. et al. An improved fractal equation for the soil water retention curve. Water Resources Research, v.32, n.2, p.281-278, 1996

PHENE, C.J.; BEALE, O.W. High-frequency irrigation for water nutrient management in humid regions. Soil Science Society of America Journal, v.40, n.2, p.430-436, 1976.

PIDGEON, J.D.; SOANE, B.D. Effects of tillage and direct drilling on soil properties during the growing season in a long-term barley mono-culture system. Journal of Agricultural Science, v.88, n.4, p.431-442, 1976.

POWERS, W.L.; BAER, J.U.; SKOPP, J. Alternative soil water release parameters for distinguishing tillage effects. Soil Science Society of America Journal, v.56, n.3, p.873-878, 1992.

RAJKAI, K.; KABOS, S.; VAN GENUCHTEN, M.Th.et al. Estimating waterretention characteristics from the bulk density and particle size distribution of Swedish soils. Soil Science, v.161, n.12, p.832-845, 1996.

RASIAH, V.; AYLMORE, L.A.G. Sensitivity of selected water retention functions to compaction and inherent soil properties. Australian Journal of Soil Research, v.36, n.2, p.317-326, 1998.

RAWLS, W.J.; BRAKENSIEK, D.L.; SAXTON, K.E. Estimation of soil water properties. American Society of Agricultural Engineers, v.35, p.13161320, 1982.

RAWLS, W.J.; GISH, T.J.; BRAKENSIEK, D.L. Estimating soil water retention from soil physical properties and characteristics. Advances in Soil Science, v.16, p.213-234, 1991. 
REEVE, M.J.; SMITH, P.D.; THOMASSON, A.J. The effect of density on water retention properties of field soils. Journal of Soil Science, v.24, n.3, p.355$367,1973$.

REICHARDT, K. Capacidade de campo. Revista Brasileira de Ciência do Solo, v.12, n.3, p.211-216, 1988.

RICHARDS, D.; ROWE, R.N. Effects of root restriction, root pruning and 6benzylaminopurine on the growth of peach seedlings. Annals of Botany, v.41, p.729-740, 1977.

RICHARDS, L.A.; WEAVER, L.R. Fifteen atmosphere percentage as related to the permanent wilting point. Soil Science, v.56, n.1, p.331-339, 1944.

RITCHIE, J.T. Soil water availability. Plant and Soil, v.58, n.3, p.327-338, 1981.

ROTH, C.H.; MEYER, B.; FREDE, H.G. et al. Effect of mulch rates and tillage systems on infiltrability and other soil physical properties of a Oxisol in Paraná, Brazil. Soil and Tillage Research, v.11, n.1, p.81-91, 1988.

RUSSEL, M.B. Soil physical conditions and plant growth. New York: Academic Press, 1952. 491p.

RUSSO, D.; BRESLER, E. Soil hydraulic properties as stochastic processes: I. An analysis of field spatial variability. Soil Science Society of America Journal, v.45, n.3, p.682-687, 1981.

SAAB, I.N.; SHARP, R.E. Non-hydraulic signals from maize roots in drying soil: inhibition of leaf elongation but not stomatal conductance. Planta, v.179, n.4, p.466-474, 1989.

$S A A D, A . M$. Apoio tecnológico à agricultura irrigada no municipio de Guaíra, SP. São Paulo: Instituto de Pesquisas Tecnológicas, 1987. 59p. (IPT. Publicação, 1746).

SANCHEZ, P.A. Properties and management of soils in the tropics. New York: John Wiley, 1976. 618p. 
SANCHEZ, P.A.; SALINAS, J.G. Low-input technology for managing Oxissolos and Ultisols in a tropical America. Advances in Agronomy, v.34, p.279406, 1981.

SAVAGE, M.J.; RITCHIE, J.T.; BLAND, W.L. et al. Lower limit of soil water availability. Agronomy Journal, v.88, n.5, p.844-851, 1996.

SAXTON, K.E.; RAWLS, W.J.; ROMBERG, J.S. et al. Estimating generalized soil-water characteristics from texture. Soil Science Society of America Journal, v.50, n.2, 1031-1036, 1986.

SCHEINOST, A.C.; SCHWERTMANNN, U. Predicting phosphate adsorptiondesorption in a soilscape. Soil Science Society of America Journal, v.59, n.6, p.1575-1580, 1995.

SCHEINOST, A.C.; SINOWSKI, W.; AUERSWALD, K. Regionalization of soil water retention curves in a highly variable soilscape. I. Developing a new pedotransfer function. Geoderma, v.78, n.3/4, p.129-143, 1997.

SEMMEL, H.; HORN, R.; HELL, U. et al. The dynamics of soil aggregate formation and the effect on soil physical properties. Soil Technology, v.3, n. 1, p.113-129, 1990.

SHARP, R.E.; WU, Y.; VOETBERG, G.S. et al. Confirmation that abscisic acid accumulation is required for maize primary root elongation at low water potentials. Journal of Experimental Botany, v.45, n.281, p.1745-1751, 1994.

SHOUSE, P.J.; RUSSEL, W.B.; BURDEN, D.S. et al. Spatial variability of soil water retention functions in a silt loam soil. Soil Science, v. 159, n.1; p.1-12, 1995.

SILVA, A. P. da; KAY, B.D. The sensitivity of shoot growth of corn to the least limiting water range of soils. Plant and Soil, v.184, n.2, p.323-329, 1996. 
SILVA, A.P. da; KAY, B.D. Estimating the least limiting water range of soil from properties and management. Soil Science Society of America Journal, v.61, n.3, p.877-883, 1997a.

SILVA, A.P.; KAY, B.D.; PERFECT, E. Characterization of the least limiting water range. Soil Science Society of America Journal, v.58, n.6, p.1775$1781,1994$.

SILVA, A.P.da,; KAY, B.D. Effect of soil water content variation on the least limiting water range. Soil Science Society of America Journal, v.61, n.3, p.884-888, 1997b.

SILVA, M.S.L.; RIBEIRO, M.R. Influência do cultivo contínuo da cana-de-açucar em propriedades morfológicas e físicas de solos argilosos de tabuleiro no estado de Alagoas. Revista Brasileira de Ciência do Solo, v.16, n.3, p.397-402, 1992.

SINOWSKI, W.; SCHEINOST, A.C.; AUERSWALD, K. Regionalization of soil water retention curves in a highly variable soilscape: If. Comparison of regionalization procedures using a pedotransfer function. Geoderma, v.78, n.3-4, p.145-159, 1997.

SMEDEMMA, L.K. Drainage performance and soil management. Soil Technology, v.6, n.1, p.183-189, 1993.

SMITH, C.W.; JOHNSTON, M.A.; LORENZ, S. The effect of soil compaction and soil physical properties on the mechanical resistance of south African forestry soils. Geoderma, v.78, n.1/2, p.93-111, 1997.

SMUCKER, A.J.M.; AIKEN, R.M. Dynamics root responses to water deficits. Soil Science, v.154, n.4, p.281-289, 1992.

STATISTICAL ANALYSIS SYSTEM INSTITUTE. SASISTAT procedure guide for personal computers: version 5, Cary, 1991.1686p. 
STIRZAKER, R.J. Processing tomato response to soil compaction and fumigation. Australian Journal of Experimental Agriculture, v.37, p.477483, 1997.

STIRZAKER, R.J.; PASSIOURA, J.B.; WILMS, Y. Soil structure and plant growth: impact of bulk density and biopores. Plant and Soil, v.185, n.1, p.151-162, 1996.

TARDIEU, F. Growth and functioning of roots and to root systems subjected to soil compaction. Towards a system with multiple signaling. Soil and Tillage Research, v.30, n.2/4, p.217-243, 1994.

TAYLOR, H.M.; ROBERSON, G.M.; PARKER Jr., J.J. Soil strength-root penetration relations to medium to coarse-textured soil materials. Soil Science, v.102, n.1, p.18-22, 1966.

THENG, B.K.G. Soils with variable charge. Palmerstoon North: New Zealand Society of Soil Science, 1980. 448p.

TOPP, G.C.; GALGANOV, Y.T.; BALL, B.C. et al. Soil water curves desorption. In. CARTER, M.R. (Ed.). Soil sampling and methods of analysis. Boca Raton: Lewis Publisher, 1993. cap. 15, p.569-579.

TOPP, G.C.; GALGANOV, Y.T.; WIRES, K.C. et al. Non limiting water range (NLWR): an approach for assessing soil structure. Ottawa: Soil Quality Evaluation Program, 1994. 96p. (Techinical report, 2).

TOPP, G.C.; ZEBTCHUCK, W. The determination of soil water desorption curves for soil cores. Canadian Journal of Soil Science, v. 59, n.1, p.1926, 1979.

TOWNEND, J.; MTAKWA, P.W.; MULLINS, C.E. et al. Soil physical factors limiting establishment of sorghum and cowpea in two contrasting soil types in the semi-arid tropics. Soil and Tillage Research, v.40, n.1/2, p.89-106, 1996. 
TRAPNELL, C.G.; WEBSTER, R.;HESSE, P.R. Microaggregates in red earths and related soils in East and Central Africa, their classification and occurrence. Journal of Soil Science, v.37, n.1, p.109-123, 1986.

TREIN, C.R.; COGO, N.P.; LEVIEN, R. Métodos de preparo do solo na cultura do milho e ressemeadura do trevo na rotação aveia+trevo/milho após pastejo intensivo. Revista Brasileira de Ciência do Solo, v.15, n.1, p.105111,1991

TROUSE Jr., A.C.J.; HUBERT, R.P. Some effects of soil compaction of the development of sugarcane roots. Soil Science, v.91, n.1, p.208-217, 1961.

TSUJI, G.Y.; WATANABE, R.T.;SAKAI, W.S. Influence of soil microstructure on water characteristics of selected Hawaiian soils. Soil Science Society of America Proceedings, v.39, n.1, p.28-33, 1975.

TURNER, N.C. Further progress in crop water relations. Advances in Agronomy, v.58, p.293-325, 1997.

UTOMO, W.H.; DEXTER, A.R. Age-hardening of agricultural top soils. Journal of Soil Science, v.32, n.3, p.335-350, 1981

VAN GENUCHTEN, M. Th. A closed form equation for predicting hydraulic conductivity of unsaturated soils. Soil Science Society of America Journal, v.44, n.5, p.892-898, 1980.

VAN GENUCHTEN, M.Th.; NIELSEN, D.R. On describing and predicting the hydraulic properties of unsatured soils. Annals of Geophysical, v.3, n.5, p.615-628, 1985.

VAN WAMBEKE, A. Soils of the tropics: properties and appraisal. New York: McGraw Hill, 1992. 192p.

VEEN, B.W.; BOONE, F.R. The influence of mechanical resistance and soil water on the growth of seminal roots of maize. Soil and Tillage Research, v.16, n.1, p.219-226, 1990. 
VEREECKEN, H.; MAES, H.; FEYEN, J. et al. Estimating the soil moisture retention characteristics from texture, bulk density, and carbon content. Soil Science, v.148, n.6, p.389-403, 1989.

VIEHMEYER, F.J.; HENDRICKSON, A.H. Soil moisture conditions in relation to plant growth. Plant Physiology, v.2, p.71-78, 1927.

VOORHEES, W.B.; FARREL, D.A.;LARSON, W.E. Soil strength and aeration effects on root elongation. Soil Science Society of America Journal, v.39, n.5, p.948-953, 1975.

VOORHEES, W.D. Wheel-induced soil physical limitations to root growth. Advances in Soil Science, v.19, p.73-95, 1992.

VYN, T.J.; RAIMBAULT, B. A. Long-term of five tillage systems on corn response and soil structure. Agronomy Journal, v.85, n.5, p.1074-1079, 1993.

WEAICH, K.; BRISTOW, K.L.; CASS, A. Preemergent shoot growth of maize under different drying conditions. Soil Science Society of America Journal, v.56, n.5, p.1272-1278, 1992.

WEAICH, K.; CASS, A.; BRISTOW, K.L. Pre-emergent shoot growth of maize (Zea mays, L.) as a function of soil strength. Soil and Tillage Research, v. 40, n.1/2, p.3-23, 1996.

WILLIAMS, J.; PREBBLE, R.E.; WILLIAMS, W.T. et al. The influence of texture, structure and clay mineralogy on the soil moisture characteristic. Australian Journal of Soil Research, v.21, n.1, p.15-32, 1983.

WILLIAMS, J.; ROSS, P.; BRISTOW, K. Prediction of Campbell water retention from texture, structure and organic matter. In. VAN GENUCHTEN, M. Th., LUND, L.J. (Ed.). Indirect methods for estimating the hydraulics properties of unsaturated soils. Riverside: University of California, 1993. p. $427-441$. 
WOLF, J.M. Soil-water relations in Oxissolos of Puerto Rico and Brazil. In: BONERMIZA, E.; ALVARADO, A. (Ed.). Soil management in tropical America. Raleigh: North Carolina State University, 1975. cap.3. p.145-167.

WOSTEN, J.H.M.; VAN GENUHTEN, M.Th. Using texture and other soil properties to predict the unsatured soil hydraulic function. Soil Science Society of America Journal, v.52, n.6, p.1762-1770, 1988.

XU, X.; NIEBER, J.L.; GUPTA, S.C. Compaction effects on the gas diffusion coefficients in soil. Soil Science Society of America Journal, v.56, n.4, p.1743-1750, 1992.

YET, T.C.; GELHAR, L.W.; WIERENGA. Observations of spatial variability of soil water pressure in a field soil. Soil Science, v.142, n. 1, p.7-12, 1986. 